ONGOING COMMUNITY RESILIENCE FROM THE GROUND UP: A RELATIONAL PLACE BASED APPROACH TO GRASSROOTS COMMUNITY RESILIENCE

by

Raven Marie Cretney

Thesis

ENVIRONMENTAL STUDIES 591

[2013]

A 120 point thesis submitted to Victoria University of Wellington as partial fulfilment of requirements for the degree of Masters of Environmental Studies

School of Geography, Environment and Earth Sciences

Victoria University

[March 2013] 


\title{
ONGOING COMMUNITY RESILIENCE FROM THE GROUND UP: A RELATIONAL PLACE BASED APPROACH TO GRASSROOTS COMMUNITY RESILIENCE
}

\author{
Raven Marie Cretney
}

\begin{abstract}
When the devastating 6.3 magnitude earthquake hit Christchurch, Aotearoa New Zealand, at $12.51 \mathrm{pm}$ on $22^{\text {nd }}$ February 2011, the psychological and physical landscape was irrevocably changed. In the days and weeks following the disaster communities were isolated due to failed infrastructure, continuing aftershocks and the extensive search and rescue effort which focussed resources on the central business district. In such moments the resilience of a community is truly tested. This research discusses the role of grassroots community groups in facilitating community resilience during the Christchurch 2010/11 earthquakes and the role of place in doing so. I argue that place specific strategies for urban resilience need to be enacted from a grassroots level while being supported by broader policies and agencies.
\end{abstract}

Using a case study of Project Lyttelton - a group aspiring towards a resilient sustainable future who were caught at the epicentre of the February earthquake - I demonstrate the role of a community group in creating resilience through self-organised place specific action during a disaster. The group provided emotional care, basic facilities and rebuilding assistance to the residents of Lyttelton, proving to be an invaluable asset. These actions are closely linked to the characteristics of social support and social learning that have been identified as important to socio-ecological resilience. In addition this research will seek to understand and explore the nuances of place and identity and its role in shaping resilience to such dis-placing events. Drawing on community narratives of the displacement of place identity, the potential for a progressive sense of place as instigated by local groups will be investigated as an avenue for adaptation by communities at risk of disaster and place destabilisation.

Keywords: Resilience, Relational Place, Christchurch Earthquakes, Grassroots Community 


\section{Acknowledgements}

The creation of this thesis and research has been an emotionally charged but incredibly rewarding process. Through this time many people have supported me. I wish to thank the following people for their unending patience:

Firstly, to my Mum, not only would I not be here without you but also this thesis would not be here either. Without your wise rant about why there was no community anymore and how I should study that, I would never have taken up a thesis and found my calling as a researcher. I will never forget that!

To my supervisor, Sophie Bond, thank you for sharing your knowledge with me and for your tireless efforts to edit my work and share your wisdom on the do's and don'ts of grammar and writing (a big job as most of my prior English teachers would agree!). Your guidance has been invaluable.

To my partner Zack, for taking care of me, reading my drafts and being ever so patient as I woke up in the middle of the night and had to scribble down or tell you my ideas. I couldn't have done this without you!

To my family, we have been through so much in the past few years; your strength has helped me get through the best and worst times.

To Emma, for being my thesis buddy and always keeping me company and reading my crazy abstracts!

I also wish to extend my heartfelt gratitude to those who participated in my research. Discussing trauma and disaster is not a fun topic for many who have first-hand experience. I appreciate your time and stories and I hope I have done them justice in this work.

Thanks also to: Nathanael Boehm, Helen Devereux, Bevan Triebels, Zack Dorner and Ross Becker for their permission to use their images.

And lastly I wish to dedicate this research to all of those who have been through the earthquakes in 2011/12 in the Canterbury region. These times have been incredibly trying and I hope that the lessons learnt from our collective experiences can help those in the future. 


\section{Contents}

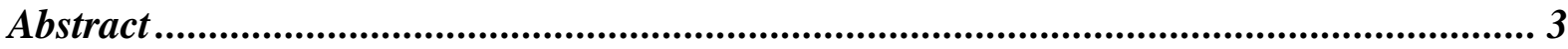

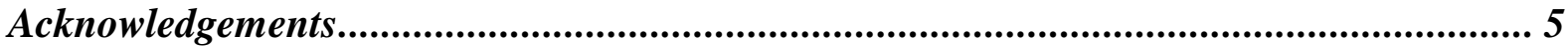

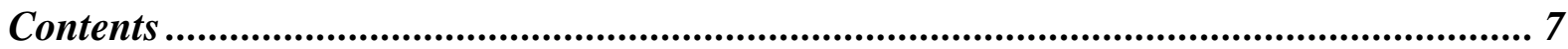

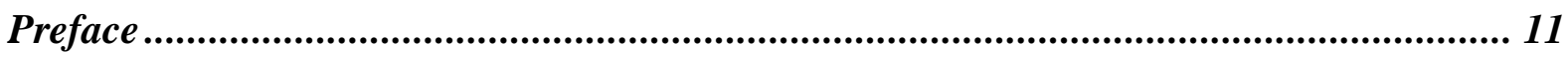

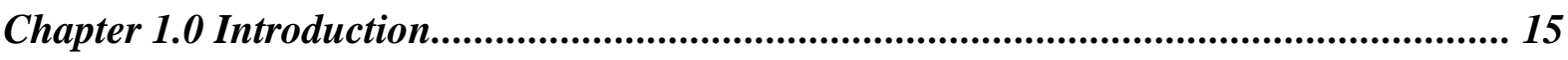

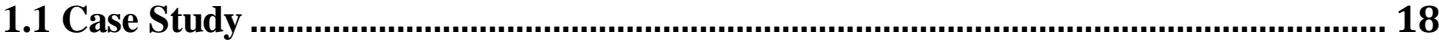

1.2 Research Questions ................................................................................................ 20

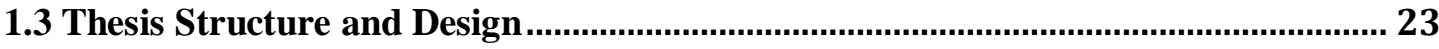

Chapter 2.0 Communities and Resilience ......................................................................... 25

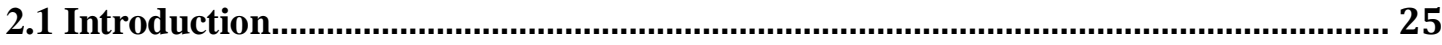

2.2 Resilience- ecological to socio-ecological approaches .................................................... 25

2.2.1 Social Support and Participation........................................................................... 30

2.2.3 Social Learning and Social Memory ….......................................................................... 31

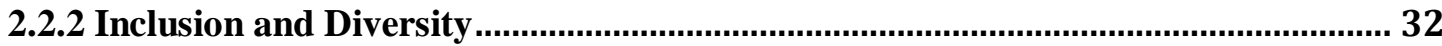

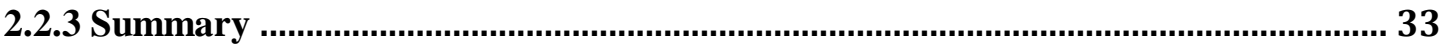

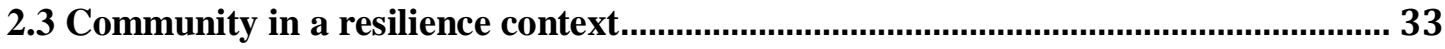

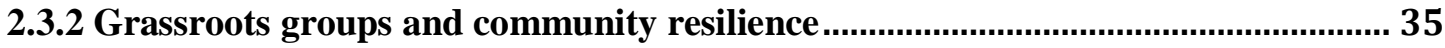

2.4 Summary

Chapter 3.0 Relationships between the Self and Place .................................................... 39

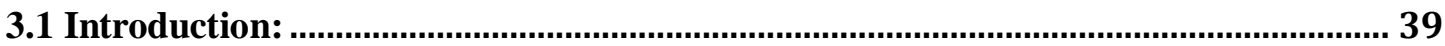

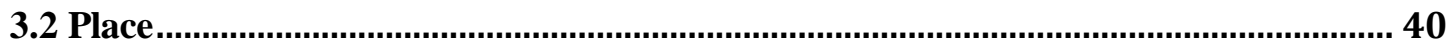

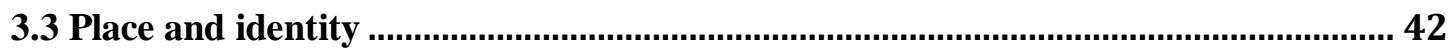

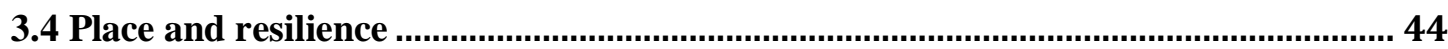

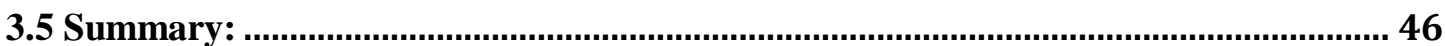

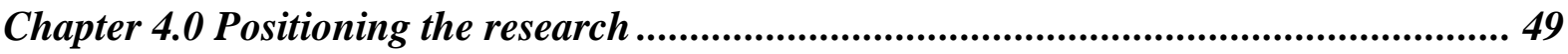

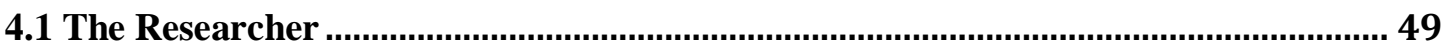

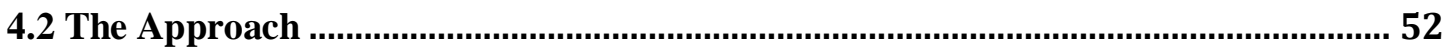

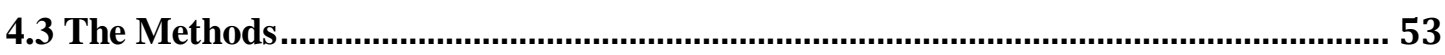

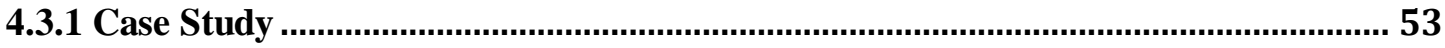

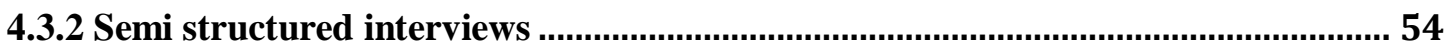

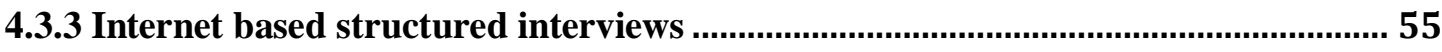

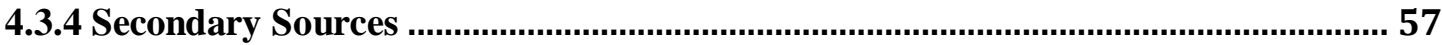


4.4 The Data .57

4.5 Summary .58

Chapter 5.0 Findings: Grassroots resilience

5.1 Introduction

5.2 Project Lyttelton . 62

5.3 Perceptions of Resilience. 64

5.4 Resilience in Action - September $4^{\text {th }} 2010$ and February $22^{\text {nd }} 2011$ 66

5.4.1 Social Participation. .67

5.4.2 Social Support 70

5.4.3 Inclusion .73

5.5 Trajectories of Adaptation . 77

5.5.1 Social Learning. .77

5.5.2 Social Memory 79

5.6 Summary 82

Chapter 6.0 Findings: Putting theory into place

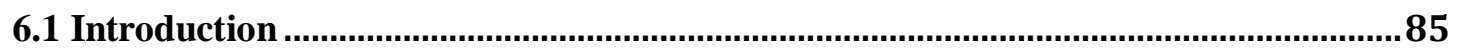

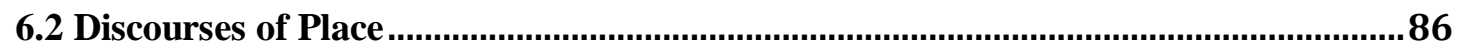

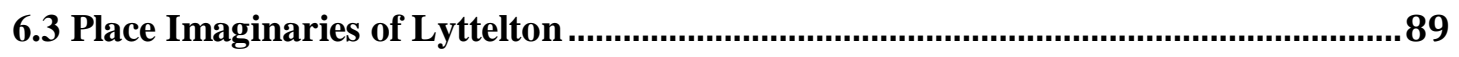

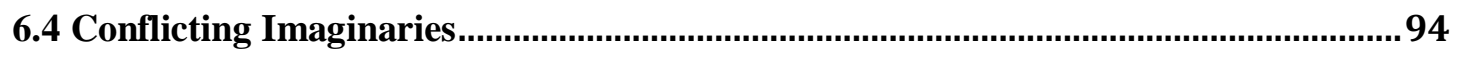

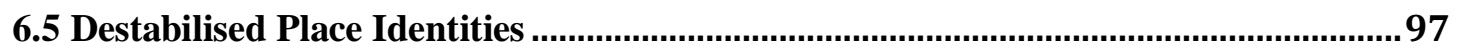

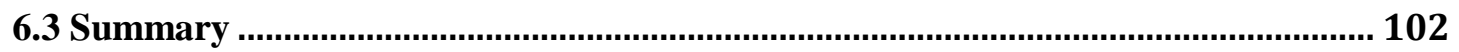

Chapter 7.0 Discussion: Towards a Place Based Perspective of Resilience

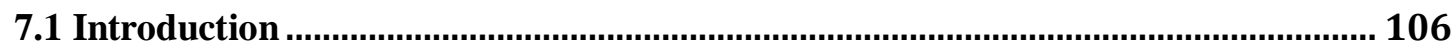

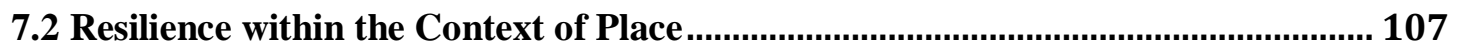

7.3 A Framework for Relational Place Based Resilience ................................................ 109

7.4 Possibilities for a Progressive Politics of Place ........................................................... 114

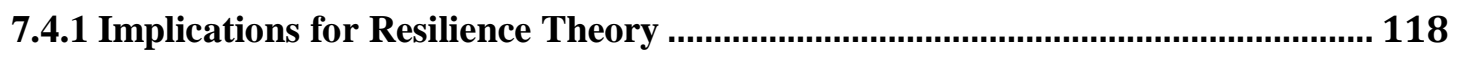

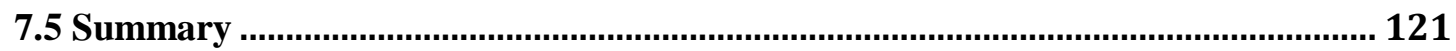

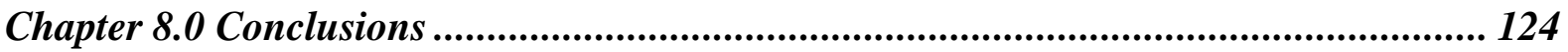

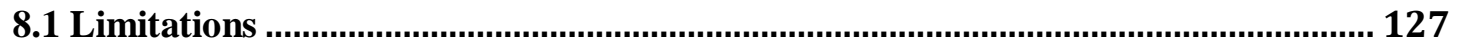

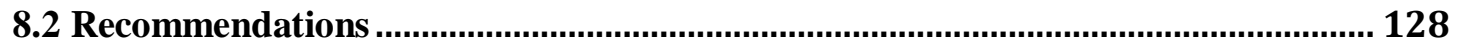

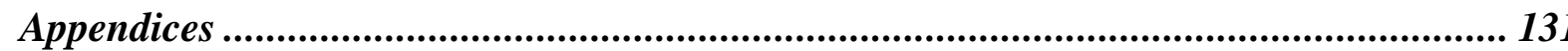

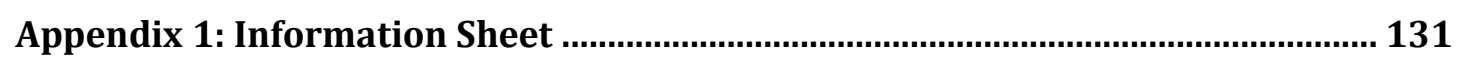

Appendix 2: Consent Form................................................................................. 133

Appendix 3: Semi structured interview guide - Project Lyttelton members ....... 134 
Figures:

Figure 1: Map showing the location of Christchurch in Aotearoa New Zealand

Figure 2: Google map of Lyttelton showing the township in relation to the Harbour, Road Tunnel (orange) and Evan's Pass (yellow). Christchurch city and suburbs lie North West to Lyttelton township.

Figure 3: Diagram displaying the two threads of inquiry being drawn on for the analysis of the final thread of inquiry surrounding place based community resilience

Figure 4: Google map of Lyttelton showing the township in relation to the Harbour, Road Tunnel and Evan's Pass. Christchurch city and suburbs lie North West to Lyttelton township.

Figure 5: Visual representing two dominant place imaginaries, 'old' and 'new' Lyttelton alongside associated discourses as derived from interview data.

Figure 6: Visual depiction of how the DROP model integrates place and resilience

Figure 7: Web diagram showing the integration of place and resilience concepts. Web also displays the factors of relational identity that individuals draw on for their place identities

\section{Tables:}

Table 1: Multiple definitions of resilience - drawn from variety of authors

\section{Images:}

Image 1: Tulips emerge from the rubble in Christchurch

Image 2: Lyttelton Harbour

Image 3: Damaged sustained by St Joseph's Catholic Church in Lyttelton

Image 4: Lyttel stitches hearts attached to fence surrounding rubble

Image 5: A person sits in an art instalment on a vacant lot in Lyttelton (Source:

Becker Fraser Photography)

Image 6: The Project Lyttelton Community Garden mentioned by interview participants

Image 17: A Lyttel Stitches heart on the fence outside St Joseph's Church

Image 8: Damage sustained to Old Union Church

Image 9: A damaged building next to a vacant plot of land left behind from the demolition of another damaged building. Lyttelton Harbour can be seen in the background

Image 10: London St - main street of Lyttelton during demolition of earthquake damaged buildings.

Image 11: Time ball Station - further damage sustained on June $13^{\text {th }} 2011$ caused the 
remaining tower to collapse (Becker Fraser, Photographer).

Image 12: A woman places a tribute to the fallen building on London St, Lyttelton Image 13: Kia kaha (stay strong) London St - a Lyttel Stitches heart is tied to a fence restricting entry to the London St, the main street of Lyttelton. Many of the buildings shown are being supported by brackets. 


\section{Preface}

On the $22^{\text {nd }}$ of February 2011 at 1.51pm, the earth under Christchurch shook in what was to be one of the worst natural disasters to ever affect New Zealanders ${ }^{1}$. On the $22^{\text {nd }}$ of February 2011 at 2.00pm I sat in front of a television and watched in real time as the city I loved and grew up in fell. I watched in horror as a woman clung to the window of the symbolic cathedral tower as the spire came toppling down; as the policemen said the cameras could not go down the road to my old school because of casualties; and in disbelief as many of the historic and well known icons of Christchurch collapsed amongst its citizens.

On the $23^{\text {rd }}$ of December 2011 at 1.58pm as I was walking into my family home the earth shook again. I stumbled, lost my footing and fell against the door frame. Within 30 seconds it was all over and the world was the right way up again. Minutes later the ground we walk on and take for granted erupted and poured out of the earth's surface, flooding the street and our house with liquefaction. Later at $3.15 \mathrm{pm}$ the earth moved again, but this time worse. I clung to a fence as it heaved back and forth and the houses and cars around me bobbed up and down like boats in the water.

This thesis is about documenting change; how we respond and adapt to change and how we change in times of change. On these two occasions (two offour major earthquake events in the Canterbury region so far) the world and my perceptions of it shifted. The mind assumes that places and cities are always there and the brain assumes that the ground beneath us is solid and unchanging. Disasters fundamentally reconfigure the way we view the world and experience the 'natural' environment. Disasters also destabilise and deconstruct our perceptions of place and the way we shape our identity in relation to certain places and symbols of place. This is at the heart of this research - to understand the way in which resilience is

\footnotetext{
${ }^{1}$ The 6.3 magnitude earthquake was the second largest event in an on-going sequence, the first of which was a 7.1 magnitude quake on the $4^{\text {th }}$ of September 2010. Other magnitude 6.3 and 6.0 earthquakes occurred on the 13 June and $23^{\text {rd }}$ December 2011 (respectively). These earthquakes caused widespread damage and injury, in particular the $22^{\text {nd }}$ February quake which resulted in the loss of 185 lives (Geonet, 2012).
} 
affected by this destabilisation of place and identity and how communities can use this to strengthen or weaken resilience.

Many people have talked of the stoicism of the Canterbury people, and without a doubt the residents of Christchurch are a hardy bunch. But the story of Christchurch and its earthquakes is not solely about the hardiness of the people and their ability to push through, it is about their ability to grieve, cope with change and adapt to new circumstances. This research is about those people, their stories and their lessons for others in times of crisis. It is my hope that the learnings from this thesis will be applied to other communities in the aim of lessening the damage and easing the recovery for other communities in crisis. 
This page is intentionally blank. 


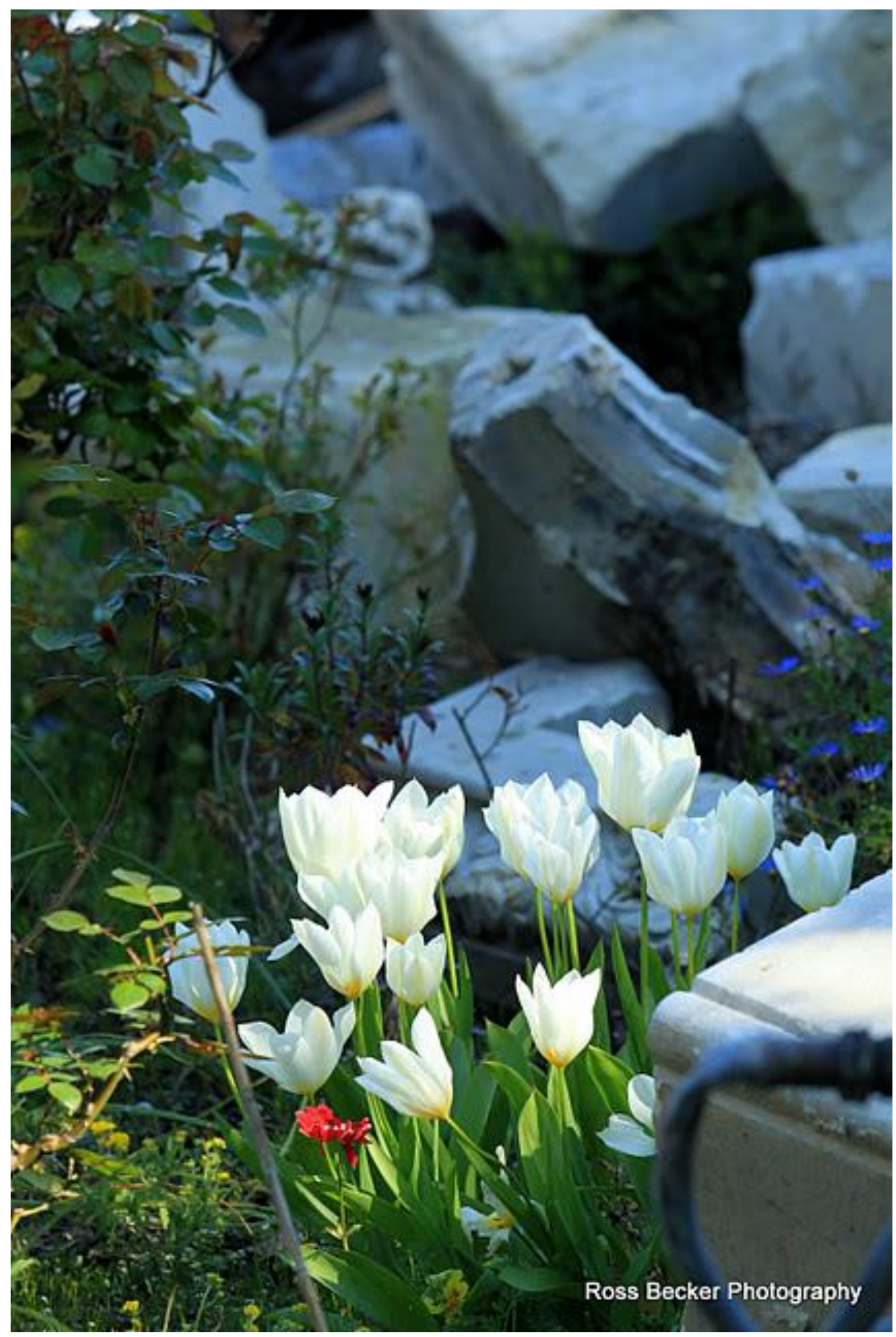

Image 1: Tulips emerge from the rubble in Christchurch 2011 (Becker Fraser Photography) 


\title{
Chapter 1.0 Introduction
}

\author{
He aha te mea nui o te ao? \\ He tangata! He tangata! He tangata!
}

What is the most important thing in the world?

It is people! It is people! It is people!

Māori Whakataukī

(Korero Maori, 2012)

Chain eil thu tuilleach's sean airson ionnsachadh fhathast

We are to learn as long as we live

Scottish Gaelic Proverb

(Gyula, 1997)

It can be said that the destruction caused by natural disasters is never purely natural. As the failure of human systems to prepare and respond to threats of disaster often causes catastrophe when an event occurs, the ability to minimise and manage these threats also lies with human systems (Olwig, 2012). The two proverbs above come from the Indigenous people of Aotearoa New Zealand, the Māori, and the Scottish who settled in this land over a hundred years ago. They illustrate an understanding of the world that emphasises the integral role of people and the continual process of learning that can contribute to understanding causes and solutions to disasters. Through improving resilience, communities can build the fabric for the wider areas of cities, countries and societies from a grassroots level (Tobin, 1999). Resilience will be essential for societies and settlements in the coming decades as the world struggles to cope with a nexus of environmental, social and financial crises (Haxeltine \& Seyfang, 2009). Researching resilience at a local grassroots level 
following a natural disaster allows for unique insight which may prove integral for communities to prepare for future disruptions and change.

In the past two decades, the onslaught of neoliberal ideology and the continuation of the forces of globalisation has seen claims of widespread loss of community and connection (Cheshire \& Lawrence, 2005; Mishra, 1998). This potential loss is problematic for many settlements, especially given the increased potential for natural disasters, particularly from climate change (O'Brien, Hayward $\&$ Berkes, 2009). At the heart of how communities respond to these challenges is resilience - the community's ability to respond, change and adapt to threats (Magis, 2010). Resilience is defined within the discipline of biology as the ability of an ecological system to absorb and adapt to disruption and disturbances (Holling, 1973). However a newer socio-ecological framework outlines how resilience can operate at differing levels of society, including the city, country and community spheres (Norris, Stevens, Pfefferbaum, Wyche, \& Pfefferbaum, 2007). The evolution of this framework has grown to encompass learning and change in response to disturbances in addition to bounce back capacity (Folke, 2006).

Within a community affected by disaster there are varying approaches to dealing with the trauma and stress of the event (Brown \& Perkins, 1992). There are also multiple ways in which people envisage a place before and after a disaster. Such disasters can have a profoundly destabilising effect on how individuals view their home, their place and their community (Manzo \& Perkins, 2006). The loss of symbols of place such as churches, monuments and buildings may affect people differently depending on their history and their relationships with people and place. Place is an important part of resilience as it is inextricably linked to the condition of the environment and the socio-economic conditions that build and support resilience (Cutter et al., 2008).

Place will be defined in this research using a relational perspective developed by Doreen Massey as part of her thoughts on a relational theory of place (Massey, 1993). In this way place will be used as a lens to investigate the contributions of place identity and geographical location in relation to resilience. Place identity is theorised as potentially positive to resilience outcomes through the strengthening of group identity and cohesion (Scannell \& Gifford, 2010). Yet it has also been 
suggested that it can negatively influence communities by contributing to conservative attitudes towards difference and change (Scannell \& Gifford, 2010). The literature on place will be compared to a resilience framework in relation to elements of social capital. Social capital has been widely acknowledged to provide a foundation of support and skills from which communities can draw on in times of hardship (Aldrich, 2010; Gunderson, 2010; Magis, 2010). Drawing on a variety of academics, I will address three specific elements of social capital. These are:

-Social memory and learning - the ability to learn from and remember lessons from events in history (Ö. Bodin, Crona, \& Ernstson, 2006; Gunderson, 2010)

-Social support and participation - networks of informal and formal support that can be drawn on for real assistance in disaster (Cutter et al., 2008; Norris et al., 2007)

-Diversity and Inclusion - the ability to encourage and foster diversity through inclusive practices (Folke, 2006; Tidball, Krasny, Svendsen, Campbell, \& Helphand, 2010)

This study will contribute to the literature by investigating and analysing the interplay between place, identity and resilience in disasters. Through exploring the role of grassroots community groups and their contributions to resilience theory this research will also establish the case for the possible involvement of grassroots level involvement in resilience policy and theory. Numerous academics have commented on the role of community resilience but there is little work linking grassroots groups and their role in supporting these capacities (Gunderson, 2010; Magis, 2010; Norris et al., 2007; Sherrieb, Norris, \& Galea, 2010; Tobin, 1999). This work forms the first thread of inquiry in this research. The interactions between place identities and disasters will be investigated as the second thread of inquiry. I will draw these two threads together in a discussion of the merits of place based perspectives of local resilience capacity at a grassroots level. This discussion will provide insight into what supports on-going long term community resilience. It is hoped the recommendations from this research will lead to preventative community solutions that can be enacted before disasters occur to support the process of building resilience in our communities. 


\subsection{Case Study}

Community resilience, as a level of socio-ecological resilience, is one of the main aims of (re)localisation community groups such as transition towns (Connors \& McDonald, 2011). This resilience is often related to slow onset disasters such as peak oil and climate change but is of the same socio-ecological perspective as disaster resilience (Haxeltine \& Seyfang, 2009). Following what Cutter et al (2008) state about the need for greater understanding of the multi-dimensional nature of socio-ecological resilience, this project investigates the role of grassroots community groups and the way place shapes their responses to disaster and change.

The case study for this research is the community group 'Project Lyttelton' which is based in Lyttelton harbour on Banks Peninsula. Lyttelton is based over the epicentre of the devastating $22^{\text {nd }}$ February Christchurch earthquake (see Figure 1 for location of Christchurch) which resulted in the devastation of much of the main street and many iconic venues and buildings. Despite this the community has rallied and come through the disaster. The response provided by Project Lyttelton was desperately needed in the days immediately following the $22^{\text {nd }}$ February quake as centralised services were largely concentrated on urban search and rescue efforts in the Central Business District of Christchurch City. Lyttetlon is also only accessible to Christchurch via an underground tunnel and a steep hill road (Evans Pass Rd) see Figure 2. Both of these arterial routes were cut off following the earthquakes; this introduced a further issue of interest regarding physical isolation and resilience. 


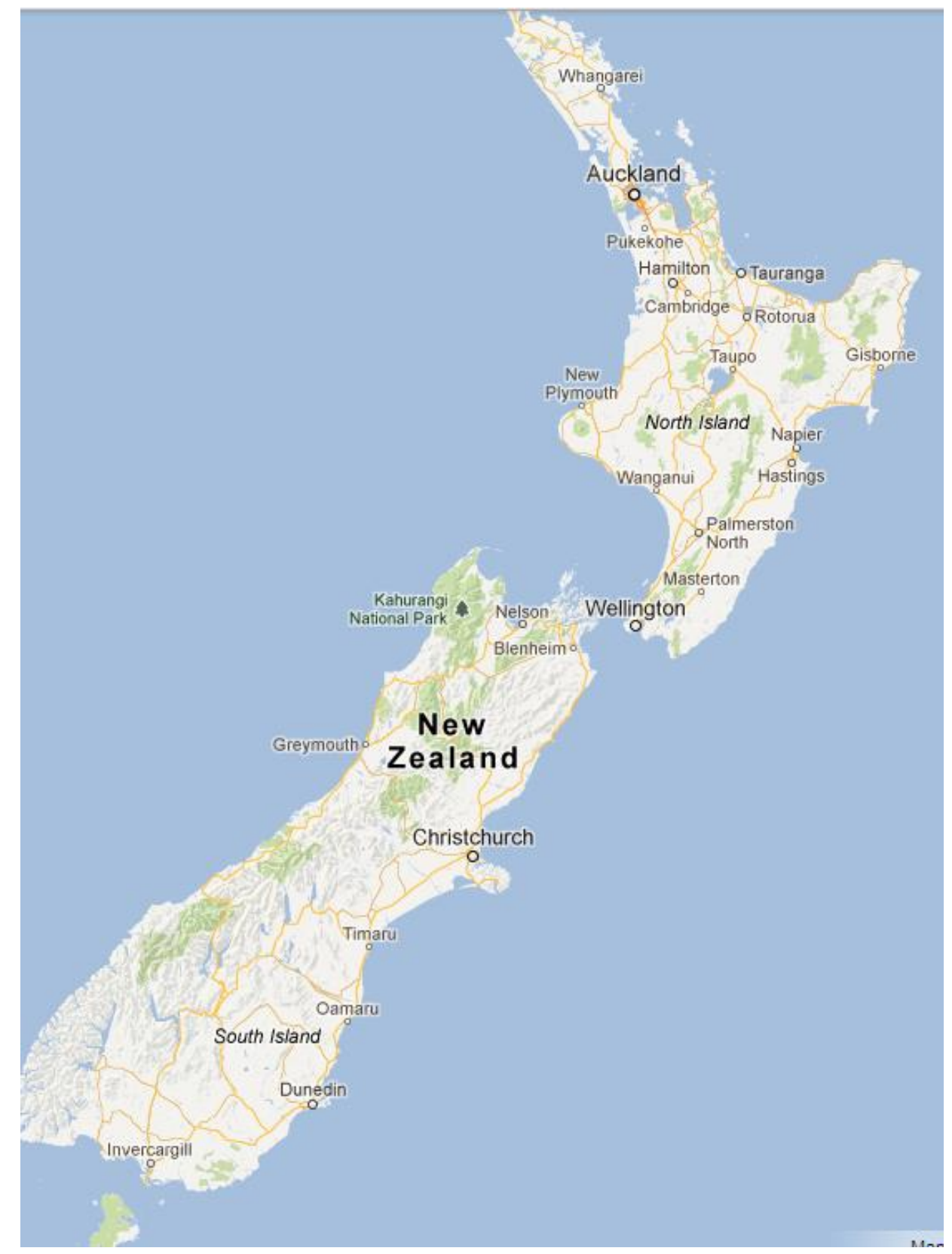

Figure 1: Map showing the location of Christchurch in Aotearoa New Zealand (Source: CGoogle 2012).

Project Lyttetlon is a grassroots community organisation which has been active since 2003 as an incorporate society (Hall, 2009). The group is not an official transition town but is associated with the transition movement through their dedication to 'cocreating a sustainable, empowered, resilient community based on values, inclusion and participation' (Hall, 2009, p. 8). The Project Lyttelton organisation operates under a strong vision statement and undertakes community projects that are guided by a 'champion' and supported by the wider organisation. To date they have worked on projects such as establishing a regular farmers market, time bank, seasonal 
celebration festivals, courses and workshops (Project Lyttelton, 2012). During the earthquake recovery period they also ran a heart sewing project to brighten up the rubble from collapsed buildings.

Working with the Project Lyttelton group and wider Lyttelton community on this research project provided an excellent opportunity for understanding the intricacies of place and identity within a functioning grassroots community group during a time of great disturbance and change. To work with the group I undertook face to face interviews with key members of the organisation and from the wider community. An e-interview online survey was also used as a way of engaging the wider population. More details on these specific methods are outlined in Chapter Two.

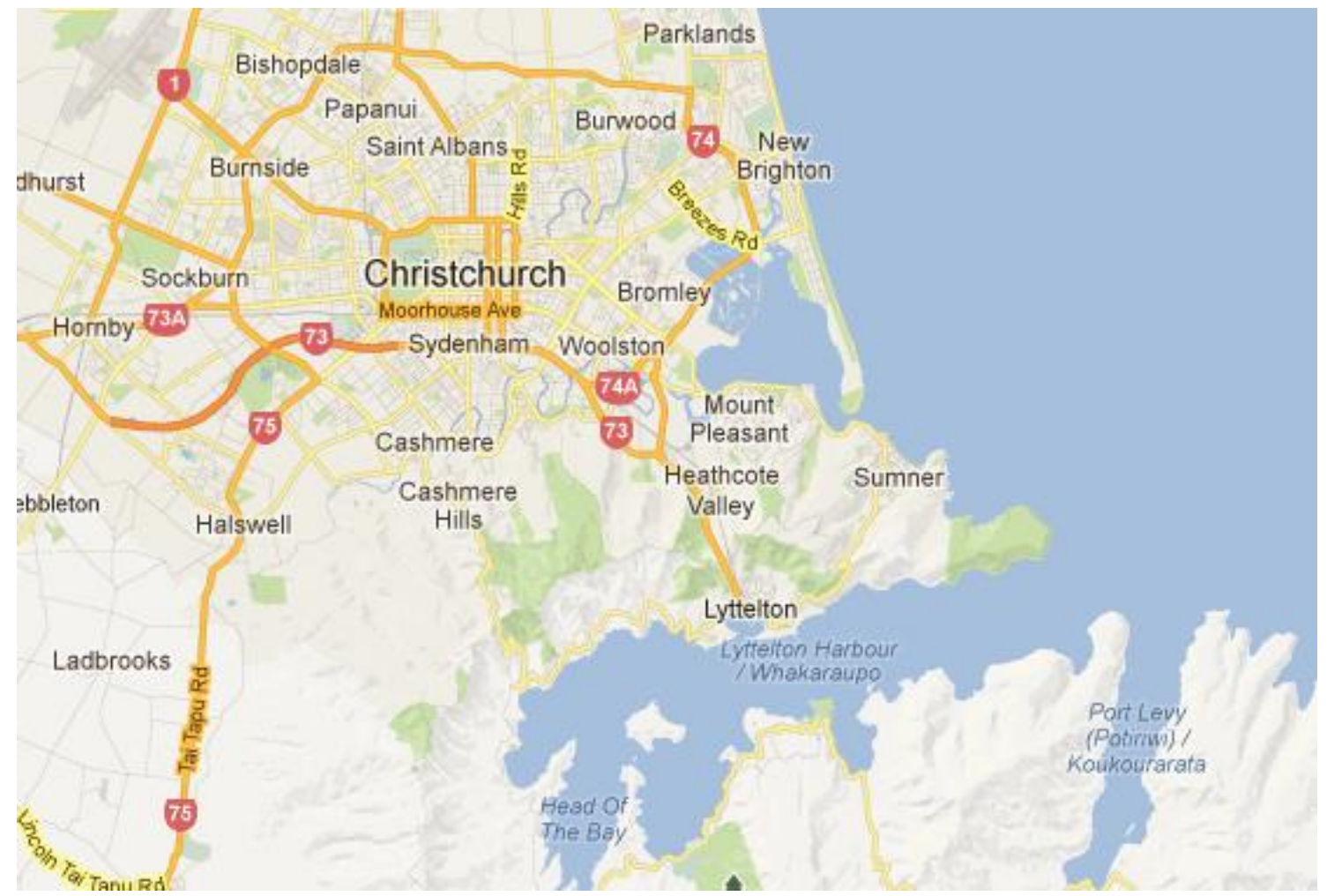

Figure 2: Google map of Lyttelton showing the township in relation to the Harbour, Road Tunnel (orange) and Evan's Pass (yellow). Christchurch city and suburbs lie North West to Lyttelton township. (Source: @Google 2012).

\subsection{Research Questions}

The central aim of this research is to investigate how grassroots community groups strengthen on-going community resilience in response to disasters and the extent to 
which intricacies of place and identity affect community resilience. Thus the following questions will be addressed.

\section{Research Questions:}

1) What is community resilience and how is it defined in relation to grassroots community organisations?

This question addresses the links between community resilience and the case study of a grassroots community organisation allowing for understanding to be gained on the potential for community groups to contribute to on-going resilience. I draw on resilience, community development and geography literature to look for the interactions between resilience and grassroots groups.

2) How can community organisations like Project Lyttelton facilitate the strengthening of resilience at a grassroots level?

The role of community organisations as catalysts for resilience during disasters is investigated through this question. I focus on five characteristics of resilience which can be acted on in a community context. These are; social support and participation, social memory and learning and inclusivity. Drawn from the literature and explored in relation to research question one, this question defines and examines the importance of these characteristics. Use of interview data to on how Project Lyttelton as a group has supported or hindered the development of these factors is used to build a case specific to Lyttelton. The data gathered for this question and question one will provide the backbone of analysis for the thread of inquiry relating to community resilience and grassroots groups.

3) How does place affect individual and group identity and how does this contribute to on-going community resilience?

The relationship between place identity and the work of grassroots community groups is articulated through this research question. The focus is on how concepts such as place identity interact with the characteristics of resilience explored in research question two. By drawing on literature from across the geography discipline the tensions between different definitions of place and identity are explored. Data gathered from interviews and internet surveys provide insights into how the place 
identity of individuals contributed to their resilience following the major earthquake on February $22^{\text {nd }} 2011$. The findings from this research question will be used for the analysis of a thread of inquiry discussing the role of place identity following a disaster.

4) How do different conceptualisations of place affect the levels of resilience enacted by a grassroots community group?

The final research question assesses the differing perspectives of place and evaluates the potential for incorporating Massey's progressive politics of place into resilience theory. This question explores the possibility of place identity as a positive or negative contributor to resilience. Interviews and internet surveys provide data to engage these two perspectives in order to more fully understand relational place interactions and community resilience following the three major earthquakes in September 2010, February and June 2011. This question brings together the two prior results chapters to articulate the role of place in shaping not only responses to disasters but also in working towards resilience. The relationship between these questions is shown in Figure 3.

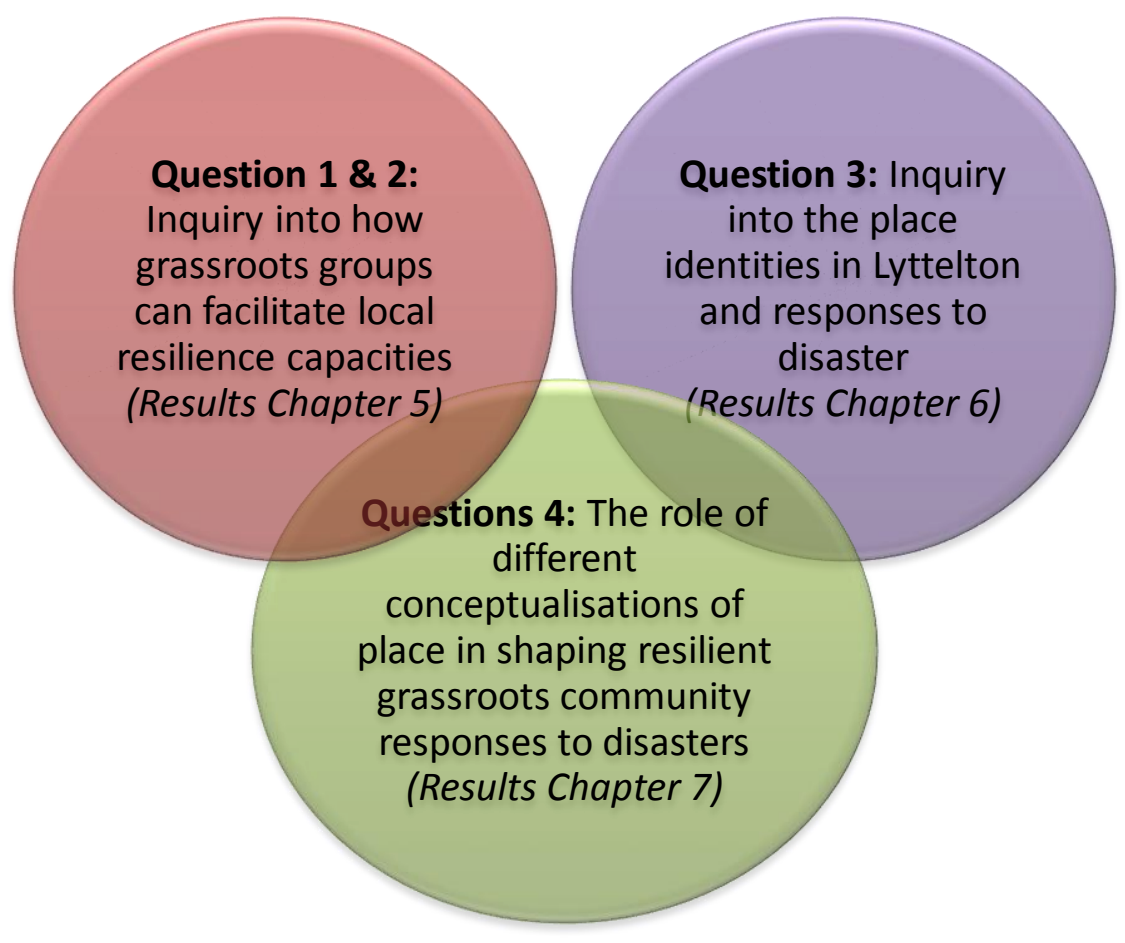

Figure 3: Diagram displaying the two threads of inquiry (purple and red) being drawn on for the analysis of the final thread of inquiry surrounding place based community resilience (green) (Source: Author) 


\subsection{Thesis Structure and Design}

The approach used to structure and design this thesis incorporates the use of images, quotes and poetry to integrate a visual representation of Lyttelton and the effects of the earthquakes. My aim is to give the reader a context within which to place this research and to draw out the human experiences of this event.

In this chapter I have provided an overarching context for this research and introduced the case study of Project Lyttelton. Chapters Two and Three review literature surrounding resilience theory, community and place. Chapter Four positions the research and myself within a methodological framework. Specific methods are outlined. Chapters Five, Six and Seven explore the findings. Chapter Five analyses the activities undertaken by Project Lyttelton and how they contributed to grassroots resilience capacities. Chapter Six discusses the place imaginaries discussed in interviews and how these were affected by the earthquakes. Finally Chapter Seven draws these two threads of research together and discusses the implications of disrupted and shifting place imaginaries on resilience. Chapter Eight concludes the thesis by summarising the research aims and findings and making recommendations relating to grassroots groups and local and central governments. 


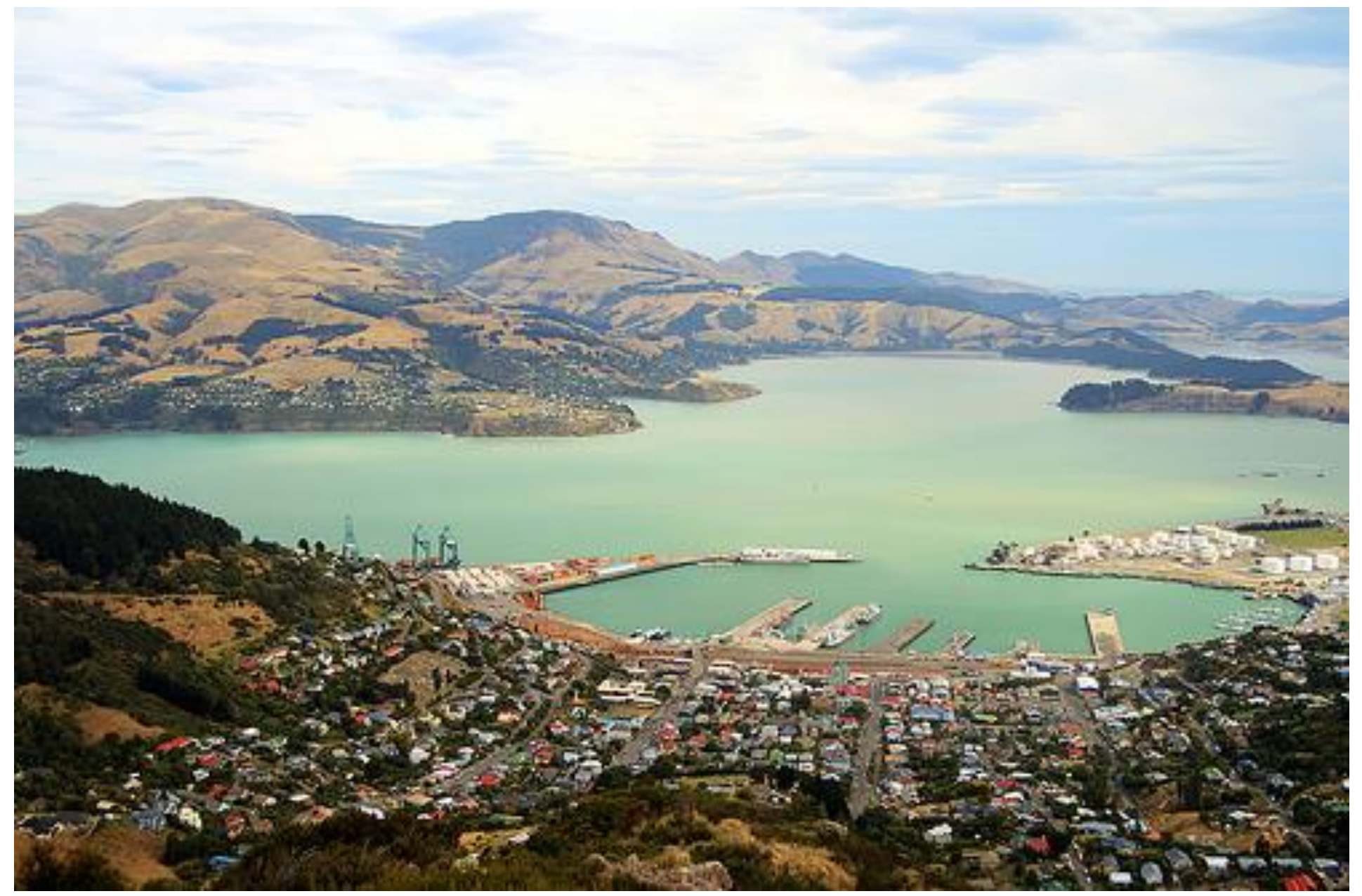

Image 2: Lyttelton Harbour February 112011 (Source: Nathanael Boehm) 


\section{Chapter 2.0 Communities and Resilience}

And the irony of it all is when we were at my friend's house on Friday night there was a big shake and she said, "Have you got your civil defence kit ready?" And I said "No, I don't" and my son said -he is 10- "No, there is no point, we had the big one. And the community will look after us. And also Mum, children and women first". And I had to laugh. He's got completely blasé about the whole thing, so I need to work on that for a bit. So yes, the community would look after us, but we still have to look after ourselves.

Quote from 'Shaken Heart' a community produced book of interviews with residents of Lyttelton (Evans, 2012, p. 33)

\subsection{Introduction}

As the above story illustrates, the community can be a source of resilience in times of disaster. Yet there also exists a broader interaction between the resilience of an individual and the resilience of a community. Resilience theory exists in various forms and within debates across the disciplines of geography, psychology, biology and sociology. I will review the work of academics that have been integral to these theories such as Holling, Berkes, Folke \& Tidball. Following this I will discuss work on conceptualisations of community and how these link with resilience theory. The final section will conclude with a review of the literature relevant to considerations of the nature of the case study as a grassroots (re)localisation group and how this interacts with resilience concepts. This section of literature review will partially address research question one which asks what community resilience is and how it is defined in relation to grassroots groups. The way members of Project Lyttelton conceptualise and understand resilience will be covered in Chapter Five.

\subsection{Resilience- ecological to socio-ecological approaches}

The word resilience is related to Latin word resalire, which translates to 'walking or leaping backward' (Gunderson, 2010, p. 2). This captures the essence of resilience from an ecological perspective - the ability to bounce back having recovered from 
disruption, crisis or change to the previous state. Resilience frameworks have risen in popularity as a tool for analysing and interpreting responses to change since its inception in the 70 s as a concept related to ecological change and disturbance (Folke, 2006). Holling (1973) was the first to outline and extrapolate this concept of resilience, which he equated to the idea of a buffer zone, reflecting the level of disturbance a system could absorb before switching states. He also considered the ability of an ecological community or system to recover to previous levels of functioning following a disturbance a crucial element of resilience (Holling 1973).

Relating the concept of resilience to socio-ecological frameworks has been the next step in the evolution of resilience theories. This newer conceptualisation of resilience takes into consideration multiple interconnections between ecological and social systems during times of change, as well as how resilience relates specifically to the societal context of a community (Cutter et al., 2008). Developments in this area have resulted in the coupling of social and ecological theories that are considered interlinked and interdependent (Peterson, 2000; Ruiz-Ballesteros, 2011). Given notions of the separation of nature and culture, especially in the physical sciences, this evolution has created space to expand resilience into a more multidimensional theory with greater relevance to wider society (Nelson \& Stathers, 2009; Ruiz-Ballesteros, 2011).

Vulnerability is another important concept that is related to the multidimensional nature of socio-ecological resilience. Vulnerability is considered in the context of the inherent characteristics of a community prior to a disturbance that produces potential for harm (Cutter et al. 2008). The concept is intimately linked with how communities respond and react to disturbance as it provides a context to the circumstances present prior to an event (Olwig, 2012). Resilience differs from vulnerability in that it is the ability of a system to respond and react to a disturbance (Cutter et al., 2008). One similarity between the two concepts is that they are often both viewed as static. However, in the opinion of some they are dynamic, ever evolving and changing processes (Cutter et al. 2008). There are tensions between the two concepts. For example, Olwig (2012) argues that while resilience focuses on the capacities of local populations, concentrating on vulnerability alone can reduce these people to passive victims, overlooking the abilities of the population. 
One particular current element of research in the socio-ecological framework that is becoming more understood in relation to community resilience and is distinctly separate to vulnerability concepts involves what Holling (1973) describes as an 'alpha phase'. This phase is the period immediately following a disturbance in which opportunities open up for change and reorganisation of the previous state that will allow for a more resilient future state to occur. Folke (2006) describes this as a process through which structures and processes combine with a renewal of the system and result in the possible emergence of new opportunities. This is an element of resilience theory that has evolved to encompass the idea of a system progressing to new adaptive trajectories and ways of functioning following a disturbance rather than 'bouncing back' to the old way of operating (Magis, 2010).

Adaptive capacities are an important consideration to make regarding resilience related to social and ecological systems, especially resilience in the context of disasters and hazards. If societal systems reconfigure in a manner that is identical to the system before the disturbance then it can be argued that there would not have been an increase in resilience as no adaptation has been made to the existing vulnerability before the disturbance (Magis, 2010). Arguably, if there are no changes to how the system functions then any further disturbances are likely to have a similar effect (Tobin, 1999). Magis (2010) supports this claim by arguing that significant transformation through disturbance and change are healthy and necessary for survival. Ultimately, this distinction suggests there is a need for a social ecological systems approach to resilience in order to reduce the likelihood of further disruptions as a result of disasters.

Focussing on resilience at such a socially determined level requires an understanding of the complex intra and cross-scale interactions which contribute to the challenging nature of studying resilience (Dale, Ling, \& Newman, 2010). Folke (2006) states that these attempts to integrate social impacts into resilience theory are occurring with more frequency. Despite this, lesser understood elements regarding societal capacity for renewal and reorganisation require further analysis due to the complexity of resilience in human and ecological systems (Folke, 2006). In order for greater understanding to occur, it is said that the inter-disciplinary nature for socioecological resilience needs to researched in more depth (Okvat \& Zautra, 2011). 
Within the social-ecological perspective there exist a number of different and varied definitions regarding different levels of resilience. As cited in Norris et al. (2007), a selection of these definitions are outlined in Table 1, which displays the contrasts and similarities between these different definitions. This research will draw on two framings of resilience. First, it will look at how community resilience is related to the successful recovery from disasters by utilising community strengths and abilities. Secondly, the research will look at encouraging adaptation in response to disturbance to minimise the harm of further changes to the status quo (Norris et al., 2007). Through using the community based definition of resilience the focus for this research will build on social-ecological resilience frameworks while also working at the community scale.

According to O'Brien et al. (2009), elements that support an increased socioecological resilience (SES) through transformation and adaptation in relation to a disturbance include: the ability to live with change and uncertainty, the nurturing of diversity, a combination of different styles of learning, and the creation of opportunity for self-organisation. Folke (2006) also claims that in addition to these elements of resilience, a socio-ecological perspective also needs to be more alert to concepts such as human agency, power relationships and equity issues among present and future generations. 
Table 1: Multiple definitions of resilience - drawn from variety of authors (Norris et al., 2007)

\begin{tabular}{|c|c|c|}
\hline Level of Resilience & Definition & Sources - \\
\hline Physical & $\begin{array}{l}\text { The ability and speed of a } \\
\text { system to return to } \\
\text { equilibrium following a } \\
\text { displacement. }\end{array}$ & (Bodin \& Wiman, 2004) \\
\hline Ecological System & $\begin{array}{l}\text { The capacity of a system, } \\
\text { individual, group or } \\
\text { organisation to continue its } \\
\text { existence, adapt and } \\
\text { reorganise following a } \\
\text { disruption. }\end{array}$ & $\begin{array}{l}\text { (Holling, 1973; Klein, } \\
\text { Nicholls, \& Thomalla, 2003; } \\
\text { Longstaff \& Yang, 2008; } \\
\text { Walker et al., 2002) }\end{array}$ \\
\hline Social & $\begin{array}{l}\text { The ability of communities } \\
\text { and social unities to } \\
\text { mitigate against and } \\
\text { withstand shocks such as } \\
\text { disasters. }\end{array}$ & $\begin{array}{l}\text { (Adger, 2000; Bruneau et al., } \\
\text { 2003) }\end{array}$ \\
\hline City & $\begin{array}{l}\text { A sustainable network of } \\
\text { physical systems and } \\
\text { human communities, } \\
\text { capable of managing } \\
\text { extreme events; during } \\
\text { disaster, both must be able } \\
\text { to survive and function } \\
\text { under extreme stress }\end{array}$ & (Godschalk, 2003) \\
\hline Community & $\begin{array}{l}\text { The development of } \\
\text { material, physical, social, } \\
\text { political and physiological } \\
\text { resources that aid } \\
\text { recovery, promote safety } \\
\text { and provide avenues for } \\
\text { adaptation. }\end{array}$ & $\begin{array}{l}\text { (Ahmed, Seedat, van } \\
\text { Niekerk, \& Bulbulia, 2004; } \\
\text { D. Brown \& Kulig, 1996; } \\
\text { Coles \& Buckle, 2004; } \\
\text { Ganor \& Ben-Lavy, 2003; } \\
\text { Paton \& Johnstan, 2001; } \\
\text { Sonn \& Fisher, 1998) }\end{array}$ \\
\hline Individual & $\begin{array}{l}\text { The process and capacity } \\
\text { for successful adaptation, } \\
\text { under extenuating } \\
\text { circumstances or severe } \\
\text { trauma }\end{array}$ & $\begin{array}{l}\text { (Masten, Best, \& Garmezy, } \\
\text { 1990) }\end{array}$ \\
\hline
\end{tabular}

As resilience itself features numerous emergent properties (Dale et al., 2010), so too does the research on the nature of resilience. This research will focus on three of the many characteristics of community resilience when analysing the importance of place in the role of grassroots organisations. These aspects are highly influenced by social factors within a community setting and have continually been mentioned by various academics as contributing to the socio-ecological foundations of 
community or local scale resilience (Cutter et al., 2008; Dale et al., 2010; Folke, 2006; Gunderson, 2010; Magis, 2010; Sherrieb et al., 2010; Tobin, 1999). They are not representative of resilience theory that focuses on hazards management and vulnerability discourses. The chosen foci are;

- Social support and participation.

- Social memory and learning

- Group diversity and inclusion

These three main themes are discussed further in the following sub-sections.

\subsubsection{Social Support and Participation}

Social support and participation are facets of the more well-known concept of social capital which is widely recorded throughout the literature as a facilitator of resilience (Aldrich, 2010; Gunderson, 2010; Magis, 2010; Sherrieb et al., 2010; Tobin, 1999). Several different forms of capital such as economic and physical capital are seen as essential for post disturbance recovery. However, social capital is often acknowledged over and above others as important in shaping community resilience (Gunderson, 2010). Sherrib et al (2010) describe social capital as one of the four capacities that they associate with shaping community resilience. In the context of community resilience they define social capital as the levels of social support, social participation and community bonds. Social support and participation have been chosen as elements for investigation in this research as they are considered essential elements in Norris et al.'s (2008) definition of community forms of social capital. Social support and participation also encompass the role of networks in communities which have also been shown to play a large role in community based resilience (Cutter et al., 2008; Gunderson, 2010; Magis, 2010).

Social support is represented by informal networks within a community such as family and friendship relationships which build support mechanisms (Sherrieb et al., 2010). Similarly, social participation is based on formal networks at an organisational level that provide community support mechanisms in times of need (Sherrieb et al., 2010). These elements of social capital, are widely documented as contributing immensely to socio-ecological resilience (Aldrich, 2010; Gunderson, 
2010; Magis, 2010). Social support and participation are important elements of social capital as they provide actual networks of assistance, caring and support (Norris et al., 2007; Sherrieb et al., 2010). Activities based around social support and participation that build trust and communication such as community garden projects are one way that social capital can be improved (Gunderson, 2010).

In addition, the loss of these frameworks can cause the disintegration of positive community dynamics, indicating their significance to well-functioning individual and community systems (Norris et al., 2007). Norris et al (2007) state that the decline of these facets of social capital is common after disasters but it should not be seen as inevitable. Therefore, retaining and improving networks and support mechanisms should be considered a goal for improving community resilience.

\subsubsection{Social Learning and Social Memory}

The ability of a system to advance to a more resilient state through adaptation and learning is a large part of SES resilience - especially as related to human systems in times of disaster (Ö. Bodin et al., 2006). Social learning and social memory form essential frameworks for processes of adaptation and learning (Gunderson, 2010; Krasny \& Tidball, 2009; Sherrieb et al., 2010). Social memory refers to the ability of society and institutions to remember and learn lessons from previous crises or disturbances (Ö. Bodin et al., 2006). Social learning is held in the memory of individuals and communities and results in the production of social memories (Berkes, 2006). In many indigenous societies the elders hold social memory and pass important social lessons down from generation to generation (Berkes, 2006)

Social learning is related to social memory, but is more focused on the adaptive management (Krasny \& Tidball, 2009). The term social learning is often referred to in adaptive co-management strategies - particularly for natural resource management (Pahl-Wostl et al., 2007). Despite this, social learning is frequently referred to as important for community resilience, in particular for the adaptive capacity of a community to move forward following a disruption (Adger, 2005). This process generally involves collaboration from multiple parties and stakeholders in the community to focus on the learning of the social entity as whole (Pahl-Wostl 
et al., 2007). Encouraging a diverse range of perspectives and knowledge is thought to enable more robust adaptation (Adger, 2005; Krasny \& Tidball, 2009). This is especially useful following a disaster in order to improve the resilience of a community.

Research shows that social memories relating to hurricane preparedness in the Pacific Islands can last for at least twenty years, other examples show it is unlikely to last more than sixty to eighty years (Berkes \& Campanella, 2006). This raises interesting questions around the role of social memory in the current globalised world, especially given research shows important sources of resilient social memories can be dismissed as inefficient or irrelevant during times of stability or gradual change (Adger, 2000).

\subsubsection{Inclusion and Diversity}

Diversity through inclusionary approaches is another element of particular interest in terms of community resilience as it relates to both ecological and human communities. Diversity within the ecological resilience paradigm is seen as integral to the capacities of biological communities where it aids recovery from disturbance by providing new and varied capabilities for the ecosystem to utilise (Krasny \& Tidball, 2009; O'Brien et al., 2009). In human communities the importance of diversity for resilience has not been widely measured or researched. However, authors such as Tidball et al, (2010), Dale, Ling \& Newman (2010) and Folke (2006) have all pointed to the importance of diversity in their work on resilient social systems. For example, Tidball et al. (2010) suggests that efforts after disasters seek to integrate one or more attributes of resilient systems such as cultural diversity and social and adaptive learning. This suggestion provokes the question as to the potential for cultural diversity to improve resilience before a disaster or disturbance occurs.

This research focuses on the wider concept of social and cultural diversity within grassroots community groups as well as the related concept of inclusion. Drawing on conceptualisations of diversity from the discipline of management (as an alternative to biological definitions), diversity will be framed as the characteristics of members of a group in relation to demographic differences such as age, gender, 
ethnicity, experience, religion and social class (Hanson, Wolfberg Craig, Morgan, \& Gutierrez Deidre, 1998; Roberson, 2006). Inclusion is thus defined as the way in which the diversity of individuals is maximised in an organisation. This is judged by the extent to which members have the ability to influence decision making processes, are empowered and have access to resources (Lorenz, 2010; Roberson, 2006). The under investigated nature of social and cultural diversity within socio-ecological resilience frameworks is an important area of further research in order to gain a more nuanced understanding of the role of culture and society in resilience processes.

Within ecological frameworks, the role of diversity is said to increase the adaptive capacity of a system by providing alternative forms of operating following a disturbance (Lorenz, 2010). One way that diversity has been shown to be important to the resilience of social systems is through providing different avenues for communities to respond, cope and grieve for the loss and change that has occurred as a result of the disaster (Lorenz, 2010). In addition, inclusion and exclusion processes are said to interfere with power and the way it is distributed. According to Lorenz (2010) this disruption is a significant source of reduced social resilience capacities.

\subsubsection{Summary}

Combined, the three main themes of social support and participation, social memory and learning, and diversity and inclusion are situated within a socioecological resilience context. They provide the background for exploring the contribution of grassroots groups following a disaster. As mentioned previously, this research draws on the definition provided by Norris et al (2007) which outlines community resilience as the development of resources to support the recovery from and adaptation to disruptive events. As this is situated within the context of 'community', the following section will outline the philosophical grounds and issues with displaying community as a concept.

\subsection{Community in a resilience context}

While there are numerous developments in the field of theoretical resilience, the practical implementation of these theories is often elusive (Tobin, 1999). Despite 
this, there is an extensive focus in the literature on the resilience of communities. This is potentially due to the smaller scale nature of communities, and the ease of undertaking research at a community level compared to a national level.

Nevertheless, communities garner significant attention with regards to socioecological resilience. This research also will focus on the community level due to intentional engagement with (re)localisation grassroots community movements. The nature of these (re)localisation grassroots groups will be discussed in more detail in Section 3.3.2 following a discussion of intricacies of the concept of community within the context of this research.

Community can be a problematic and contested construct. It is difficult to define and involves both positive and negative aspects of engagement. Positive aspects of community may include social support and cohesion while negative aspects can involve the (re)production of rigid norms, conformity and the segregation, exclusion and disrespect for diversity and difference (Prilleltensky \& Nelson, 2005). Rose (1995) identifies community as a powerful term for collective identity that practices inclusion and exclusion based on differentiated 'others' who are placed beyond the bounds of the 'community'. These tensions are important to take into consideration in this research, especially considering the contested notions of place and identity that will also be explored in relation to resilience.

Community can be analysed at different levels. For example, one can look at the micro level of family, friends and neighbours, the meso level of relationships between micro level groups, and the macro level of wider communities in societal and cultural contexts (Prilleltensky \& Nelson, 2005). Similarly there are other ways of categorising community such as communities of place based on geographic location, communities of practice based on similar interests and communities of affiliation (Collins, Glavovic, Johal, \& Johnston, 2011). Silk (1999) takes a different approach and identifies community not as a collection of relationships but as attachments that individuals discover, leading to the formation of communal bonds. These bonds result in people putting the notion of common interest before individual interests. These communities need not be territorially based and may consist of communities of choice, imagined communities, communities of memory and stretched out communities (Silk, 1999). These examples illustrate the highly contextual nature of community and how community can be defined. 
For the purpose of this research, I define community at the most basic level as a group of citizens who have something in common (Prilleltensky \& Nelson, 2005). I also stress the relational nature of community definitions as emphasised by Silk (1999). Within many grassroots community groups the point of commonality often extends beyond physical place to values and ideas about lifestyle and how their community should look like. The tensions between community, inclusion, exclusion and diversity are essential to understanding resilience at a local level. This is because as Olwig (2012) argues, people living in the local area need to undertake and fulfil their agency and self-organisation capacities to actualise their resilience potential. By working in the community of Lyttelton alongside a grassroots community organisation this research includes several different types of community such as, communities of place, communities of practice and communities of identity.

\subsubsection{Grassroots groups and community resilience}

In recent years there has been an increase in the number of groups adhering to what can be termed a (re)localisation philosophy (Transition Network, 2012). These groups work of the premise that society should be re-localised due to concerns surrounding environmental degradation, climate change and peak oil (Haxeltine \& Seyfang, 2009). Many of these groups are aware of the nexus between environmental sustainability issues and resilience and have linked the two issues in their philosophies and projects. This research focuses on the role of community groups that adhere to (re)localisation aims due to their intense involvement in their local community and the relevance of place considerations to their operation.

The convergence of issues surrounding sustainability with concepts of resilience has also occurred in academia, where the two perspectives have been theorised as interlinked and interconnected. One way this has been expressed is in the consideration of community vitality which is often seen as the cornerstone of any sustainable development project as indicative of strong, resilient communities (Dale et al., 2010). Tobin (1999) agrees, and suggests that there is a strong role for sustainability and environmental concerns in resilience approaches to disaster recovery. This, he argues, is due to interconnected nature of environmental and disaster issues in the current globalised context (Tobin, 1999). More research on 
these interconnections is slowly beginning to emerge, leading to a more holistic and interdisciplinary approach to resilience theory (Folke, 2006).

The Transition Town movement is an example of a movement that understands and works with the nexus between resilience and sustainability (Connors \& McDonald, 2011). The movement shows resistance to systems that remove the power of self-determination from local communities and strongly advocate practical and ecologically imbued responses (Mason \& Whitehead, 2011). Resilience is one of seven core principles and is often used to promote their activities (Connors \& McDonald, 2011). This is consistent with a resilience approach according to Tobin (1999), because a community that is both sustainable and resilient will have elements of sustainability such as lowered vulnerability for all members of society which support adaptation and recovery from disturbances and disasters. He also stresses the importance of local participation in building resilience which is one of the main tenets of (re)localisation movements and Transition Towns (Tobin, 1999).

The Transition Town approach is consistent with the literature. This literature indicates that working on a community level to build resilience is important for facing both sudden onset disasters and slow onset challenges such as climate change. Examples of common projects include seed banks, community gardens, awareness raising film nights and community currencies (Hopkins \& Brangwyn, 2010). Such activities are not only associated with transition towns and are often considered a part of a wider community development and sustainability strategy. In this research, the case study of Project Lyttelton is not an official Transition Town. However, they do engage in similar community activities as well as subscribe closely to the philosophies of the transition movement, allowing for similarities to be drawn between Project Lyttelton and the wider global (re)localisation movement.

\subsection{Summary}

In summary, this chapter has addressed research question one in regards to how resilience is defined in relation to community organisations. While resilience is a multifaceted and often poorly understood concept it can refer to a number of different definitions such as individual, ecological, structural and community 
resilience (Norris et al., 2007). The current study focuses on community based definitions of resilience to understand the role of grassroots organisations in facilitating resilient responses to disasters. Community resilience involves the ability of a community to respond to a crisis in a way that minimises harm and suffering, while providing adequate support in the period following the disaster or disturbance (Norris et al., 2007). Elements of community resilience are largely focused around social needs (Sherrieb et al., 2010). From an evaluation of this literature three main foci have been chosen for this research, these are; social support and participation, social learning and memory and diversity and inclusion. These characteristics cover a broad range of potential factors for improving resilience at a community level.

One of the distinguishing factors of community and socio-ecological resilience from ecological or structural resilience is the concept of adaptation to further disturbances (Folke, 2006). Adaptation is important for ensuring that further crises do not result in a similar or increased level of risk for the community. This is said to be one of the most important aspects of socio-ecological resilience as it allows for a period of change that can result in new trajectories of operating which improve resilience and the operation of the system. Furthermore, the role of community groups in the process of building resilience and adapting to disturbances is seen as important for maintaining community development (Tobin, 1999). The role of place in shaping how these groups and individuals respond to disasters and adapting to change will be explored in the following Chapter Four to further explore how place interacts with resilience. 


\section{Chapter 3.0 Relationships between the Self and Place}

"I thought about it the other day, would I want to move? A part of me has this feeling of flight, you know, lets get out of here and live somewhere else, but then you leave too much behind. We live in a lovely community and I really wouldn't want to leave all that. I think the only reason to move - all my family are overseas, if they were here that would be different.

One thing it does is, it brings home to you that we are quite insignificant, in the scheme of things, and that there is nothing you can do if there is a big event like an earthquake or tsunami, you are just like a little ant."

Quote from 'Shaken Heart' a community produced book of interviews with residents of Lyttelton (Evans, 2012:28).

\subsection{Introduction:}

This chapter examines literature on the topics of place, identity and resilience in relation the research questions three and four, surrounding the role of place in shaping resilience. The above story outlines the tensions surrounding attachment to place when disaster strikes, shedding light on the way that places have been redefined in terms of damage and the tension she feels between being attached to a place and feeling the need to flee from a disaster zone. In this chapter I argue that a relational view of place is the most appropriate lens for viewing place, especially in relation to resilience. The theoretical debates and contestation around definitions and constructions place and space will be linked to the experiences of those in disasters. In order to do this I review the theories of academics such as Doreen Massey and Robert Sack. In addition, I develop these concepts further by drawing on the links between place and constructs of identity. Finally, I conclude this chapter by discussing the literature on place and identity as it is applicable to community resilience. 


\subsection{Place}

Place as a construct and concept has received increasing attention from the academic discipline of geography in the past thirty years (Antonsich, 2011). From place as territory, landscape and nation state to place as an ever evolving and changing group of identities, place definitions have been increasingly interrogated due to the increased 'global' nature of modern society (Antonsich, 2011; Harvey, 1996; Massey, 1991). This section will describe these explorations of place and discuss the role of relational place, specifically the potential for Massey's theories of a relational framework to facilitate resilient place identities in the face of disasters.

The definition of place and the role it plays in society has always been highly contested. From the role of place in conflict to the way in which individuals associate and identify with place, the ability to describe and elaborate on the nature of space and place has resulted in an array of different conceptualisations and theories. Theories such as Sack's genealogy of places (Sack, 1997), Castells' space of flows and place (Castells, 1997) and Massey's relational theories of place (Massey, 1991, 1993, 2004) have all shaped the way place is constructed and envisioned. For example, Sack's the genealogy of places is strongly focused on the role of individual relationships to place. It emphasises place as an element of life that humans and society cannot live without while also stating that these places cannot in turn exist without humans (Antonsich, 2011). Theories such as these seek to understand and explore the complicated relationships between place and individuals. In the case of Castells, his theory challenges the typically perceived role of globalisation in shaping place, thus destabilising the assumptions of numerous economic and urban geographers (Castells 1997).

One of the many ways to view place is based around understanding place as multi-dimensional, heterogeneous, fluid and ever changing (Massey, 2004). This stance - often termed relational place, is in opposition to other theories that see place as based on fixed locations, structured social relations and territorial boundaries (Nicholls, 2009). In contrast, relational place suggests that one location will not produce a singular cohesive identity as a result of interactions between actors in a geographical location (Massey, 1991a). Place in this framework is thus based on the contingent interactions of a diverse range actors that are not geographically bounded (Nicholls, 2009). Understanding the perspectives behind theories of the construction 
of place and space is important as they are linked to the way society produces and reproduces societal relations and institutions (Agnew, 1987). Proponents of more bounded notions argue that attributes of society become meaningful once embedded in geographical locations (Massey 1993, Nichols 2009). The move towards broadening the definition of place to include different societal attributes and place definitions allows for important discussions surrounding exclusion and territoriality (Massey, 2004). These discussions become even more necessary in an ever changing globalised world, but can be difficult to undertake when imbued with nostalgia and parochialism, as is often present through bounded notions of place.

Another way of expressing the sentiment of relational place is through the concept of multi-locality, which is seen as a way of constructing "regional worlds in experience" (Rodham, 2003, p. 205). In other words, this theory searches for multiple constructions of a place in order to become familiar with the unfamiliar and to see new places in familiar ones (Rodham, 2003). Multi-locality, which draws on Foucault's concept of heterotopia, also views places as sites of multiple identities (Rodham, 2003). Foucault describes heterotopias as "a kind of effectively enacted utopia in which the real sites, all the other real sites that can be found within the culture are simultaneously represented, contested and inverted" (Foucault, 1986, p. 24). Here, Foucault sheds light on how places can at the same time present different versions of a place to different individuals. Thus, place is able to contest, represent and invert concurrent ideas of the same place.

Massey's relational view of place has played an influential and pivotal role (re)shaping academia's perceptions of place and space, especially in terms of such relational perspectives. Her inaugural piece on a progressive sense of place in 1993 developed a notion of the relational identities of place based on the multiple identities present in the people of a particular location (Massey, 1993). She argues that, like people, places have multiple identities. These identities are constructed through the way the individuals in a place relate to each other, the locality, the past and others in the world (Massey, 1993). Her contribution to the distinction between space and place is one that has also attracted much attention in the place debate. She states that the binary between space/place is unhelpful as it contributes to an essentialist and binary view of a construct. This she argues sees space as fluid and 
general and place as fixed and particular, thus reinforcing more territorial notions of place (Massey, 2004).

The basis of the argument for the need for relational perspectives of place lies in the universalist and essentialist features of bounded and territorial notions which result in exclusive characteristics of belonging (Massey, 2004). These conceptions of place are seen as undesirable as they create tension and conflict within a world with increasing migration (Massey, 1991a). While the focus of this study is not on forced migration and physical displacement due to the earthquakes, it is focused on the displacement of place identity due to the destabilisation of the physical landscape. This still bears the same considerations to essentialist and exclusionary forces. The following section will explore more closely how place is linked to identity and the disruptions caused by place destabilising disasters.

\subsection{Place and identity}

Place identity is an important concept to understand how individuals interact with disaster scenarios that threaten or destroy familiar symbols of place. This concept is most often utilised in the disciplines of psychology and sociology. However, it has been more recently been taken up by geographic disciplines, especially in relation to debates on the nature of place (Dale et al., 2010; Silk, 1999). In simple terms, place identity and attachment describe the bond between people and places (Norris et al., 2007). Altman and Low (1992) define people-place attachment as an affective bond, while Manzo and Perkins (2006) state that place identity is a dimension of the self that develops in relation to elements of the physical environment. These concepts underscore a shift in perceptions of self to include notions of place, thus shifting definitions of personal identity from a matter of 'sheer consciousness' to one involving intrinsic awareness of the importance of place and relationships (Altman \& Low, 1992; Manzo \& Perkins, 2006).

Understanding the meaning attached to a place by individuals aids the understanding of preferences, connections, and perceptions linked to place in a community (Manzo \& Perkins, 2006). Established communities are said to have a 'sense of place' however it is often unclear what this is and how it affects those in the community (Dale et al., 2010). There has been an increasing focus on place 
identity in recent times due to the perceived fragility of place that has come with the globalisation (Antonsich, 2011; Scannell \& Gifford, 2010). Part of this focus has led to an increasing awareness of the notion that without place there is no self and vice versa (Easthope, 2004).

Other concepts of place identity cover the multi-dimensional nature of attachment as a process. For instance, Gillian Rose discusses how 'sense of place' is understood as the way place interacts in people's lives and is highly constructed and influenced by political, economic and social practices (Rose, 1995). She suggests this has led to sense of place as defined as having inherent meaning beyond that which is given to it (Rose, 1995). Tuan's concept of Topophilia is similar to Rose's 'sense of place', but is less linked to the way place pervades every element of life (Easthope, 2004; Tuan, 1974). Instead, Tuan focuses on the 'rootedness' of place identity setting up the idea that place constitutes identity and vice versa. Thus, he rejects what he believes is a distance between self and place which Rose sets up in the 'sense of place' concept (Easthope, 2004)

Rose on the other hand notes that there are several main arguments that are often used regarding the construction of 'sense of place', all of which maintain the premise that place does not hold any inherent meaning (Rose, 1995). The importance of power is central to her theorisations particularly when sense of place is part of the politics of identities (Rose 1995). Sense of place is therefore part of a system of identification that is used to attribute meaning and distribute power (Rose, 1995). Robert Sack's theory on place also draws on this assertion, claiming place and sense of place are used to define and express power (Sack, 1997). There are strong parallels here between the aforementioned ideas that place is imbued with multiple identities. Many of these identity theorists also seek to connect the personal to the external world through investigating the integration of multiple facets of life into the place identities people hold.

Clearly, the debates surrounding place and identity are complex and multifaceted. What is clear is that place is intimately linked with ideas of the self, personal identity and power (Antonsich, 2011; Easthope, 2004; Rose, 1995; Tuan, 1974). The consideration of exclusionary and essentialising constructs of place and place identities has far reaching implications for the nature of place as a factor in 
community resilience. The ability for constructions of place to impact on the diversity in a community, and the levels of social support and participation found before and after a disruptive event, are all concerns which are raised from this shift in perspectives. However, the debate surrounding definitions of place involves widespread argument as to the nature of place and identity and the extent to which the definition reconfigures how the politics of place is considered (Massey, 2004).

\subsection{Place and resilience}

As discussed in Chapter Three - community resilience can be understood as the ability for communities to respond and adapt to disturbance and disaster, while exploring possibilities for alternative ways of operating to reduce vulnerability to further disruptions (Cutter et al., 2008; Magis, 2010; Tobin, 1999). Several authors commenting on resilience and place have noted that conditions such as disasters result in a destabilisation of the basis for what many people relate to as part of their place identity (Manzo \& Perkins, 2006; Norris et al., 2007). The disruption to a place that a disaster causes, through damage to buildings and landscapes can threaten individual, communal and group aspects of identifications with place (Norris et al., 2007). This situation can cause a disturbed sense of reality and continuity, grief and feelings of loss and alienation (Manzo \& Perkins, 2006). Thus, displacement can be based on physical relocation and can also occur within place (Milligan, 1998).

Place identity in relation to disasters has been theorised as both a positive and negative influence on the resilience of a community. Attachment to aspects of place identity can be positive through strengthening group identity and bringing people together (Berke \& Campanella, 2006). Others also suggest place identity is fundamental to community spirit which is often at the forefront of resilience responses to disasters (Manzo \& Perkins, 2006). However, Scannell \& Gifford (2010) suggest that place identities attached to the pre disaster state can negatively affect resilience and community responses. This form of place identity can result in settlements being rebuilt in the same way following a disaster and not in a way that contributes to the future adaptability of a location to disturbance or disaster (Norris et al., 2007). 
The concern that place identities could impair resilience through attachment to a static idea of place is similar to issues raised in the wider debate around place definitions. These concerns have often been theorised in terms of migrant communities or other introductions of difference into a community threatening a perceived singular and stable identity of place (Massey, 1991a). However, as with the change induced by a new cultural presence in a community, it is possible that the disturbance caused by disasters can also cause people to assert place identities in an exclusive and conservative manner to the detriment of those who do not identify with a place in the same way. Silk (1999) also raises these concerns stating that communities that are based predominately singular place definitions can reinforce inequalities, differences and pre-existing power relations found in the wider society.

Diversity is considered a key tenet of community resilience. Therefore, it is important to understand tensions as a result of place in a community during a disaster may not only hinder physical rebuild efforts, but also isolate and exclude certain groups in the community. Research question four (how different concepts of place influence levels of resilience) seeks to explore this question further by investigating the conflict and common ground that may have arisen as a result of shared or differing place imaginaries in Lyttelton. The effect of the destabilising nature of the earthquake on place identity provides a context for understanding the way people view Lyttelton, and how this has helped or hindered their resilience.

These concepts are important to understand due to the significance of diversity and inclusion in building social capital - an important facet of community resilience. Working with place identity also allows for a focus on how individuals and as communities deal with the loss of place attachments, further providing opportunities to reinforce and build community resilience following the disaster. I address this final point in Chapters Six and Seven within the context of Massey's progressive politics of place in order to explore how encouraging a more progressive and relational attachment to place may improve a community's resilience to future disasters and relieve tensions between varying strata in a community. 


\subsection{Summary:}

In summary, place is a contested concept, commonly conceived either as relational or as a territorially bounded location. Place identity is often seen through a relational perspective as the multiple ways in which different individuals conceptualise, identify with and imagine places. It is important to understand place and identity in relation to community resilience as disasters disrupt the physical signifiers of place such as buildings, landscapes and monuments. Disasters can also cause the forced relocation of individuals and communities. This research however focuses in on the impact of nonphysical displacement of place identity during the 2010/2011 earthquakes.

In the current study I will adopt a relational theory of place as outlined earlier and as espoused by Massey (1991b, 1993, 2004), Foucault (1986) and Rodham (2003) as a framework for analysing the multifaceted and multiple imaginaries of place. This framework draws on place and identity theory to understand in more depth the way individuals relate to and construct places. Relational theories of place allow me to fully explore the fluid and multiple place identities that are present in Lyttelton and will provide insight into how they contribute both positively and negatively at varying levels to the community resilience capacities discussed in Chapter Three. 
This page is intentionally blank. 


\section{Chapter 4.0 Positioning the research}

The branches of my family tree have trickled into this country on boats and planes over the last one hundred and fifty years. My people come from across the British Isles; Ireland, Scotland and the Isle of Man, lands both familiar and different to the country we now call Aotearoa New Zealand. The British authorities - signed the Treaty of Waitangi in 1840, a deal which has legitimated our presence in this country but one that is to this day fraught with injustice and colonial legacies.

I was born in Central Otago alongside the mighty Mata-au Awa, known also as the Clutha River. A representation of the dual identities which can exist in one place, the name of my river reflects my Scottish heritage and ancestors while the Mãori name reflects my presence in a country that is not of my ancestors but of the Tangata whenua - the people of the land. In my adolescent years I lived in Ōtautahi, Christchurch. Whakaraupo, Lyttelton Harbour was my playground; I sailed, swam and walked the hills of the harbour in my weekends and holidays. My history and stories of these places serve as one small example of the numerous and complex intersections of place and identity. Place is entwined in our identities intersects with cultural and historical phenomenon and integrates the core of what we hold dearly as part of who we are.

\subsection{The Researcher}

This research integrates understandings of place and resilience in the context of the case study of a community hit by the 2010/11 Christchurch earthquakes. This topic is emotional both for the interviewees and myself as the researcher due to my close ties to the region. These considerations are part of the fundamental elements of my positionality which influence any research I am involved in. The process of acknowledging and working with my position as a researcher involves more than simply listing and acknowledging the aspects that contribute to it (Browne, Bakshi, \& Law, 2010). Postionality is understood as how research and knowledge is interpreted and produced through interactions between participants and the researcher (Browne et al., 2010). Analysing and critiquing my social characteristics 
and working with them in order to mitigate the aspects are important elements of this process.

Positionality is important to consider in order to understand how my identity interacts with my research and the way interviewees may receive or react to me. This especially applies when dealing with issues of diversity and inclusivity. Thus I must acknowledge that I am a young Pakeha (NZ European) woman of Irish, Scottish and Manx descent, that I am from a working class rural background and that I am university educated. All these elements of my identity will influence how I research, as well as how I interact with participants. These aspects of my positionality will also influence how participants interact with me. This may mean I interpret what some people say without a wider historical context that they may have. Conversely, because I am not from Lyttelton I may be considered an outsider and thus may not be privy to certain information that others in the community may be. In addition, aspects of my identity may shape who I interact with. As a woman I found it intimidating to meet with men I did not know in situations where I was isolated, this may not have been the case were I of another gender. Furthermore, while I have experienced many large earthquakes in Christchurch, I did not experience the February $22^{\text {nd }}$ event and was thus not able to relate to participants on this level. This may have affected how comfortable individuals were with talking about their more personal stories.

To mitigate against these aspects of my positionality significantly interfering with my research, I openly acknowledge the bias I may carry in my research and incorporate this into a carefully considered research process (Rose, 1997). Through acknowledging these elements of my identity I am able to try to with them. For example, I endeavoured to meet a male participant in a work place rather than a home environment. I also attempt to openly recognise my outsider status, and made further attempts to understand the background issues for the community. In addition, I endeavoured to avoid universal claims and over-generalisations which, according to Rose (1997), marginalise other world views and knowledge claims and privilege my own bias.

In this research I also needed to be sensitive to the experiences of the interviewees, especially because many people in the Canterbury region are suffering 
post-traumatic stress from the earthquakes. I attempted to minimise any distress to the participants through designing research questions around the positive aspects of working with Project Lyttelton during the quakes and not focussing on any recollections of the actual event. I was aware that the questions may for some people prompt them to discuss their recollections and memories which needed to be handled sensitively. As I have experienced one of the large earthquakes and many of the aftershocks, I felt I was able to do this with some understanding of what it is like to experience large earthquakes and the disruption to place and identity they cause.

One way I engaged with my positionality through this research is the use of story. I have done this through prefacing each chapter of this thesis with stories. The initial two stories follow my progression through the research and explore my positionality in relation to the research. The remaining stories in Chapters Three through Eight are those of Lyttelton residents recalling their experiences relating to the earthquake events and the recovery period. The aim here is to use narrative to write in the stories of participants and residents to shed light on the personal element of disaster and to privilege the experiences of these individuals. As Czarniawska (2004) notes, narrative provides an alternative form of knowing and also act to challenge representation by revealing the complications of trying to 'represent' others. By including these voices I am introducing another form of knowledge into the typically academic arena of the thesis as well as representing earthquake stories as complex and multifaceted.

When working with place and identity I believe it is vital to the integrity of the research to speak to the history of a place and the Tangata Whenua (people of the land). The acknowledgement of my histories and own place identity allows me to acknowledge the past and the colonial legacies we as a country experience every day and that we all carry with us - as Māori, Pakeha and Tau Iwi (Indigenous, New Zealand European and Migrants). Unfortunately, due the scope of this research I have not been able to focus extensively on Māori conceptions of place and identity. Despite this, I want to acknowledge Māori and their place as Tangata Whenua along with my positionality as a Pakeha researcher. 


\subsection{The Approach}

In accordance with research methods that take into account positionality and the multiple constructions of place and identity, I use a post-structural approach in this thesis. Post-structural approaches imply the understanding of language as constitutive of knowledge and reality. The research process employs discourse analysis of interview data and texts which act as an interpreting tool between society and culture, and allows for the deconstruction of the multiple messages imbued within participants' experiences (Kitchen \& Tate, 2000). Acknowledging and working with my positionality also aligns with these post-structural perspectives, because they require an acknowledgement that all knowledge is situated through the positioning of researchers and research institutions (Panelli, 2004).

Post-structuralism argues that relationships between society and culture and cultural significance are communicated through language (Murdoch, 2006). This is similar to the premise of qualitative research described by Dwyer and Limb (2001), that knowledge is constructed through the intersection of cultural, historical and political forces. Post-structural perspectives further explore the contested nature of knowledge by investigating the interaction between systems and knowledge and the concept of knowledge as situated within a context of extensive relations (Murdoch, 2006). This approach is appropriate given my research aims which seek to understand the multiple identities and contested nature of place in times of disaster and how this is related to resilience. These are concepts that rely on post-structural perspectives that see the world as layered with different meanings.

Thus the foundation of this research methodology is the post-structural assertion that knowledge is socially constructed in a context shaped by different norms. Here, there is no assumption of a measurable and knowable pre-existing world, rather reality is considered dynamic and ever changing due to the multiple forces of cultural, economic, social and political forces (Dwyer \& Limb, 2001). Consequently, I will utilise techniques to understand the multiple messages being conveyed through language through the use of discourse analysis of material gathered through qualitative methods (Kitchen \& Tate, 2000). 


\subsection{The Methods}

Qualitative methods have been chosen as the framework for this research as they are fundamentally based on assessing the constructed nature of the 'real' world, this aligns with the post-structural lens I have chosen (Dwyer \& Limb, 2001). The integration of the assertions on the nature of reality and knowledge in this research form the foundation of an epistemology and ontology typical of qualitative methodologies. Qualitative methods provide a means to interpret peoples' relationship to place and identity in community resilience processes. The use of qualitative methods in this context is essential to this research as it is fundamentally based around understanding participant's constructions of place and community in the context of disaster and resilience.

Qualitative data was collected via semi-structured interviews and e-interview questionnaires with participants involved in the case study of Project Lyttelton. This qualitative data allows a discourse approach to analysis that provides depth and nuanced understanding of individual experiences surrounding the earthquakes. Subsequently, the use of discourse analysis of the data is useful for gaining an understanding of the forces at play in the creation and understanding of place and resilience. In addition, the focus on in depth analysis rather than extensive and numerical data allows for greater comprehension of the relationships between disaster responses and place (Dwyer \& Limb, 2001).

\subsubsection{Case Study}

Utilising a case study allows engagement with issues of place and identity at greater depth through investigating a specific example of community resilience (Creswell, 2003). Creswell (2003) states that case studies are bounded by time and activity and are used by researchers to collect detailed information over a sustained period of time. This allows for experiential insight and knowledge to be understood as it arises directly from a specific situation (Stake, 2005). Stake (2005) identified several types of case study. Lyttelton is both an exemplary and instrumental case study. The case is exemplary as it is the sole example used in this research but it is also instrumental as it draws insights into the intricacies of place and identity in a community 
resilience context using the specific philosophy of Project Lyttelton and the circumstances surrounding the earthquakes (Stake, 2005).

The research data is based around my interactions and interviews with members of the (re)localisation focused community group Project Lyttelton. The township of Lyttelton was badly affected by the earthquake on $22^{\text {nd }}$ February 2012, in which the organisation played a large role in the recovery effort. The group is largely based on (re)localisation and transition town philosophies and aims to build and create a 'sustainable and vibrant' community (Project Lyttelton, 2012). As the relocalisation philosophy behind their actions is based upon their location and increasing the community's dependence on the immediate geographical region it provides an interesting context for analysing relationships to place.

\subsubsection{Semi structured interviews}

Semi structured interviews were undertaken to address research questions two and three (how resilience is defined in relation to community groups and how these groups seek to improve resilient capacities). Semi structured interviews enable an understanding of participants' experiences and views at a deeper level than surveys or quantitative data collection can enable (Creswell, 2003). This allowed me to delve into the meanings and constructions of place and identity (research question two), as well as the ability to understand experiences around diversity and inclusion in order to answer (research question three). Being able to conduct face to face interviews also allowed me to build a rapport with participants that increased my ability to understand how Project Lyttleton has worked in the face of disaster.

During my work in the field I carried out six face to face semi-structured interviews and one semi-structured interview over the phone. Participants were found through my personal connections in the community, the internet and through recommendations from other participants. Informed consent was received in accordance with Victoria University of Wellington Human Ethics Committee guidelines (see Appendix 6). Interviews were then recorded transcription. Participant identity is hidden through the use of numbers, for example "Interviewee 1, Interviewee 2". 
Questions were framed using plain language to avoid any confusion or unnecessary complication (See Appendix 3, 4 \& 5 for interview questions). Conversation, even though at times appearing unrelated, was encouraged both to ease myself and the participant into the interview as well as to understand the wider context of the participants' experiences and perceptions. I was also in contact with several participants throughout the research process at other times to discuss ideas and further experiences. These conversations however were not recorded but were used for context and wider understanding rather than direct quotes.

Interviews were carried out in June of 2012 in Lyttelton. The location for the face to face interviews varied. Two were carried out in participants' homes, one at Canterbury University, and three at participants' place of work. Locations for interviews were suggested by participants so as to make the interview process as comfortable and flexible for them as possible. The duration of the interviews ranged from half an hour to two hours, depending on the location and whether the interview was being undertaken during work hours. Four interviewees were from Project Lyttelton and three interviewees were from other community groups. Effort was made to contact others from the wider community and other organisations however Lyttelton organisations have been inundated with research requests which made finding participants more difficult. I was also highly aware of the sensitive nature of such experiences and the need for sensitivity when approaching people to be interviewed. To counter these issues and put less stress on potential participants I also used an internet based interview to gather more views and perspectives.

\subsubsection{Internet based structured interviews}

An internet based interview was used to gather information from a wider and more diverse range of participants than could be gained using face to face interviews given time constraints and ethical issues surrounding the earthquakes. This method is somewhat new to qualitative methods but is documented by Jensen (2010) who describes it as a method similar to internet surveys but different in its approach. Rather than determining frequency as in quantitative surveys, the data gathered covers a diverse range of perspectives on a topic of interest (Jensen, 2010). The EInterview, based on email and chat room contact is remarkably similar to this 
approach, through using the internet as a medium to gain more diverse views and participants.

According to Shepherd (2011) the method can canvas a wider group of respondents in greater numbers than other methods. One concern with the use of internet e-interviews is the potential for missing the target group or reducing the accessibility of the interview to certain age groups or groups with different technological capabilities (McLafferty, 2010). I acknowledge that this is a concern with this method. However, by using the internet in conjunction with face to face interviews and secondary text analysis I have combined a number of methods to allow for different groups of the community to participate at varying levels. In the case of the E-interviews I have been able to target a younger demographic who are computer literate through social networks whom I may not have been able to come into contact with through face to face interviews. Furthermore the use of the Einterview in my methods has meant that $\mathrm{I}$ have been able to gather more responses and perspectives.

The questions for the E-interviews were open ended yet structured, and were designed to provide insight into a diverse range of participant experiences and feelings surrounding Project Lyttelton and the earthquake response. The use of open ended questions allowed for participants to express their experiences in their own words in a way that was able to be carried out remotely yet still be useful for qualitative analysis of the data gathered (Longhurst, 2010; McLafferty, 2010). The questions were based loosely on the semi structured interview questions but included more targeted questions aimed at recording responses to do with perceptions and experiences with Project Lyttelton (See Appendix 5). I received eight responses. Participants took between twenty minutes to over an hour to fill in the e-interview form. Due to the time taken to fill out the forms I received very detailed and considered responses, the quality and diversity of which was comparable to the face to face interviews.

From a question regarding participant's origins in Lyttelton I was able to discern that the participants belonged to a variety of social groups as well as different cohorts of migration to the town. Some participants had a family history in the area going back several generations while other were more recent migrants, both to New 
Zealand and to Lyttelton. Participants were mainly found through social media such as Facebook and the associated groups relevant to the Lyttelton community, especially useful was a group created to save a historic building. Friends and family also contacted people who they knew in the Lyttelton community and asked them to consider filling in the e-interview and pass it on to their networks. Similar to face to face interviews, participant identities are hidden through the use of numbers.

\subsubsection{Secondary Sources}

I also engaged in the use of secondary texts to supplement the information in the interviews. Secondary data can be used for greater contextual understanding (White, 2010). I used data from websites for facts relating to history and the town for this purpose. At other times I used social media and locally made films to get a broader grasp on the context around the experiences of those in the community and their attitudes to Project Lyttelton as expressed over the internet. Finally, I drew on a book produced by Project Lyttelton containing 32 unaltered interview transcripts that were carried out with residents following both the September $4^{\text {th }} 2010$ and February $22^{\text {nd }}$ 2011 earthquakes. These interviews outline individuals' feelings and experiences and have been useful for providing a wider pool of data for analysis without having to cause undue stress to residents as a result of multiple research interviews.

\subsection{The Data}

Data gathered from face to face interviews and the internet based interviews was collated and analysed using qualitative data software and discourse analysis. NVivo was used as the primary tool for analysis. Interview transcripts once typed were downloaded into the software and manually coded for themes. Two types of codes were used in this process, both inductive and deductive. Deductive codes were broken down into each themes for each chapter and related to the main threads of research; resilience, grassroots groups and place identity. Inductive codes were taken from the transcripts as reoccurring trends. Several significant trends emerged from the deductive codes. 
The data was then analysed using Foucauldian discourse analysis. This involved questioning the data for who is present, who is not and the layers of power relations evident in the texts (Waitt, 2010). I used discourse analysis as my method for analysing the data as it aligned with the post-structural assertion that knowledge is subjective and subject to individual positions. Discourse analysis of the data involved inquiring into statements that were purportedly 'true', questioning privilege and interrogating the role of power in the positioning of subjects and knowledge (Cope, 2010; Jackson \& Mazzei, 2012; Waitt, 2010). I engaged with material relating to discourses of place and place imaginaries to explore how participants engaged with place and identity throughout the disaster and recovery. To carry out this analysis I broke the data into themes and used the questioning techniques outlined in several texts on Foucaldian analysis such as coding, investigating for the effects of 'truth' and noting inconsistencies (Waitt, 2010).

The three findings chapters explore the interpretations of this discourse analysis. The first, Chapter Five discusses discourses of Project Lyttelton, how they discursively construct their identity and resilience. This chapter also details how their activities contributed to the immediate functioning of the community following the earthquakes. Chapter Six explores discourses of place within participant experiences and views of Lyttelton, investigating how these shifted with the earthquakes and how this affected their place identities. Chapter Seven draws the two threads of research based on community resilience in chapter Five and discourses of place and identity in chapter Six together to investigate the role of place and identity in shaping community resilience and the role of progressive frameworks of place in instigating resilience

\subsection{Summary}

In summary, the current study adopts a qualitative methodology that engages with post-structuralism. To undertake this research strategy I conducted semi structured interviews, an online E-interview and collected secondary data. The data collected was then transcribed and analysed using coding software NVivo in a manner consistent with post-structural epistemologies through the use of Foucauldian discourse analysis. 
This page is intentionally blank. 


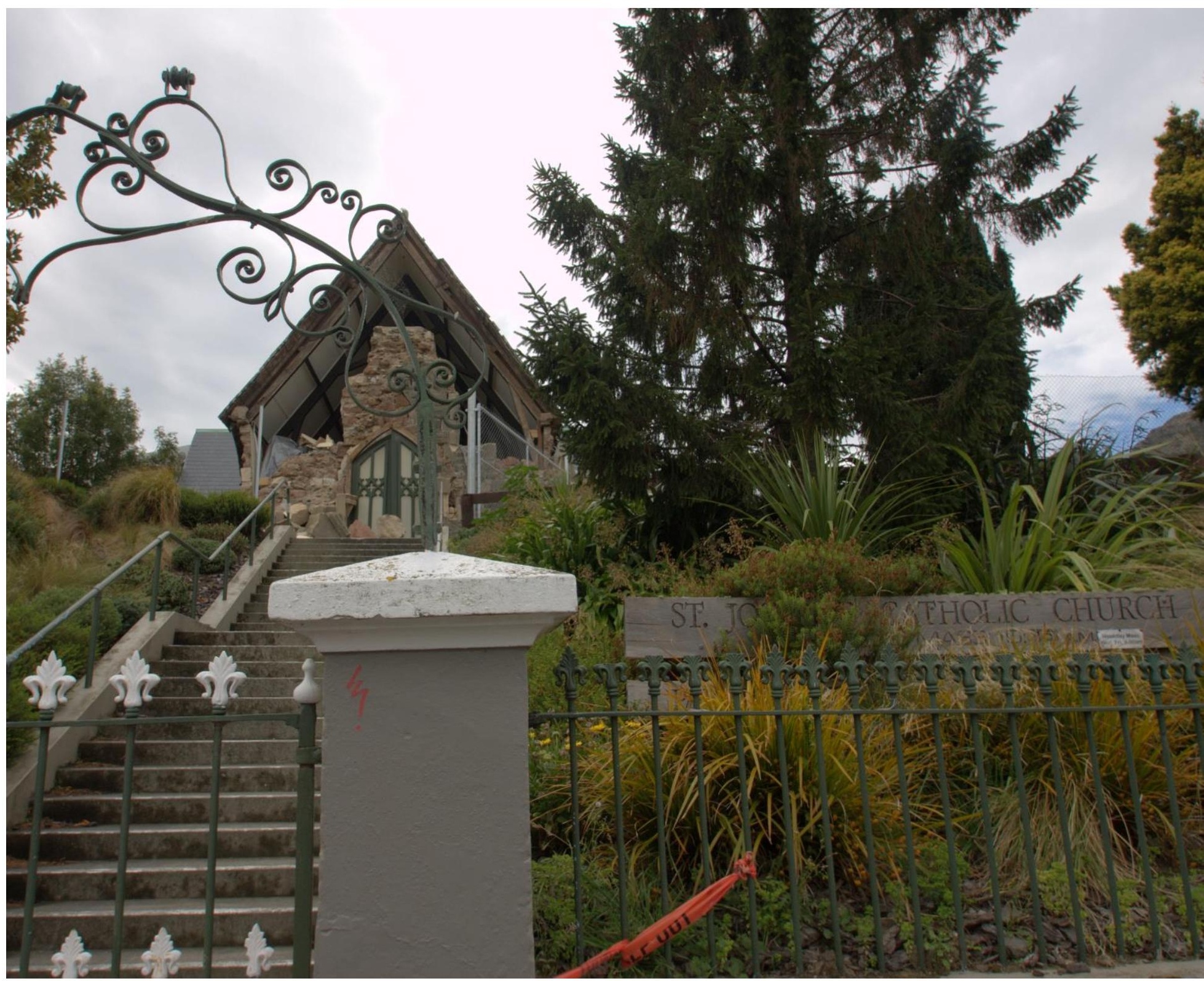

Image 3: Damaged sustained by St Joseph's Catholic Church in Lyttelton 2011 (Source: Helen Devereux) 


\section{Chapter 5.0 Findings: Grassroots resilience}

I feel a bit more settled now, but quite hesitatingly so, it felt quite nice to have suspended time where everything just stops and you can reconstruct everything however you want it, literally, just like the city I guess.

Over the last few years I have been doing quite a bit of talking about sustainable living, be it organic gardening or having solar power or living off the land. So the earthquake was really an interesting test run, in how I fared when all the systems were down, how was I coping and how ready I was. I wasn't at all. I wasn't scared because I knew the systems were going to come back up, I knew the power and water would come back on. But it just reminded me again, "Yeah, that's right, it's really important to be ready and I am not". And just a few days ago I went camping, and got totally snowed in and had to get rescued again. My car didn't cope, I didn't have enough clothing - same message again!

So this is changing for me.

Quote from 'Shaken Heart' a community produced book of interviews with residents of Lyttelton (Evans, 2012:6)

\subsection{Introduction}

Community resilience is complex, multi-faceted and not always well explained or understood. It is broadly defined as the ability for a community or group of individuals to cope with and adapt to the challenges of disruptions such as natural disasters. Rather than a concept based on the idea of homeostasis - or the stable functioning of a system at some perceived 'normal' resilience perspectives encourage adaptation and re-organisation towards new trajectories (Norris et al., 2007). Indeed, a resilience perspective sees the outcomes of disturbances as potentially positive through the reimagining of societal possibilities and thus decreased vulnerability to further events. It is this perspective that distinguishes 
socio-ecological resilience from the traditional 'bounce back' conceptualisations of ecological resilience and the vulnerability focused perspectives of hazard management. The above story introduces how these concepts become integrated in a practical way in the lives of those who have experienced disasters, emphasising how learning and adapting from these experiences is integral to changing how we respond to further disruptions.

In this Chapter I turn to Project Lyttelton to illustrate and explore how community groups support the resilience capacities identified in Chapter Three; social support and participation, social learning and memory and diversity and inclusion. I argue that the role of grassroots community within a crisis context is integral to supporting and maintaining resilience in a community To do this I describe and analyse the work of Project Lyttelton in relation to research questions one and two - how resilience is defined in relation to community grassroots groups and how these groups facilitate resilience at the community scale. The concepts utilised provide a foundation for understanding the valuable contribution of grassroots community groups in times of need, as well as exploring how the group and its members understand resilience and their role. Central to this chapter is the concept of community resilience as a fluid and ever changing process that reflects the need for communities to cope with uncertainty and flux.

\subsection{Project Lyttelton}

Project Lyttelton began as a small group in Lyttelton who wanted to grow the strength of community in response to issues such as climate change and peak oil. The group was established in 2003 as noted in Chapter One. The individuals involved in Project Lyttelton have a diverse range of backgrounds and reasons for joining the groups. To understand the effect of group activities on resilience following the earthquakes it is necessary to first understand the identity and structure of the group. The constructed identity embodied in the aims and actions of Project Lyttelton will also be useful for understanding the discursive reality of their actions.

One of the themes that emerged from several participants is that Project Lyttelton is run as a values based organisation (Interviewees 2, 6, 7). The group is organised around core values to build a vibrant, sustainable community. Anyone 
who is interested can become involved and drive their own projects as long as the project is "run past the vision" (Interviewee 2). In addition the organisation runs on the base of appreciative inquiry. The same participant described this to me:

We try to work from an appreciative inquiry point of view so we like to hear and tell the stories about ourselves while we're at our best. And that keeps on creating the good stories (Interviewee 2).

This approach, combined with the values base has constructed a discourse of Project Lyttelton as an active organisation that is open to anybody who has the drive to become involved.

Clearly then, the group aspires towards an inclusive attitude. The individuals I interviewed became involved in a variety of ways. Two were founding members from when Project Lyttelton evolved out of a National Town Pride movement called "Our Town"; two were migrants and several others became involved through their activities in the town. Project Lyttelton members pride themselves on being welcoming and inclusive to those in the community, especially those newly arrived. One participant described her experience like this:

I got involved with Project Lyttelton [when we moved here]. We arrived on the Thursday and I went to the farmers market on the Saturday and on the Sunday someone came round with a welcome bag. I don't know if you've heard about the welcome bag project but yeah so that's sort of how we got involved and then we were at the community garden the following week (Interviewee 6).

The welcome bag was mentioned by another participant who said it was her favourite activity because it welcomed new people to the community and provided them with baking, useful information such as timetables and invitations to Project Lyttelton events (Interviewee 2). Other participants told me that they are always trying to remain inclusive through inclusive imagery and wording. The reality of this identity discourse is further discussed in Section 5.4.3.

Another discourse within Project Lyttelton's identity is that of selfsufficiency and reliance on each other as a community. This discourse came up strongly as discussions with participants often revolved around the earthquakes and 
the original motivations of the group around climate change and peak oil. One participant noted:

[Project Lyttelton members] know that we can influence our own future and so we have to do something about it if we want to influence what's going to happen. So these are the sort of people who are doing something about it (Interviewee 3).

Another participant discussed the need for the community to be "in this together" in order to be resilient so that things don't turn to "mayhem" (Interviewee 2). These comments also stress a discourse of relying on the wider town as a form of community that also began to inform participant's understandings of resilience.

\subsection{Perceptions of Resilience}

Resilience is often understood in the context of hazard management, vulnerability and adaptive capacity, thus framed in academic theories and language. The aim of research question one is to understand these concepts as well as how resilience discourses are perceived and understood by grassroots groups. The former has been addressed through a literature review on the current resilience research and theory. This section addresses the former by augmenting with empirical data the ways individuals in Project Lyttelton understand and explain the importance of resilience to themselves and their group.

When asking interviewees how they envisage a resilient community the most common theme was the social relations that had supported them through the earthquakes. One participant noted "the whole thing is about the connection between people. That you're caring, that you know, you feel cared for, you can care for someone else" (Interviewee 3). This sentiment was echoed by other interviewees who also saw a resilient community as being "very connected and very responsive" (Interviewee 7) or "a community where everyone looks out for each other" (Interviewee 6). One participant even noted "I think resilience is the wrong word...It was just helping each other" (E-interview 2). Discourses of community and social relationships were commonly highlighted in relation to what participants saw 
as a resilient community. This suggests that the main focus of members is on building connections, relationships and networks that have been deemed important.

The literature discussed in Chapter Three echoes the sentiment of participants. Academics have reinforced the importance of social capital traits such as social trust and reliance that provide support and assistance during times of need (see Section 3.2.1) (Aldrich, 2010; Gunderson, 2010; Magis, 2010; Murphy, 2007; Norris et al., 2007; Sherrieb et al., 2010). The experience of the interviewees in this research shows that these social capital processes are at the forefront of individuals' conceptualisations of resilience.

Highly involved members of the group also indicated a wider understanding of resilience by discussing the implications of disasters on the resilience of physical infrastructure, food supply and broader ecological limits. Such considerations acknowledged the role of resilience beyond social connection into broader areas of concern, expressing discourses of the pragmatic realities of post disaster survival. One interviewee explained that:

For me a resilient community is one where you have resources to look after yourself in a situation when you need it. So you have access to power, food, waste management, fuel, all those things [so] that you can actually feed and heat and provide for the community if you have to (Interviewee 6).

Others displayed a strong understanding of the interconnecting systems that support resilience. Due to the precarious nature of food security resulting from the physical isolation of the town following the earthquakes one participant noted:

Food is really important, but as soon as you start thinking about food and how're you're going to produce the food and distribute the food and sell the food in one way or another you have to think about your transport systems, you have to think about your energy systems, you have to think about all the different systems that kind of connect us into a functioning community form (Interviewee 7).

These perspectives illustrate how participants see resilience as having a lot to do with the need to be prepared, as is understood in the literature as a method for reducing vulnerability (Tobin, 1999). Through these explanations interviewees also 
indicated their understandings of the interconnections and intersections of social needs, infrastructure and environmental systems during disasters.

In addition, the data shows that environmental concerns and sustainability were often linked to resilience through the core values of the group (Section 5.2). This was evidenced by one interviewee who said:

I mean it's all about resilient communities really. That's what we're about, the strap line is the soul of a sustainable community so it's about thinking about how can we be sustainable, how can we foster and build community and how can we grow it. So that's all about resilience really (Interviewee 6).

Another way this perspective was alluded to in interviews is through mentions of environmental concerns such as peak oil and climate change in relation to earthquake experiences (Interviewee 2, 6 and 7). What is uncertain in the way interviewees explained resilience is whether the onset of a disaster changed their perceptions of resilience compared to resilience in the face of environmental crises.

Despite the potential difference in contextual understandings, individuals in Project Lyttelton understand resilience during a disaster largely within social constructs. More involved members did however show a greater comprehension of the broader context of multiple systems and interconnections. This shows that members of the grassroots group interpret and understand resilience in a way consistent with the literature discussed in Chapter Three. However, there is a clear focus on discourses of community, social needs and relationships.

\subsection{Resilience in Action - September $4^{\text {th }} 2010$ and February $22^{\text {nd }} 2011$}

As social capital is deemed integral to the success of resilience frameworks it is an important focus when working to understand the nature of community resilience in Lyttelton. In this research I focus on social support, social participation and inclusivity as facets of social capital that can be understood in relation to how Project Lyttelton operated in the immediate recovery time and in an on-going capacity following the earthquakes. This section addresses how participants in grassroots groups put into action their understandings of resilience as discussed in Section 5.3. 


\subsubsection{Social Participation}

Social participation within a community is based on building formal networks and organisations to provide avenues of interaction for community members (Cicognani et al., 2007). The ability of a community group to do this and involve the wider community is seen as an important part of maintaining social capital and mobilising community responses during a disaster (Sherrieb et al., 2010). As Norris et al. (2007) point out, the decline of social capital, including social participation, is common following disasters. Yet this need not be the case in a community with a degree of resilience.

Cicognani et al. (2007) state that within the community context, formal avenues of participation can include involvement in voluntary, political, cultural and sport activities. Project Lyttelton provides avenues for the community to become involved in the group through specific projects such as community gardens, workshops and official organisational roles (both paid and voluntary). The group also operates in a way that encourages and provides support for people to become involved through initiating their own projects. One interviewee stated that in Project Lyttelton they aimed for "a culture of possibility" (Interviewee 2). Another said that "it's all really open so anyone that wants to be involved can be involved" (Interviewee 7). Such discourses of hope and possibility provide a foundation for potential social participation networks and capacities.

One of the most successful projects established by Project Lyttelton has been a time bank. Time banking is a means of reciprocity or trade, based on skills and time rather than money (Cahn, 2004). Time and skills are valued equally with trades being carried out through time credits to the value of one hour per credit (Cahn, 2004). The time bank featured strongly in almost all interviews as being of relevance (Interviewee 1, 2, 3, 4, 5, 6, 7, E-Interview 8, 9, 14, 15). Many interviewees valued the time bank highly and saw it as an important contribution not only to informal networks (discussed in Section 5.4.2) but also as a means of providing a formal social participation network. The network was utilised alongside other formal networks such as the Civil Defence and New Zealand Army immediately following 
the earthquakes - both in September 2010 and February 2011. One interviewee who was integral to the operation of the time bank described the situation:

So at the time of the earthquake [in February] you had in the emergency place [the Civil Defence Headquarters] the navy, the army, the police, the fire brigade, ambulance and time bank. So they'd have these briefing sessions every day or sometimes twice a day and they all brought their own skills and time banking's skill was being able to have the ability to link people very quickly and so you'd send out broadcasts, might say we need ten people for doing such and such and...people would self-select (Interviewee 2).

The integration of the time bank with formally recognised support agencies allowed for it to be acknowledged as an avenue for participation, as well as improving the ability of the recovery response to meet the needs of the community. For example, in the September earthquake, one interviewee described how the time bank worked with the health centre to check on the elderly:

I think nearly 300 older residents of Lyttelton were rung by time bank members, just to check in, are you okay? Do you need anything? ... And just kind of have a chat and check how they're doing (Interviewee 6).

The time bank also aided the immediate disaster response through providing people with assistance for repairs, helping the Navy distribute food and through providing meals for the elderly.

One of the ways that this formal avenue of participation was valued by interviewees was that it provided a way for untrained citizens to become involved. The time bank acted as a facilitator for this citizen engagement. In other parts of the region where this was not available there was a feeling that this volunteer capacity was underutilised. For example, the same interviewee mentioned above who dealt extensively with the Civil Defence said that they "were turning people away" in Christchurch city as they did not have a way to cope with the number of untrained people volunteering (Interviewee 2). The interviewee also noted that the ability to contribute in the period following a disaster was not only important for the community, but also cathartic for individuals. 
The time bank was able to facilitate both the social participation in interviewee's own networks and in broader networks of the response. It worked towards reversing trends of social isolation following the disaster and facilitating important processes for engaging community members. These are both important factors in providing support to the community (Cicognani et al., 2007; Rolfe, 2006).

In addition to the social participation encouraged by the time bank, Project Lyttelton also contributed to Lyttelton's response through the provision of the community garden and organising a Summer Festival. Despite the Summer Festival being scheduled for the weekend after the February 2011 earthquake, Project Lyttelton decided to go ahead with it, albeit at a different location at a grassy area above Lyttelton Main School. This allowed the community to come together following the earthquakes. For one interviewee the festival evoked a strong emotional reaction saying it was where she "started to feel better after the earthquake" (E-Interview 3). The same interviewee also noted:

Other things such as having the Farmer's Market up and running as quickly as possible really help too - make you feel like life can carry on despite the disruptions (E-interview 3).

The ability for people in the community to be a part of Project Lyttelton's events and projects following the earthquakes allowed for what Cicognani et al. (2007) describe as the ability for individuals to be a part of processes that shape the environment. This is argued to be integral to successful social participation.

One outcome that is currently emerging from these Project Lyttelton activities is the apparent increase in participation in local government processes. An interviewee expressed this view by describing a recent consultation event regarding the master plan for the rebuild of Lyttelton:

We got together in marquees and hundreds and hundreds of people came, Lyttelton residents of all sorts of ages and um, socio-economic groups. There was a, you know, real great diversity of people I thought in those tents (Interviewee 5).

Another interviewee noted that this trend in involvement with local government had improved the presence of the community in local government processes but had also 
resulted in what she termed "stroppy people" (Interviewee 2). While this sounds negative, the interviewee was quick to point out that she "loved that" element of the community indicating that it was seen as desirable to interact in this way with local government. It is difficult to say if this change in participation is a direct result of Project Lyttelton activities. However, it does indicate that there is an increased level of social participation in the wider community. This participation is possibly supported by the events and networks run by Project Lyttelton, which give individuals a sense of control and ownership over their environment.

\subsubsection{Social Support}

As discussed in Chapter Three connections between individuals, families, neighbours and acquaintances during natural disasters form the basis of social support - another facet of social capital (Norris et al., 2007). Social support is focused on the informal networks that people rely on during times of need. These networks result in the provision of actual assistance when required (Kaniasty \& Norris, 1995; Norris et al., 2007). Some of the projects run by Project Lyttelton have been involved in the social support networks of the town.

From the interview data and my time in Lyttelton it became apparent that as a town and community, Lyttelton is a friendly and engaging place. Several people noticed my frequent presence in the town, stopping to say hello to me and to ask me if I had moved to Lyttelton from somewhere. As discussed in Section 5.2, Project Lyttelton members identify the group as linked to discourses of community, openness and inclusivity. Interviewees echoed these observations and discourses when talking about their social support networks following the earthquakes. For example:

It's got a lovely energy here. People look each other in the eye here. A lot of people give each other hugs and I know that happened a lot after the earthquake everywhere but we do that (Interviewee 2)

Similarly another interviewee observed that:

There's just a lot more interaction and yeah, just a lot more acceptability that you know, you're here, you interact with people...Closely knitted and yeah, I 
think people really connect and interact a lot more than across the hill [Christchurch City] (Interviewee 7).

Kaniasty and Norris (1995) note that perceptions of social support such as those indicated above are often more important for supporting the community through a disaster than the actual social support that is received. These perceptions and experiences of Lyttelton as a friendly, close knit and welcoming community have, from the interviewees' perspectives, built a good foundation for perceived and actual social support during and after the February $22^{\text {nd }} 6.3$ earthquake.

The time bank was most often mentioned as an activity that contributed to such social support by creating informal networks between people that helped them recognise familiar faces and feel more comfortable after the earthquakes. One interviewee described how she saw the time bank's role after the earthquake:

Time banking makes ties between people, you know a lot of people, and this helps in a disaster situation. Knowing your neighbours, recognising faces on every street (Interviewee 6).

Social support by networking and introducing people to each other whose paths may not have crossed before increases an individual's identification with others in the community. This identification sometimes occurs immediately following a disaster but is often lost after the initial response phase (Kaniasty \& Norris, 1995). However, in Lyttelton, the pre-existence of the initiative may have meant that the connectedness existed prior to the disaster, promoting the efficacy of the time bank and ensuring on-going momentum of increased social connection.

Other projects that provided social support networks for the community include the community garden (Image 6), the Summer and Winter Festivals and Lyttel Stitches. Activities such as the festival provided important opportunities for individuals to meet others and gain support from the shared experience of the disaster. Opportunities to reinforce existing social support networks and create new ones following the earthquake were also experienced through the community garden which was used as a site for food security and a place to meet and seek comfort from others. One interviewee described the community garden's role as "a great place for people to come and talk and forget about the earthquake. Get their hands dirty, get 
stuck in" (E Interview 1). Similarly, a project where people sat on the main street and sewed hearts and signs to give to people and attach to the fences surrounding rubble, attracted a positive response. The Lyttel Stitches project supported those who needed company and a creative outlet for their experiences. These activities facilitate social support at its most simple level, or as one interviewee put it, gave them "an excuse to get together" (Interviewee 2).

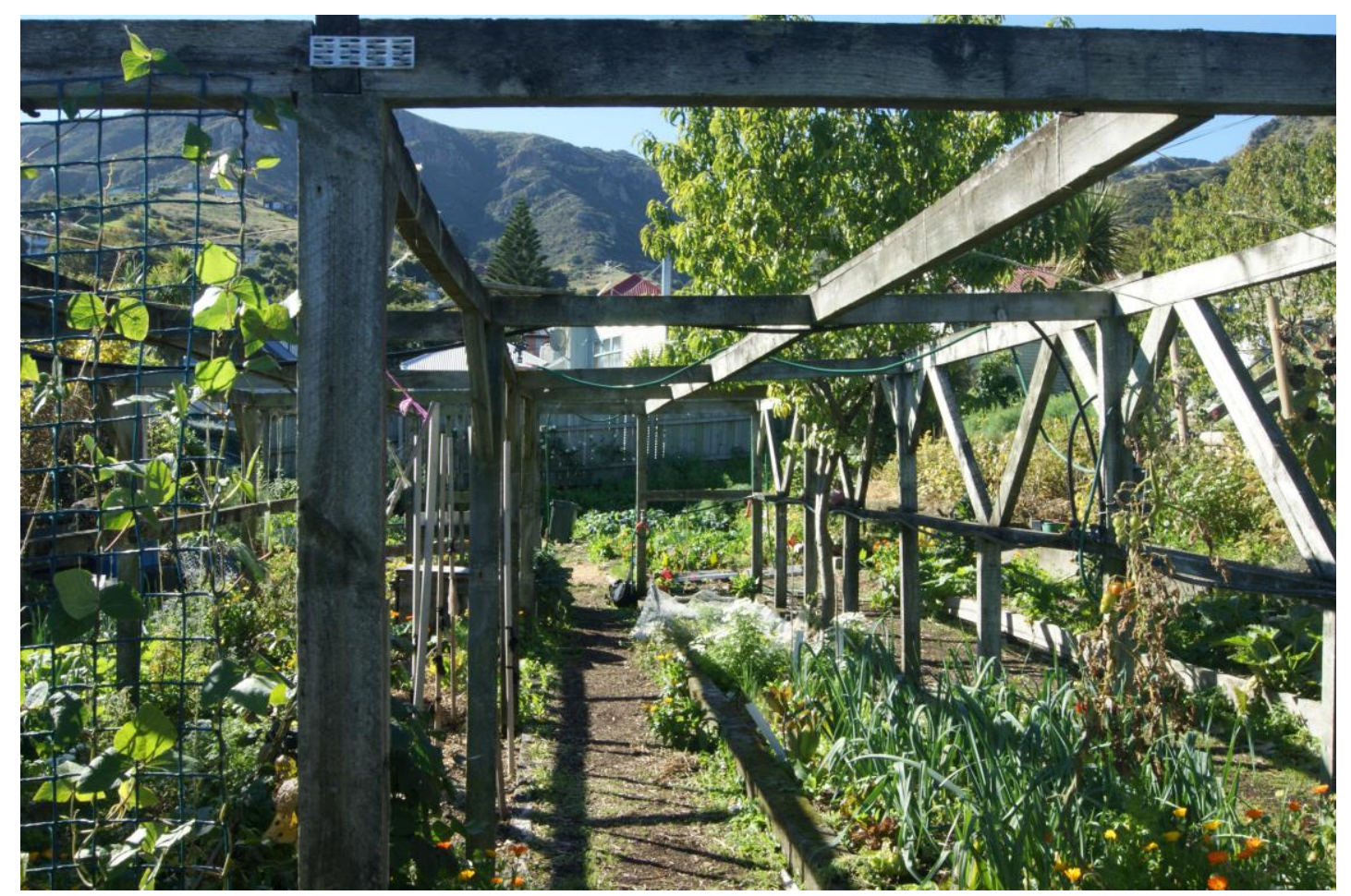

Image 6: The Project Lyttelton Community Garden mentioned by interview participants 2012 (Source: Zack Dorner)

A significant benefit of Project Lyttelton's activities during the aftermath of the earthquakes was that it provided the foundation for reciprocity. With the identity of Project Lyttelton being built on discourses of openness and community connection; activities such as the time bank represented a physical manifestation of these aims. Several interviewees described the time bank as nurturing a sense of trade that resulted in more generosity within the community and less stigma attached to receiving help:

People can volunteer really quickly and easily and there's no stigma in saying "Oh I'm on my own, can someone come and help me put my house back together?" Because that's a normal thing to ask before the earthquake, so it 
just normalised the whole thing which I think was hugely important (Interviewee 6).

The implications of the time bank on what this interviewee described as the "normalisation" of giving and receiving is of particular interest as it indicates the emergence of new social norms. Norris et al. (2007) note that social influence in groups (like Project Lyttelton) can lead to the development of social norms such as those described by the interviewee. These norms can increase a community's resilience and strengthen social support networks so they are strong enough to withstand the pressures of coping with a disaster. From the data collected it is clear that the activities of Project Lyttelton contributed to the interviewee's feelings of social connection and support following the major earthquakes, which assisted them through the recovery period.

\subsubsection{Inclusion}

Attitudes of inclusivity and diversity are considered to play a key role in the resilience of a community (Norberg, Wilson, Walker, \& Ostrom, 2008). Diversity is also considered an important component of socio-ecological resilience. However, while diversity is often referred to in the ecological context, further research on social and cultural diversity is needed (Krasny \& Tidball, 2009). Furthermore, as outlined in Section 5.2, Project Lyttelton's constructed identity strongly relies on a foundation of discourses of inclusion and diversity. This section seeks to compare this constructed identity to the discursive reality while explaining the ways that Project Lyttelton has worked to incorporate inclusivity and thus improve diversity in their practices. These findings will be explored in more depth when related to interviewee's understandings of place and identity in Chapter Six.

Asking interviewees' about their perceptions of diversity within the Project Lyttelton group elicited a wide range of responses including claims diversity of in perspective, age, gender, socio-economic status and ethnicity. Many of the responses indicated that the composition of the Project Lyttelton organisation is largely white, middle class and female although diverse across the age spectrum: 
Age...we have a variety of ages and men and women. Probably more women around than men. We're very white here...Y Yeah and we're quite middle class too. It's just who we are (Interviewee 3).

These trends did not appear to bother interviewees who generally accepted the ethnic composition of Project Lyttelton as related to elements of diversity within the wider population. Others justified the gender balance of the group in relation to perceived gender disparities in the town, one participant said:

Lyttelton as a town is a male town, you know you always see sailors and seamen around walking around the town and there's always men around you know, either from the wharf or from the ship building and I sorta think well this is just a bit of balance (Interviewee 2).

The fact that the interviewees were relatively mindful of the matters of diversity and balance within both their group and town suggests a degree of awareness and understanding towards diversity issues but also shows a tension between the group aims of diversity and the reality of involvement.

In addition to the welcome packs noted in Section 5.2, interviewees detailed the measures taken to make Project Lyttelton accessible to the wider community. One interviewee described how they run 'Garage Sales' of donated goods out of the Project Lyttelton centre that community groups can take ownership of for one week - earning money for their own projects (Interviewee 6). Groups such as the local Scout Club and Soccer Club utilise this service, broadening the impact and appeal of Project Lyttelton. The same interviewee described how they aimed to be as inclusive as possible in their materials:

We try and be open to anybody certainly. And we certainly try and connect with existing different entities that are here...And we try and make sure that anything we put out there is inclusive in its terminology and if it's got you know, pictorial references, that they're broad in what they describe. I think most of what Project Lyttelton does is done from compassion and love so it's not necessarily something that is focused on but is assumed automatically (Interviewee 6). 
The last part of this interviewee's quote is particularly interesting in that it mentions the assumption that Project Lyttelton carries about its approach to inclusion and diversity. Indeed, from the data gathered, the group both externally and internally attempts to act in an inclusive way. One interviewee described the group as "open and transparent" and that "they are always inviting people for meetings or to participate in this and that" (Interviewee 7). Internally the group cultivates this culture of inclusivity and diversity by incorporating aspects of sociocracy - a democratic way of making decisions, which encourages people to listen to each other's different opinions and agree on a decision that they can all "live with" (Interviewee 2).

These attitudes aided Project Lyttelton in their response to the earthquakes by making their activities more accessible to the wider community and allowing people to gain what they needed from events or activities without any expectations. For example, one interviewee described a woman in the Lyttel Stitches project:

Different people did different things. It was interesting, I remember one woman came and she spent most of the day there and she made this most beautiful work of art, this most beautiful thing I've ever seen and we never saw her again. And that's all she needed to do, come and make this one (Interviewee 3).

The way the group was accepting of this woman and her intentions is an example of an accommodating attitude towards difference, diversity and individual need. Another pertinent example is the community garden which became a gathering place for many people following the earthquakes. Krasny and Tidball (2007) state that community gardens can foster human diversity where they become a meeting place for people of different ages, ethnicities and socio-economic statuses. Interviewees also mentioned this aspect of Lyttel Stitches which became a meeting place for people during the aftermath of the earthquakes.

Despite the inclusive intentions within Project Lyttelton, those involved in wider community groups did draw attention to tensions and conflicts that exist within wider Lyttelton. These tensions display a discursive tension between the constructed identity of Project Lyttelton and the reality of their activities. The source of these conflicts appears to lie in different attitudes of those perceived as 'new' to 
the area, (e.g., recent migrants of both national and international origin) and those who are considered 'old' to the area (e.g., those born and raised in Lyttelton and those from Lyttelton families). This has left some groups feeling alienated from the activities of Project Lyttelton. As Interviewee 4 explained 'they ['old' Lyttelton] feel railroaded and increasingly displaced in their own community". This tension will be explored in more depth in Chapters Six and Seven but is relevant here as it illustrates the assumption by members of Project that they are inclusive already, and shows how this may blind people towards other groups in the community. One participant described how she saw the situation for this group of 'old' Lyttelton:

We have quite a few people who have lived like on our road who have been born in their house and are now in their sixties and seventies who are still working down at the port but this whole, you know, Main Street of Lyttelton, with all these coffee shops and things is just astonishing to them. And I don't know that we make space for them in Lyttelton, they go to the working men's club, that's about it really (Interviewee 5).

Other interviewees echoed this concern for this group in Lyttelton who are often associated with working class jobs at the port, and the older generations claiming that "new Lyttelton" have arrived in the town but think it's " [solely] their community" (Interviewee 4). This statement appeared to imply that it was in fact their (old Lyttelton's) community. The use of terms such as "their", "we" and "them" suggest that there is a component of 'othering' occurring which adds further complexity to the vying discourses of community, home and localness in this tension.

Project Lyttelton obviously makes explicit attempts to promote inclusivity and diversity. Despite this there is still tension in the community regarding exclusion of certain groups. These conflicts and tensions display the differing views of the future and the problems surrounding place definition and identification. Interviewee observations demonstrate the importance of inclusive and open minded attitudes towards difference of opinion when interacting in a multi-faceted community but also show how complex such issues are. Concerns of inclusivity and diversity are especially important given the often emotionally fraught disaster recovery process. 


\subsection{Trajectories of Adaptation}

One of the defining elements of the socio-ecological resilience paradigm is that resilience processes should involve capacity for adaptation or transformation (Adger, 2005; Berkes, 2007; Folke, 2006; Magis, 2010). This capacity determines the ability of a system to re-organise into a new form and onto different trajectories of development. Adaptive capacity allows a system to take heed of lessons learnt and avoid the rebuilding of the system in the same state as prior to the disturbance (Magis, 2010). This can result in reducing vulnerability to future disruptions something considered integral to resilience in the context of social systems (Tobin, 1999). Understanding adaptive capacity is not easy. However, by focussing on the emergent properties of systems, self-organisation and historical patterns the characteristics of adaptive systems can begin to be comprehended (Gunderson, 2010). This section outlines the role of Project Lyttelton in promoting these adaptive capacities by focussing on their role in social memory and social learning processes.

\subsubsection{Social Learning}

Social learning enhances the ability of systems and communities to adapt to local conditions brought about by disturbances such as earthquakes, it is thus an integral part of adaptive capacity (Adger, 2005). In relation to natural resource management, social learning denotes a process of social groups engaging with a diverse range of perspectives and each other to develop a common framework of understanding and a basis for joint action (Schusler, Decker, \& Pfeffer, 2003). Social learning occurs through societies and institutions 'learning' as people learn (Berkes, 2007). Thus, organisations such as Project Lyttelton can learn collectively through their processes and activities and contribute to learning which arises out of previous experiences of disruption and allows the institution to act as repository of social memory (further discussed in Section 5.4.2) (Adger, 2005). This process potentially increases adaptive capacity in the community as the group becomes a source of lessons and memories from the earthquakes within the community.

An activity led by Project Lyttelton as a result of the earthquakes that has facilitated social learning is the 'Harbour Resilience Project'. This project seeks to build on the experiences from the quakes to learn by doing - an important aspect of 
social learning (Berkes, 2007). The earthquakes highlighted concerns about food security. Consequently, the Harbour Resilience Project involves various initiatives based on sharing produce, building a skills base and establishing an education centre. To date the Harbour Resilience Project has successfully established an organic food co-operative in the town and a 'Plenty to Share' bartering stall. Attitudes expressed by interviewees suggested that the Harbour Resilience Project has come about as a direct result of the desire to become more resilient and prepared:

The latest project we've got is... a direct result of the earthquake. Because the tunnel was closed, Evans Pass is still closed and some of those other ones were closed (see Figure 2) ... enough for us to realise that we could be cut off, that we can be isolated. You don't get help you're on your own. So it's making us realise that we need to look at how we can be resilient by ourselves, so that has sparked this project off, of looking at how can we produce local food to [meet] our own needs (Interviewee 2).

The establishment of this project also shows an openness toward the need to accept change and reorganise systems to deal with the challenges that will enhance future resilience (Magis, 2010).

The current plan for the Harbour Resilience Project is to work towards establishing an operational organic farm that will act as a source for resilience and sustainability based learning for groups and individuals. One interviewee described the educational purpose:

So organic farming demonstrations, or like a display of sustainable housing solutions...It might be obvious to some people but not so obvious to others, just having that there as a demonstration where people can come, see, look, explore and learn about different suppliers and where to get the stuff and how to get it down (Interviewee 7).

The project enables both individual and social learning by allowing individuals to come and learn new techniques and approaches to sustainable living. It will also promote the feasibility of alternatives to traditional farming, building and cooking. By doing so the project is contributing to shared community action, building social capital and providing opportunities for learning as an outcome of interaction with the 
bio-physical environment, all of which are considered important contributors to social learning for improving resilience (Krasny \& Tidball, 2009).

Schulser et al. (2003) believe that social learning occurs when people engage with one another, sharing diverse perspectives and developing common frameworks for understanding. Project Lyttelton contributes to this through their approach to diversity (see above) and internal governance that aims to be inclusive and accepting. This approach was mentioned by several interviewees (Interviewee 1, 2, 6). Within the context of social learning, embracing open and collaborative discourses as Project Lyttelton members suggest, their approach could contribute to common purpose and collaborative relationships within the community. These relationships may have the potential to value multiple ways of knowing and being. This provides a solid context for social learning to be established across society, instilling guidance for future events (Adger, 2005; Krasny \& Tidball, 2009; PahlWostl et al., 2007; Schusler et al., 2003). That Project Lyttelton is able to position itself through the Harbour Resilience Project and their approach to diversity suggests that community grassroots groups can play an important role in facilitating individual and social learning for adaption following disruption.

\subsubsection{Social Memory}

Social memory refers to the preservation of learning that results in memories that become collective in nature (Olick \& Robbins, 1998). This process is integral to resilience as it allows for lessons from disruptions to the status quo to be passed through generations and time to strengthen a community against future threats (Adger, 2005). The lessons from these events become 'stored' in the collective memory of society, institutions and individuals acting as a transmitter of the past into the present ( Berkes, 2007). As a grassroots community group, Project Lyttelton can potentially play a role in supporting social memory of the earthquakes that will increase the resilience of the community to further events. It is however difficult to gauge their impact on this as social memory inherently relies on a perspective of how past experiences have been remembered in the present. Thus this section outlines some of Lyttelton's social memory of the past and how Project Lyttelton may potentially affect future social memories. 
Human imagination and creativity give humans the ability to perceive change at a larger scale and for a longer duration than is possible through immediate sensory experiences alone (Davidson, 2010). This capacity, and the ability to remember times of adaptation create repositories of memory that are stored in individuals and communities (Berkes, 2007). Interviews with participants of older generations with well-established connections to the wider community suggest that Lyttelton residents hold the memories of several major disruptive events that have shaped how individuals view Lyttelton in times of need. For example, a fire in 1870 burnt down most of London St - the main street (Rossie, 2010):

In the 1870 's there was a big fire too... but the fire obviously isn't remembered by anyone still living but they know that it existed and they know about the jail and what happened there and that there were hangings and stuff like that but that isn't their own personal memory but sort of a collective memory that's come down (Interviewee 1).

In 1951, a port strike resulted in the workers on the wharves being locked out and surviving without wages for over 150 days (Rossie, 2010). The geographical isolation of Lyttelton is also a significant social memory. It was only in 1964 that the road tunnel was completed, providing a direct connection to Christchurch (Rossie, 2010).These events, in particular the pre tunnel days, were referred to by interviewees regarding perceptions of Lyttelton as a resilient town. Interviewee 4 described it like this:

So, what's new? Lyttelton has always had to look after itself. And [in the earthquake] the old mechanisms kicked in, volunteer fire brigade worked with the Port Company and Starks and all the engineering companies and St Johns, and in the good old days the council, and we rescued each other (Interviewee 4).

The recollection of these events shows that there was already a strong foundation for social memory before the earthquakes which may increase the chance of retention of experiences surrounding the earthquakes. Berkes (2007) however states that it is difficult to estimate the life time of social memory as it is often passed down through generations from elders. While it is difficult to get a gauge on the prevalence of such social memory throughout the community within the scope of this research, the 
interviews did suggest that shared collective memories built on the history of the town do exist.

Some of Project Lyttelton's activities are potentially useful for establishing and perpetuating social memories related to the earthquakes. One example of this is a book produced by the group called The Shaken Heart which is the source of the stories prefacing some chapters (Evans, 2012). The book is composed of interviews with residents of Lyttelton across a variety of backgrounds and ages as to their experiences in both the September 2010 and February 2011 earthquakes. This book provides a repository of memories from people who experienced the earthquakes, as well as their thoughts and what they learnt from the experience. It provides what Olick and Robbins (1998) call a general form of commemoration and tradition that provides the basis of social memories. Another example of commemoration is the blanket of hearts which was sewn by people through Lyttel Stitches that popped up on the side of the main street following the earthquakes. Images of these hearts have become a symbol for Lyttelton following the earthquakes (Image 7). People integral to the project have been interviewed for television programs including the BBC. A blanket of hearts has been featured in Te Papa and one remains in Lyttelton which one interviewee described as their own memorial blanket:

We didn't want to fizzle out and so we decided we would stop, there was still enthusiasm and what we've got is a big woolly blanket that we've started stitching hearts on and that's sort of our memorial blanket. Someone asked me if it's finished yet but I don't think it will ever be finished (Interviewee $3)$.

Such actions by Project Lyttelton and its members also develop the social participation and support networks built by the time bank and community garden. This allows for the community to utilise the networks to provide not only support, but also a way of commemorating and remembering what happened, to ensure that those memories and experiences are passed on. 


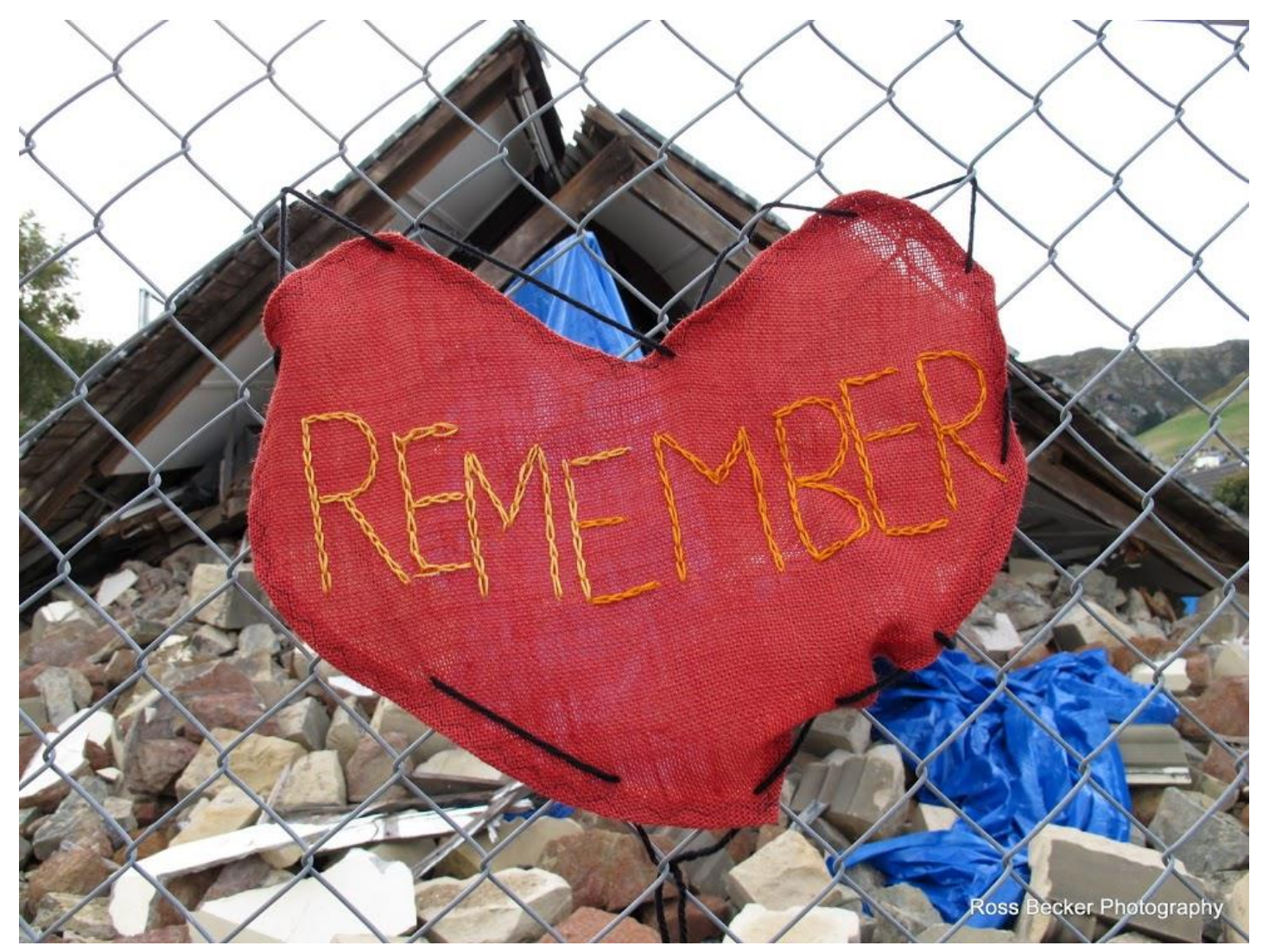

Image 7: A Lyttel Stitches heart on the fence outside the Old Union Church 2011 (Source: Becker Fraser Photography).

\subsection{Summary}

In summary, grassroots community groups such as Project Lyttelton provide important services and skills for a community during a disaster. The wider goal of the group is based on the identity of Project Lyttelton as an organisation strongly revolving around a 'values' focus. This focus stresses self-reliance and sustainability and as well as discourses of community, inclusion and openness. Resilience was understood in general by all interviewees. However, the majority of perspectives were based around understandings of resilience in a social context. Interviewees who were more involved in Project Lyttelton made more explicit links between resilience, the interconnectivity of systems and the potential for future crises such as peak oil and climate change. These perspectives were indicative of Project Lyttelton's wider goal to create a sustainable and vibrant community.

In reacting to the earthquakes of 2010 and 2011, Project Lyttelton displayed the importance of their work by providing beneficial services to the community. One 
way they achieved this was through providing avenues for social participation, such as the time bank and community garden. Here, they were able to engage the wider 'unskilled' community, which both aided the recovery process and also provided a way of letting those who wanted to help be involved. Social support networks that were in place prior to the earthquake also aided the community by supporting people to feel safe and comforted in their community. This was achieved in part by the loose ties that Project Lyttelton's activities, such as the time bank and seasonal festivals created prior to the disaster. In addition, it was shown that interviewee's attitudes to inclusion most likely supported a diverse range of involvement in the group. However there were definite issues surrounding inclusion of the wider community. These tensions illustrate the importance for community groups to work with an inclusive attitude to all sectors of the community.

Social learning was exemplified in Project Lyttelton through current activities with the Harbour Resilience Project that provide opportunities for individual and social learning from the earthquakes. It is difficult to fully analyse the group's impact on the retention of social memories from the earthquakes due to the research being undertaken so close to the event. However, there are examples of commemoration that indicate that the group may, in the future, support social memories of the event.

These examples show the importance of the work grassroots community groups do during disasters. Groups such as Project Lyttelton provide services which engage the wider community and lift some of the burden off official services. Furthermore, the group's activities built important social structures for support and participation that would not be able to be put together in haste immediately following a destructive event. Thus, this chapter has displayed how Project Lyttelton has provided a valuable contribution to the resilience of the town's community. 


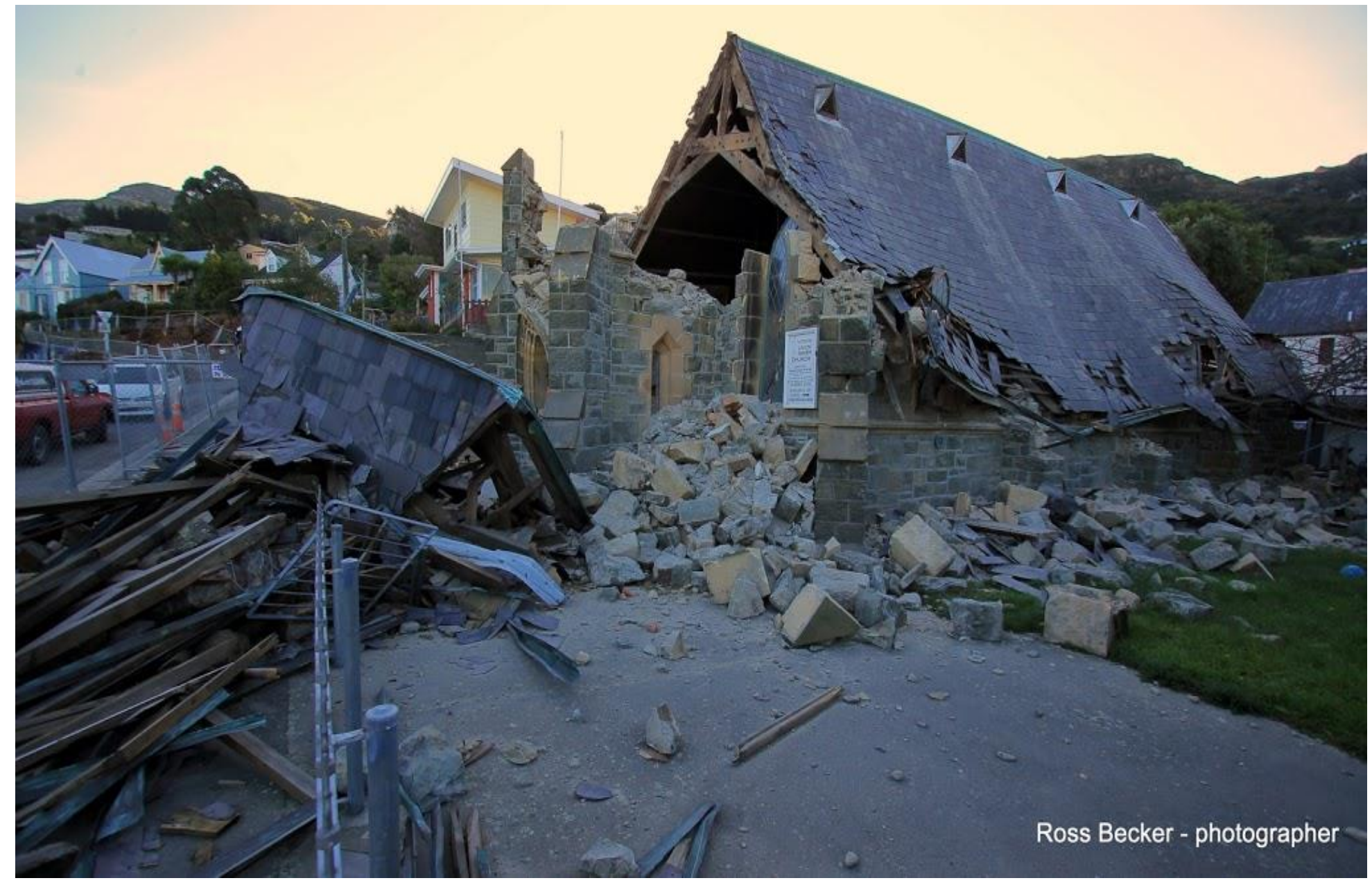

Image 8: Damage sustained to Old Union Church 2011 (Source: Becker Fraser Photography). 


\section{Chapter 6.0 Findings: Putting theory into place}

"This is the place in New Zealand I feel most at home in. I call this my home now and I did not have that so much in my life, so it's important to stay, and it feels natural to stay, even though they are knocking half of it down now, people are cold this winter maybe and people are facing difficulties, but it's my home."

Quote from 'Shaken Heart' a community produced book of interviews with residents of Lyttelton (Evans, 2012:57).

\subsection{Introduction}

The role of place identity during recovery from disaster is an issue that is not fully understood. As outlined in Chapter Four, this research has focused on a relational definition which sees place as imbued with multiple meanings, identities and relations depending on individuals and communities. As demonstrated in the previous chapter, there is evidence which suggests that Project Lyttelton's activities have supported the resilience of the community. This chapter establishes a foundation of evidence relating to the place identities of those interviewed. This data will form the foundation for a discussion which will draw together these two chapters to assess the role of place in shaping resilience.

Understanding place in a relational way as described in Chapter Four opens up possibilities for envisaging place as multi-dimensional; a prism of 'places' in one geographical location (Massey, 2004). The earthquakes in Lyttelton destabilised both the physical symbols of place and the psychological landscape that individuals had built based on their place identities. In this chapter I explore the effect of the earthquakes on place identity by first investigating the various discourses of place and the resulting place imaginaries that emerged through face to face interviews and E-Interviews with participants. Subsequently, issues of displacement between preand post-quake imaginaries and conflict between competing discourses that arose are discussed. 


\subsection{Discourses of Place}

Geographical constraints, history and the future were drawn into interviewee descriptions of Lyttelton. Participants were asked how they would describe the town, what their favourite part of Lyttelton was and how this had been affected by the earthquakes. To understand the multiple layers, identities and interpretations of place it is necessary to understand discourses of place that are at play within a locality. Discourses are specific sets of representations and practices through which meanings and identities are produced and constituted (Gregory, Johnston, Pratt, Watts, \& Whatmore, 2009). In this context, discourses of place represent the ways individuals and groups constitute the identity of a particular locality, the histories and values which are privileged and how these are represented.

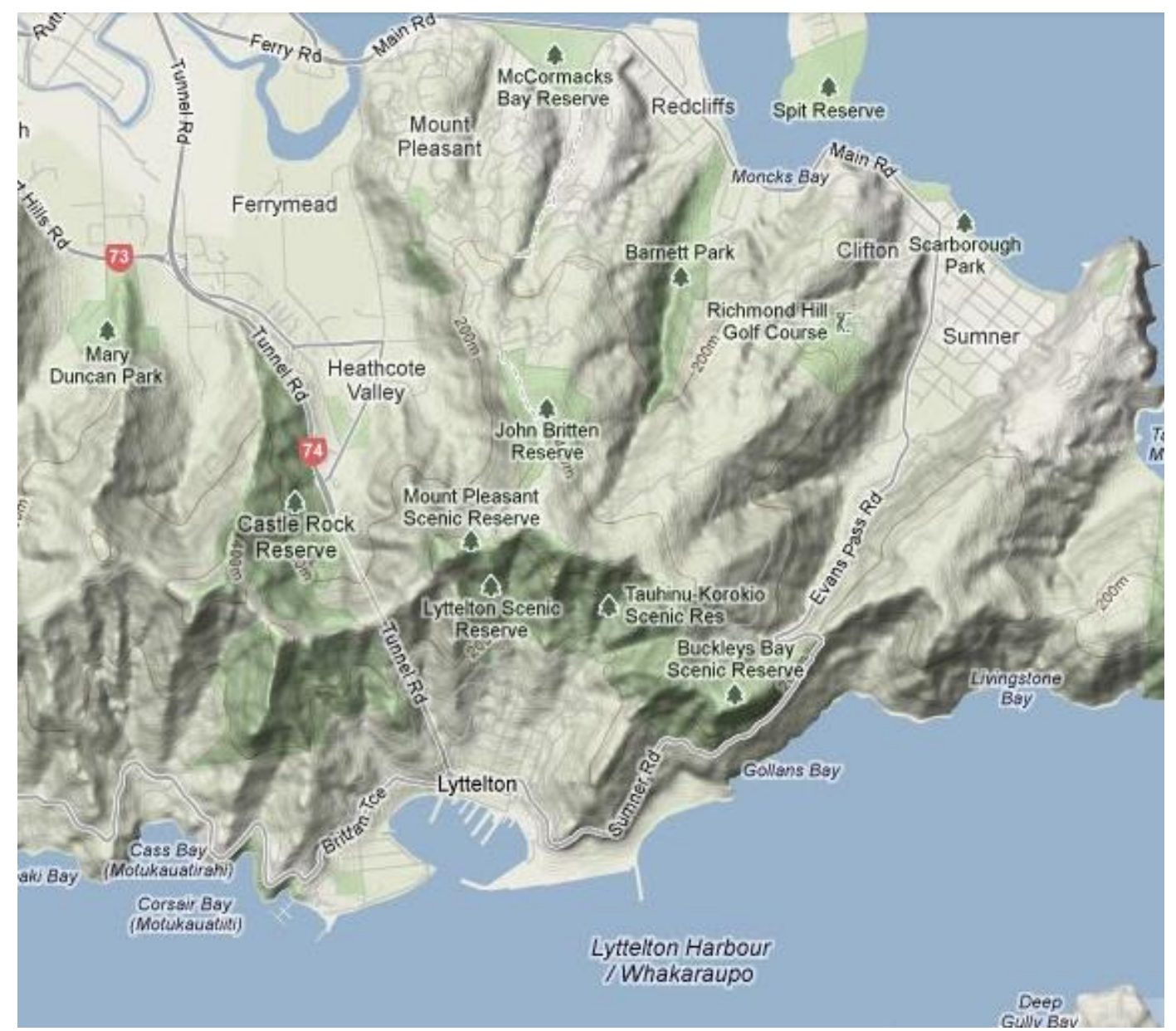

Figure 4: Google map of Lyttelton showing the terrain of the township in relation to the Road Tunnel and Evan's Pass. Christchurch city and suburbs lie North West to Lyttelton township. (Source: (C)Google 2012). 
As shown in Figure 4, Lyttelton is geographically enclosed by the Port Hills which physically separates it from the urban area of Christchurch City. Several participants described Christchurch as "over the hill” (Interviewees 2, 6, E-Interview 8) (Figure 12). Discourses relating to difference and separation originating from this physical boundary occurred when interviewees mentioned the city of Christchurch which in terms of political boundaries, Lyttelton is a suburb of (Interviewees 4, 1, 2, 7, E-Interviews 2, 3, 4). One participant noted that the merging of Lyttelton and Christchurch local authorities has caused tensions. Several interviewees noted that Lyttelton is a port town in its own right, being the first place many immigrants, sailors and traders arrived when coming to Aotearoa New Zealand historically (Interviewees $4 \& 1$ ). The town was separated from the growing city of Christchurch by the Bridal Path, a steep path over the hills which was the most common route in and out of the town by horse and cart or foot until the construction of a rail tunnel through the hills in 1867. Following this development the town was still highly isolated until a road tunnel was built in 1964. One interviewee emphasised how important that it was important for outsiders to understand the isolation of Lyttelton as part of the identity of the place:

Cause if you remember, Lyttelton was originally a port town that had little connection with Christchurch pre road tunnel which came in '64...there was a vibrant taxi service in Lyttelton and people didn't own cars. If you went to [go to] Christchurch it was by way of train and it was a major exercise (Interviewee 4).

The feelings of differentiation expressed by interviewees are not necessarily unkind feelings towards those in Christchurch. Some participants expressed sorrow that Christchurch did not have what they perceived to be the community spirit they had in Lyttelton. One interviewee wished she could "bottle this stuff up and throw it over to the rest of Christchurch" (E-interview 8). This attitude was also indicative of the popular discourse, discussed in Chapter Five, of Lyttelton as a warm, caring and community focused place. Another interviewee recalled a Lyttelton resident saying "I hear people in Christchurch are saying that people are getting to know their neighbours. That's weird, we already know ours" (Interviewee 2). Another stated that "people really connect here and interact a lot more than across the hill [Christchurch]" (Interviewee 7). These expressions of the difference between 
Lyttelton and Christchurch help to form a common but not necessarily universally held discourse of Lyttelton as a caring and connected place. The use of reactionary differentiation is a common trend when investigating place identities as it can allow people and groups to build common understanding based upon traits which stand out as being different to those in other groups or individuals (Massey, 1991).

Other place discourses that were affected by the earthquakes related to the loss of buildings and the physical alterations to the town. One person said "You could hear people saying, it's sad about the buildings, but it's not about the buildings, it's about the people" (Interviewee 2). While this was conveyed by some participants (Interviewees 2, 3, 6, 7), others still articulated strong attachment to physical markers of place such as buildings and monuments (Interviewees 1, 4, EInterview 3, 4, 5, 6, 7). These attachments were often linked to discourses relating to the importance of history. Such discourses draw on Lytteton's history as a port town and were justified in terms of the importance of going forward while remembering and honouring the past. As one participant said "What have you got if you don't have the past?"(Interviewee 4).

Discourses of history and at times nostalgia for the past also coincided with a strong identity of a working class "port town" (Interviewee 1, 5, 4; E-Interview 2) or a "quaint village" (E-Interview 8). The discourse of a port town was highly prevalent among several interviewees who often discussed it with pride as related to a straight talking, no nonsense hard working ethic (Interviewees 1, \& 4 E-Interview 3). In addition, the port town identity was linked to class and gender attributes. One participant described the town as a "male port town" (Interviewee 2) and others commented that those from the port town side of Lyttelton were from working class backgrounds using metaphors such as “diamonds in the ruff” (E-Interview 3).

A more recent side of the town which emerged through interviews was the development of a discourse of Lyttelton as "trendy: (Interviewee $2 \& 4$ ). This discourse was linked to an increase in bars, cafes and boutique stores in the town, which several individuals perceived as a form of gentrification which was "changing [the] town" (Interviewees $4 \& 5$ ). Others however embraced these changes, although even they hastened to add that they did not want to be subject to people 
"freeloading" off this image through taking advantage of the community, but not providing anything back (Interviewee 2).

From those interviewed, the most dominant place discourses were those relating to geographical location and difference from Christchurch city, community connection, working class port town ethics and a newer trendy scene which some perceived as a form of gentrification. These discourses were present in different ways across the community -in conversations, publications and the material conditions of the town.

\subsection{Place Imaginaries of Lyttelton}

Just as Whitridge (2004) explores representations of place as spatialised imaginaries, this research will draw on the concept of imaginations to investigate individual identifications with discourses of place. A geographic imagination is based on the unreflective and unconscious creation of mental images that individuals carry as to how the world is (Massey, 2006). Through the concept of geographical imaginaries, place imaginaries can be thought of as the mental image of places that individuals use to construct representations of place. Place imaginaries in this research are thus the collection of discourses which individuals unconsciously draw on as part of their personal identification with a place. Such imaginaries are specific to individuals, but it may be possible that for certain discourses to coalesce with a group of people to form a commonly held identity of place.

By understanding place imaginaries we gain insight into the multiple expressions of belonging and identification that can exist in one location. While there are most likely countless place imaginaries in Lyttelton, this section explores the most prevalent themes from the interviews based on history, the present, migration, gender and class.

Project Lyttelton's website and mission statement declare the town a "portal to Canterbury's historic past" emphasising the historic place discourses discussed in Section 6.2. However, this imaginary of a historic port town suspended in time on the hillside of Banks Peninsula is not the only way residents of Lyttelton see their community. These evocations of the past demonstrate a particularly dominant place 
discourse in Lyttelton that for some, although firmly grounded in history, is represented in the present through symbols, buildings and attitudes to place. One interviewee said that history is "what brings people to our community going forward and gives it vibrancy" (Interviewee 4). Others described the town as "rich in history [with] rich layers of historic buildings and style" (E-Interview 2). These perspectives indicate a wider historical narrative that is woven through the place imaginaries of the town that privileges the past in a particular way. It is clear that this historic place imaginary is linked to physical symbols such as buildings, churches and historical sites (Interviewees 1, 4 E-interviews 2, 3, 4, 5, 6).

Another place imaginary that was articulated evoked a progressive and sustainable community. Indeed, many of those who aspired to such discourses were members of Project Lyttelton, which itself has the tagline "the soul of a sustainable community" (Project Lyttelton, 2012). This imaginary was built on a foundation of discourses relating to making change for sustainability, being on the edge of society and growing community (Interviewees 2, 6, 7). In addition, it was strongly focused on people rather than buildings or physical symbols of place. As one participant said, "Yeah, they're only buildings. And I think people really realise that" (Interviewee 6).

Differences in place imaginaries became more evident when issues such as buildings arose. As discussed briefly in Chapter Five, those who are newer to the town are seen as less attached to the past and more attached to discourses related to the future while longer residing residents believe they put more value on history and the past. Many of those from Project Lyttelton are associated with the perceived 'new'. In interviews, Project Lyttelton and 'new' Lyttelton were used interchangeably and many of the frustrations expressed about 'new' Lyttelton were also levelled at the group. Those who were identified by others as 'new' Lyttleton were also linked to the perceptions of Project Lyttelton as "new agey" and full of "hippie types" (Interviewee 4, E-Interview 2,).

From the data it appears that this idea of 'old' and 'new' Lyttelton constitutes two conflicting place imaginaries. In five of seven face to face interviews and four of eight E-interviews, participants described groups of people as either 'new' or 'old' Lyttelton, or referred to conflict between the two perceived groups. One participant 
who was new to the town described what they saw as the foundation for this "new vs old' conflict:

Um I do hear that there is this sort of imbalance between older and new Lyttelton, that's how they term it which I dunno what exactly it means but I guess it could be a bit similar to what I was talking about before, you know, the generational differences, older people being a lot more retrospective and kind of past oriented and not that visionary for futuristic which kind of makes sense you know it's just the nature of things, you know people get old and when most of your life is behind you, you know, that's probably where most of your focus lies, but with the generation I'm in touch with most, it's really about things in the future and how do we make things better and achieve a lifestyle that is more sustainable and more resilient and so on (Interviewee 2).

In addition, the dichotomous split between place imaginaries of 'old' and 'new' Lyttelton is linked to a variety of other discourses other than historical perspectives. For example, participants linked the divide of 'old' and 'new' as related to mobility, gender and status divisions. Interviewee 1 described it like this:

Then you get the new Lyttelton who have come in in the last 20 years and tend to be arty and sort of excited about doing really cool stuff, and love Lyttelton in their own way but the two groups don't mix that well. 'Cause new Lyttelton coming in is seen as they're coming in to take over. And so there's a bit of defensiveness on the part of old Lyttelton and new Lyttelton tends to be wealthier and younger and more able to get around, more mobile and more um, often they work in town and live in Lyttelton, they come home at night (Interviewee 1).

The differing place imaginaries also led to a discourse of what 'local' means to residents. It appeared that when faced with increasing migration from other areas and "gentrification" (Interviewee 5), the group who identify with Lyttelton as "diamonds in the ruff " (Interviewee 10) or from "a working class port town"(E-Interview 9) have further strengthened their identities as linked to a discourse of being locals. This identity has a strong territorial foundation, and has led to feelings of defensiveness over what being from Lyttelton means. One interviewee suggested that you were only considered a local if you had been born in the Lyttelton maternity 
hospital called "Chrissie House" (Interviewee 4). Such conditions for being considered a 'local' suggest a strong discourse of place definition that is built on ideas of belonging and birth right. These place discourses further strengthen conflict between those perceived as 'old' and 'new' Lyttelton.

Others also contrasted themselves from this 'new' Lyttelton by describing certain prerequisites for being a local other than being born there:

You have two or three sides to Lyttelton. You have the old set that are locals which are born there.... You have young locals that are savvy and have travelled and start up the shops and bars. Then you have a very green almost hippy type. I think that most people slot the project people into the green movement. The work with the farmers market is great but sometimes the whole green side of it is a bit much. It's a port first with locals coming from a sea trade background (E-Interview 2).

Here the participant is referring to Project Lyttelton members (as project people) who are not necessarily considered "locals" - especially with the town being considered a "port first".

In order to display the complex nature of the discourses and interactions between these two place imaginaries of 'old' and 'new' Lyttelton, Figure 5 demonstrates the two perceived place imaginaries. The diagram illustrates the fluidity of self-definition, illustrating that an individual may associate with the imaginary at varying points along the continuum. In addition, characteristics have been overlaid onto the diagram to show some of the perceived prerequisites identified by interviewees associated with those imaginaries. It is important to explore the nuances within such classifications that stress the lack of boundaries between place imaginaries and emphasise the multifaceted nature of many individuals identify with a place. It is also essential to acknowledge that while the 'old' and 'new' imaginaries are particularly dominant among some individuals many place imaginaries are not captured by this diagram or this research due to the extensive diversity and individual nature of relationships to place 


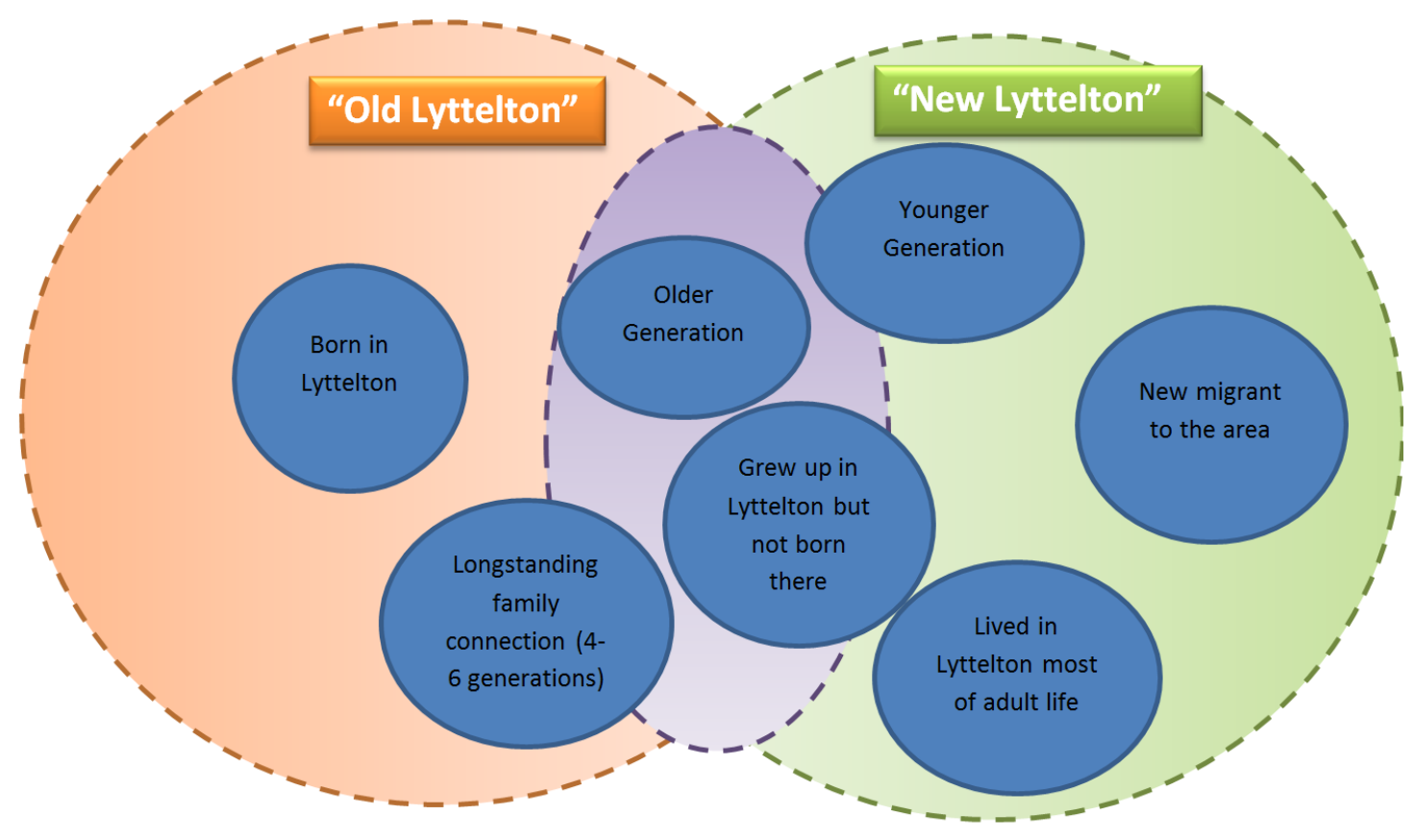

Perceived traits:
-Working class
-'Port Town'
-"Diamonds in the ruff"
-Nostalgic
-Attitudes of self sufficiency
-Accepting of diversity

\section{Perceived traits:}

-Middle/Upper class

-University educated

-Medium to high earners

-Project Lyttelton members

- Driving gentrification

\section{Potential commonalities:}

-Desire for self sufficiency

-Aspirations for diversity

-Love of Lyttelton

-Appreciation of natural environment

-Common experience of earthquakes 
Figure 5: Visual representing two dominant place imaginaries, 'old' and 'new' Lyttelton alongside associated discourses as derived from interview data (Source: Author)

\subsection{Conflicting Imaginaries}

As Doreen Massey (1991) argues, place based identities created on the basis of reactionary responses that differentiate one idea of place against another, can lead to conflict and tension within a community. Defining place with a relational lens acknowledges the socially constructed nature of an individual's identification of place and sheds light on why people hold different imaginaries. These differences can, as Massey suggests, result in conflicting identities in communities, most commonly seen in cases of racism, anti-immigration stances and nationalist politics (Massey, 2004). Lyttelton is no stranger to these tensions - in a town where there are two strong place imaginaries and countless others linked to discourses of history, class and status there is a level of tension especially surrounding those newer to the area.

Interestingly, interview data revealed a high level of awareness of these tensions. As introduced above, the conflict between 'old' Lyttelton and 'new' Lyttelton received extensive comment in the data and often differentiates the participant as 'old' or 'new'. In addition, much of the conflict around these place imaginaries is based in the value placed on history and heritage. Massey (1995a) comments that non-relational place identities are often formed on the basis of differentiation and nostalgia in a way that can create defensiveness over place. This sheds light on why many of those who self-associate with 'old' Lyttelton appear defensive and protective of the town they deem to be theirs.

At the same time it is important to remember that those who had lived in the town for longer also expressed concern that their views were not being respected or taken into consideration. One interviewee suggested that for a group doing a lot of working trying to represent the 'community', Project Lyttelton did not involve or communicate with the older group of Lyttelton residents:

It would have been really good if they'd actually had some community meetings in the Working Men's club eh? Yeah?...Did they actually ask those men that lie on the leaners instead perhaps of judging them as dead wood 
without vision, if they had actually found out what was going on in their minds? (Interviewee 4)

This tension appears to be between the perceived groups over who has the power to control the changes in Lyttelton, who is involved and who determines who is involved. It also indicates the deeper tensions surrounding who is 'local' and what determines belonging to the 'community'.

The issue of generational difference and attachments to history have raised an interesting issue surrounding places and the past. Massey (1995a) notes that while trying to understand the identity of places we cannot and should not separate place from history or time. This is because the past informs the present as much as the present informs the past. History will always be an articulation of who is telling the story, how the story is told and which story is dominant (Massey, 1995a). Nostalgia that prompts reactionary responses to change is one way of interpreting history that can be viewed as counterproductive to acknowledging the relational nature of place. This is because it is a retelling of history that privileges an essentialist view, excluding the multiple and interconnecting forces that have and will always influence fluid place identities.

However, failing to consider history ignores these multiplicities. Through focussing on the a perceived goal of sustainability or even resilience, as Project Lyttelton aims to do, there is also potential for a singular temporality to be privileged, one that sees time as linear - with the past in the past and the goal the desired future. The danger in this is that multiple histories and constructions of the present are marginalised. The data from Lyttelton suggests that this is one element of the struggle between the perceived 'old' and 'new' groups. There is a lack of recognition of the multiple histories and presents within the town and a struggle for each to be recognised as the legitimate identity.

Another consideration regarding the two conflicting place imaginaries of 'old' and 'new' is that it excludes the possibility for other place imaginaries to be visible. While this was not raised often in the interviews one interviewee did mention that overall her perception of Lyttelton was that the town was not entirely comfortable for migrants with an ethnicity other than the dominant European Pakeha culture: 
Lyttelton's very white, we had Pakistani friends who shifted [away] from Lyttelton cause they got tired of being picked at. Went to Auckland, feel much more comfortable there, they don't stand out. Nothing bad, but you know they got a lot of continual kind of, that sort of low level verbal abuse. (Interviewee 5)

This experience challenges the caring and welcoming community discourse that many interviewees mentioned and shows that the discursive reality may often differ from constructed ideals - such as Project Lyttelton's aspirations of diversity.

However, the interview data on this area of diversity is complex and at times contradictory. Several participants pointed to Lyttelton's 'port town' history as creating a welcoming and tolerant atmosphere due to the history of migration, this lead to individuals feeling pride for the community having an inclusive attitude (Interviewees 2, 3, 6, 7 E-Interview 8). One interviewee put this in the context of how new migrants see the older residents:

This nice new set [Project Lyttelton] with their academic veneer don't even know. The [wider] community is actually accepting. I mean there are people in the community who I could tell you have been to jail, have gotten out and the community has accepted them back (Interviewee 4).

Such contradictions amongst participants' ideas of the town serve as a caution not to perpetuate conclusive or territorial ideas of place by espousing that there are only two dominant and fixed place imaginaries in Lyttelton. It is doubtless that there are multiple ways residents see Lyttelton in relation to their own history, the history of the town and their own experiences. Indeed even within those who self-identify as 'old' or 'new' Lyttelton there is variation, those who do not associate with either term but are grouped that way by others and those that associate with both terms.

Despite some interviewees feeling as though part of the community has been marginalised it is important to acknowledge that the power relations surrounding the contestation of the place identity of Lyttelton are not straight forward. It can be argued that the migrants to the area have been asserting their own place imaginaries, often based around ideas of sustainability and community. While this has in the opinion of some people, excluded other place imaginaries present in residents in the 
town, these people are not necessarily passive to this marginalisation (Interviewees 1 \& 4). Indeed one can view 'old' Lyttelton's assertions to localness as a way in which they are asserting agency and power over the situation in order to gain whatever purchase they can in emphasising their own place identity.

While paying close attention to the multi-dimensional nature of such place imaginaries present in the interview data it became apparent that there was both underlying and overt tension over the identities present in Lyttelton. There is a defensiveness that often represents the past in a way that is divisive and has caused conflict between people new to the area and those who have resided there long term. But there is also great value in exploring the multiple histories of a place. By considering these dynamics of place, space and time, a greater understanding can be gained of the multiplicity of diverse albeit at time contradictory imaginaries in Lyttelton.

\subsection{Destabilised Place Identities}

A feature of many disasters is that they often cause physical destruction to landscapes, streetscapes and monuments of places. Lyttelton, being near the epicentre of the $6.3 \mathrm{M}$ February $22^{\text {nd }}$ earthquake suffered drastic loss of buildings. This destruction resulted in the loss of almost every church, many historic buildings, hotels and theatres, the London St streetscape of store fronts (Image 10) and the rare and iconic time ball station (Image 11). The effect of the loss of these physical symbols of place bears meaning for how a community carries resilience through to the future. 


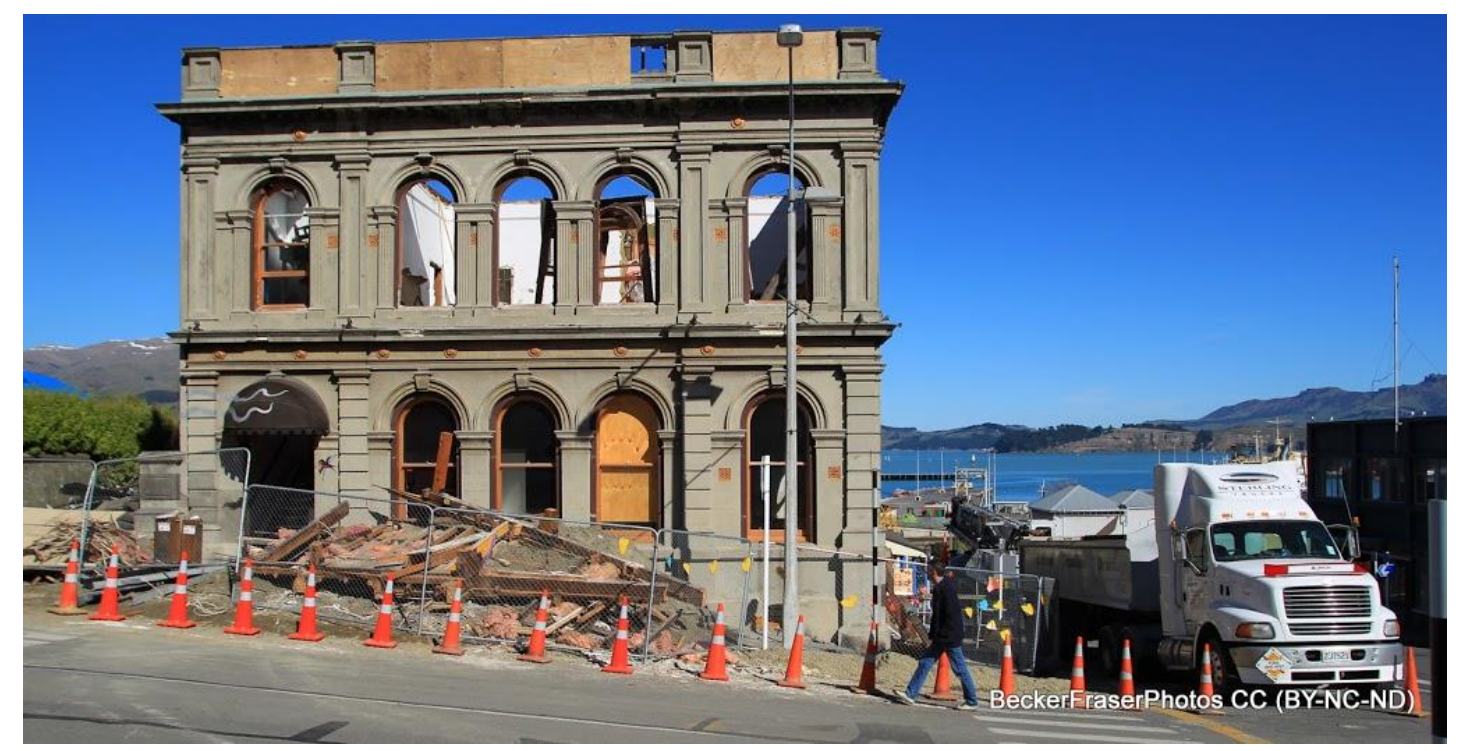

Image 9: A damaged building next to a vacant plot of land left behind from the demolition of another damaged building. Lyttelton Harbour can be seen in the background 2011 (Source: Becker Fraser Photography).

The residents of Lyttelton and those that I interviewed were undoubtedly affected by the loss of these buildings and monuments. Interviewees described at great length the wonders of the buildings that were gone and utilised a range of metaphors to describe the feelings of loss and grief. One participant described it like this:

I remember someone saying it's like we've lost Lyttelton, it's just not going to be the same. And in one sense she's right, but in another sense she was very depressed about it at the time and she can probably see a way through now. Someone else described Lyttelton as being like a gummy mouth with so many gaps post-quake... and there were people really keen on the historic side of things. And then suddenly that's all taken away from them and there's a real sense of what are we going to do? We're losing what we identified as being the heart of Lyttelton (Interviewee 1).

Another interviewee described similar feelings:

If I remember what the streetscape of Lyttelton used to be, we were so proud of our heritage... so many firsts in New Zealand started there. The streetscape was, the buildings anchored the streetscape, those critical buildings on those corners and it created full stops and now you've got all this openness and this 
bareness and key buildings that were Lyttelton are gone. Key buildings that have been there for some people's whole lifetimes are gone, and so all those memories and all those things they used to do, how they socialised, how they lived has been literally wiped out (Interviewee 4).

Understanding how the loss of buildings affected residents in Lyttelton gives insight into the role of physical symbolises in maintaining and constructing place imaginaries and attachment. It also allows us to see how those aspects of a community are remembered or continued into the future in another form.

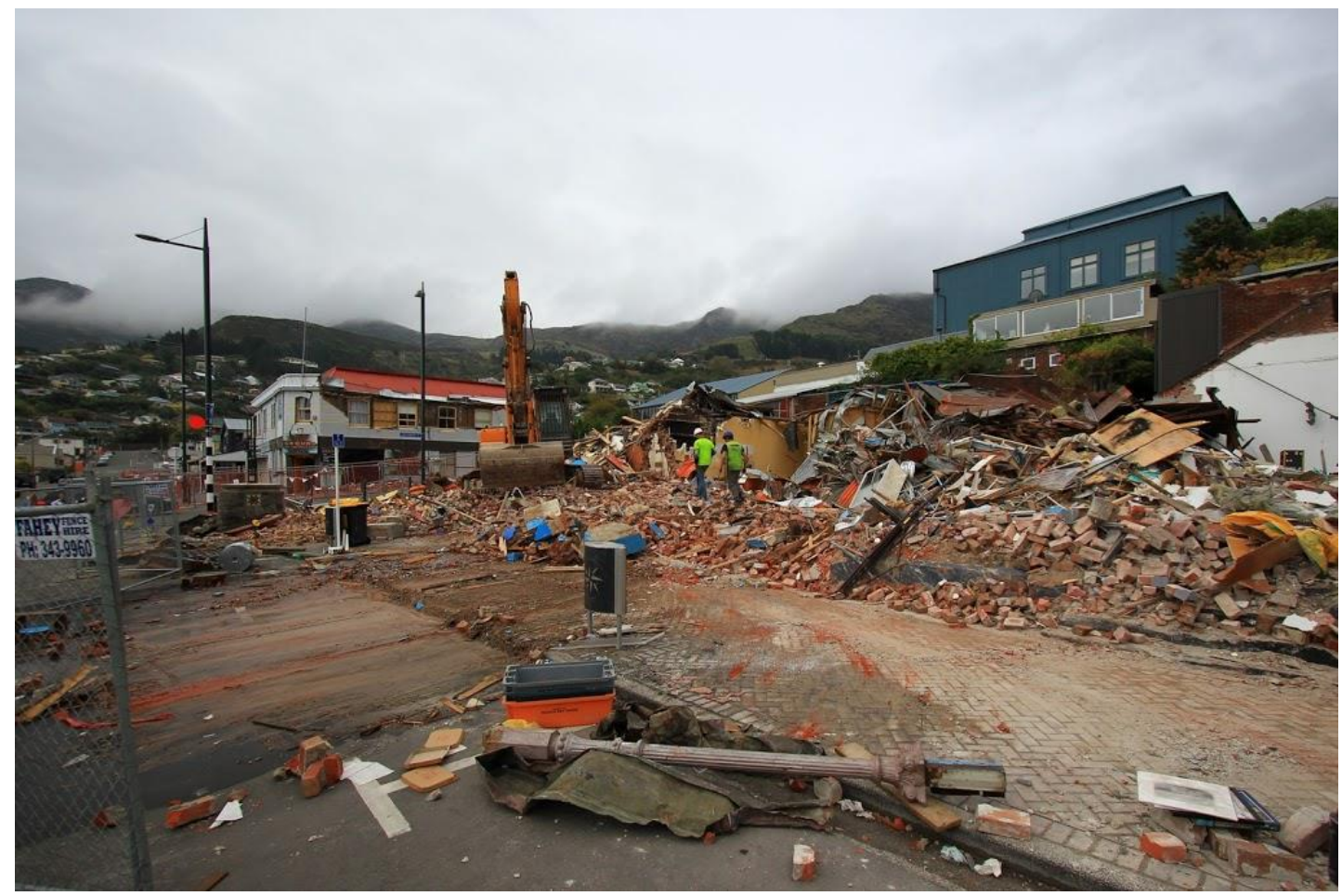

Image 10: London Street, Lyttelton during demolition of earthquake damaged buildings 2011 (Source: Becker Fraser Photography).

Another way interviewees described the effect of the earthquakes on place was through metaphors of violence. These individuals drew on the current state of the town, vacant properties and land, damaged buildings and continuing issues with infrastructure to illustrate the trauma experienced through disruptions to place. One interview transcript in the Shaken Heart book released by Project Lyttelton described the earthquakes as like a "home invasion". She continued to say: 
You close your curtains and you lock your door when you go to bed at night and they enter your house without an invite (Evans, 2012, p. 10)

Others compared the town to a "war site" saying that it was like a bomb had gone off and that even the lack of maintenance done on the road tunnel since the earthquakes showed the ugliness of what was left behind from the disaster (Interviewee 4).

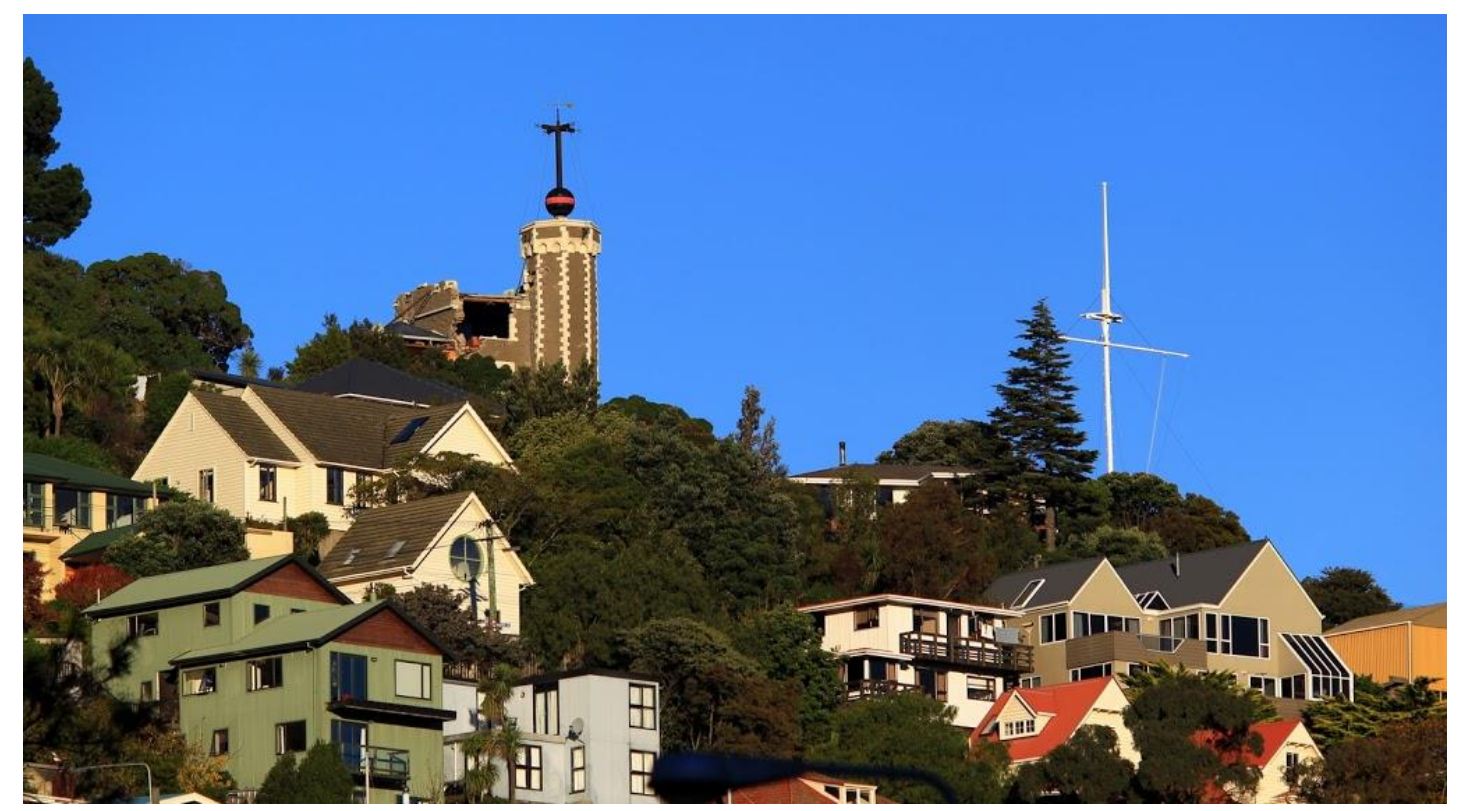

Figure 11: Time ball Station - further damage sustained on June $13^{\text {th }} 2011$ caused the remaining tower to collapse (Source: Becker Fraser Photography).

One of the interesting trends from the data was that some members of Project Lyttelton were not as perturbed by the loss of buildings and streetscapes as others. Several interviewees expressed sadness at the loss of buildings, but also illuminated their perceptions of the positives to come out of the event "in a weird way I think it has been improved by the open spaces" (E-Interview 3). Another interviewee expressed her feelings in this way:

I've got friends who are lamenting the loss of buildings and such and it doesn't really hurt me that much. Sometimes I might go into town and get lost or think oh that's gone, that's sad but you know it doesn't last for me for that, not that I'm aware, there might be stuff happening in my body that I'm unaware of but it doesn't seem so important to me... I'm in a hurry really to 
move to getting this place to [be] resilient, [and] there are far more urgent things (Interviewee 2).

These sentiments exposed a difference in the way that physical representations of place were valued and how they contributed to different people's place imaginaries. For those who were not as attached to the physical symbols of place, the most important thing to them was often the community aspect of Lyttelton:

It still has lots of life and vibrancy... I love the new petanque court and open area on the corner of London and Canterbury Streets. It's quieter during the week I think now - there is no supermarket and fewer cafes and no real pubs! (E Interview 3).

Despite the lack of immediate conflict regarding loss of buildings it become apparent that the tensions between perceived 'old' and 'new' Lyttelton imaginaries (as outlined in Section 6.4) have been amplified by the earthquakes and subsequent rebuilding process. Several interviewees (Interviewees, 2, 3, 4, 6) noted that the disaster bought the groups together narrowing the perceived distance between the 'old' and 'new'. But this was discussed as a short term thing that did not last for a significant length of time. Instead, conflict was reignited post-earthquake surrounding differing visions for the rebuild of the town. This task has further exacerbated issues between those who do have strong attachment to the symbols of place identity such as buildings and those who do not. One participant explained:

They've got their plans for this that and the other while old Lyttelton are still grieving. They're grieving for those things that they have lost, the home that they grew up in, that their grandparents grew up in, the things that were always there have now gone. And whilst they were in their shock and their grieving new Lyttelton have gone right we can have this, this and this and suddenly there's this plan out there...[but] they were still in shock and grieving so they're just kind of feeling helpless and hopeless and railroaded some more while all these creative and wondrous trendy new agey concepts are being agreed to (Interviewee 4).

Again this interviewee is emphasising the tensions between the old/new place imaginaries. This led to heightened tension as some people felt increasingly left out or not heard within the process of rebuilding and recovering from the earthquakes. 
The same interviewee described the process of Project Lyttelton planning new developments for the town and not listening to their concerns as akin to "how Māori would describe colonisation" (Interviewee 4). These strongly worded sentiments are indicative of the isolation that this group feels.

The conflict has been rationalised by both sides of the argument. At times the inclusive approach of the group was often used as a justification for the assumption of inclusion as members did not perceive any barriers to people becoming involved in the group (Interviewees 7, 6, 2). Some individuals said they felt like "tall poppy syndrome" and "jealousy" were at play in the tension over the new plans (Interviewees 2, 5). While others justified the tension in terms of "being on the edge":

Some oppose it [Project Lyttelton activities]. We are at the edge and pushing for change, this ruffles some feathers. But that is fine, feathers need ruffling! (E-Interview 1).

These tensions and conflicts over place, the past, the present and the future show the importance of not only understanding place and its impact on individual and community identity but also how place identity is intensified after a disaster. These findings suggest that latent tensions between place identities can become stronger and more forceful due to the increased pressure on places to re-create, re-cover and re-imagine the town that was once there.

\subsection{Summary}

In summary, place is a relational concept constructed by social groups and individuals is evident from the research data presented here. The data suggests that the residents of Lyttelton hold multiple and sometimes contested place identities. The difference in these identities is of no surprise - what is of interest is the way these identities are formulated and how this leads to cohesion or conflict amongst the vying place imaginaries of Lyttelton. Clearly conflict existed prior to the earthquake, based around assumptions of the identity of the town and the status of some individuals as exclusively 'locals'. These place imaginaries have clashed with those of new migrants to the area who have a different way of interpreting the history and 
present state of Lyttelton. These place imaginaries draw across lines of difference such as gender, class and wealth.

The context of the earthquakes provides insight into how these place imaginaries are affected by a disaster. The destabilisation of the physical representations of place in the form of buildings and the subsequent push to rebuild and (re)imagine the town have put further pressure on individuals to cope with the conflict that existed prior to the disaster. In addition, the grief from losing symbols of place has affected individuals differently leading to further tension in the town 
This page is intentionally blank. 


\title{
Chapter 7.0 Discussion: Towards a Place Based Perspective of Resilience
}

\author{
"State houses by the river, \\ State houses by the sea, \\ I don't remember the city, does the city remember me? \\ I don't see nothing coming, \\ no matter what the government says. \\ Some things are clear to me, \\ Some things will never be"
}

-“State houses by the river” - The Eastern (2012)

\subsection{Introduction}

As Gieryn (2000, p.466) notes "everything we study is emplaced". Tobin (1999) echoes this sentiment observing that it is unlikely that successful disaster recovery and mitigation can occur without due consideration to contextual issues of place. Through a relational perspective we can gain a more nuanced understanding of the emotional, experiential and individual nature of relationships to place and how these can be disrupted. Thus, this study of place and resilience has moved away from emphasising the ability to bounce back from disaster, instead focussing on the role of identity, place and conflict in mediating community resilience. In this chapter I argue that the role of place within resilience and disaster recovery goes further than the contextual. Rather, relational place underlies not only the specific resilience outcomes that materialise in a locality but also the individual identity and power dynamics that shape elements of resilience capacities. Further, conflict in Lyttelton suggests that there is a strong case to argue for an open minded interpretation of 
place. Thus, I argue that Massey's progressive politics of place provides valuable insight into the relationship between place and resilience.

The aim of this research is to understand how grassroots community groups support resilience and how this is affected by place processes such as attachment and identity. Evidence in Chapter Five explored perceptions of resilience and established how the work that Project Lyttelton has undertaken supports the resilience of Lyttelton. Chapter Six has likewise recognized that there are multiple place discourses and subsequent imaginaries in the town. These multiple identities have resulted in some conflict surrounding the past and future identity of the town, especially following the damage sustained in the earthquakes. This chapter brings together these two strands of inquiry to explore how resilience and place are interconnected and how in the case of Lyttelton this is demonstrated.

The following section will outline the interconnections between the resilience processes I have covered (social support and participation, inclusion, social learning and memory) and multiple relational place identities. First, the most basic connections between contextual place and resilience capacities will be explored. Following that I will detail a potential framework for incorporating relational place identities into resilience theory by demonstrating how the two concepts are embedded within each other. Finally, I will conclude with a discussion on the merits of a progressive sense of place for building resilience in a grassroots community context.

\subsection{Resilience within the Context of Place}

Through the initial presentation of data it became clear that grassroots organisations have the potential to make strong contributions to community resilience capacities both prior to and following a disaster. At the most basic level, place contributes to resilience through shaping the needs and responses of local communities and settlements - illustrating the contextual nature of place in resilience. In Lyttelton, this can be observed in how the town's resilience has been shaped by projects that have been launched in response to the earthquakes, but that are also specific to place. The most prominent example from this research is the Harbour Resilience Project that was created in response to place specific demands following the earthquakes. 
The project emerged as a means to further support the community, increase food security and provide a repository of experiences and learning from the earthquakes. The design of this venture is highly place specific and has been envisaged based on the geographical location of the town and the surrounding area. One component of this physical location is the geographical isolation that resulted in Lyttelton being cut off from the wider city following the February $22^{\text {nd }} 2011$ earthquake. This concern in particular has led to the project taking on food security as an issue. One participant noted the need to look beyond the immediate settlement with regards to this:

It's actually the harbour basin that is a natural bioregion where things need to happen and we do need to pull in people from other settlements and not just think about Lyttelton as one isolated bubble because it really, even just for Lyttelton to create you know more food security you need to think about land that's around it and you do need to have this bigger picture of bioregion one way or another if you talk about food and say water systems and so on. So it was kind of a natural evolution I guess to expand our area to harbour basin (Interviewee 7).

Furthermore, the Harbour Resilience Project is an example of social learning (see Section 3.2.3). Social learning and thus adaptive capacity are highly contextual and based upon localised experiences and understandings (Olick \& Robbins, 1998). The Harbour Resilience Project displays these capacities through providing a physical location for place specific sustainability and resilience initiatives to be developed as a result of motivation generated from the earthquakes. This does not necessarily imply that lessons from Lyttelton cannot be applied or related to another place but it does highlight the place specific nature of many experiences resulting from the earthquakes.

These examples of the social learning and memory exemplify at a simple level the basic interactions between the physical geography of a place and the circumstances around community resilience. It is at this level that other academic texts have addressed the role of place in shaping resilience (Norris et al., 2007; Scannell \& Gifford, 2010). This is an important consideration, especially for the resilience of practical concerns such as infrastructure. However, the role of place in shaping resilience to disasters can go much further than the contextual in a more 
nuanced and complex interaction between power, differing place imaginaries and discourses.

\subsection{A Framework for Relational Place Based Resilience}

To more fully explore the role of relational place in shaping resilience is to understand the co-constituted nature of the two concept's influences. Cutter et al's (2008) DROP (Disaster Resilience Of Place) model is one of several papers mentioned which emphasises the place specific conditions that effect resilience or vulnerability. Here, place is considered as one of many factors contributing to resilience (Figure 6). In this theorisation place is regarded as the condition of the environment and the management of resources. Increasing resilience through place is thus considered to be, in extension, an improvement of these conditions (Cutter et al., 2008). Although social resilience is mentioned as part of resilience, place as understood in this research does not feature strongly in this model (Cutter et al., 2008). The triangle in the diagram below shows that place is built on social systems, the built environment and natural systems, to provide the context (or antecedent conditions) from which mitigation, preparedness and disaster responses occur.

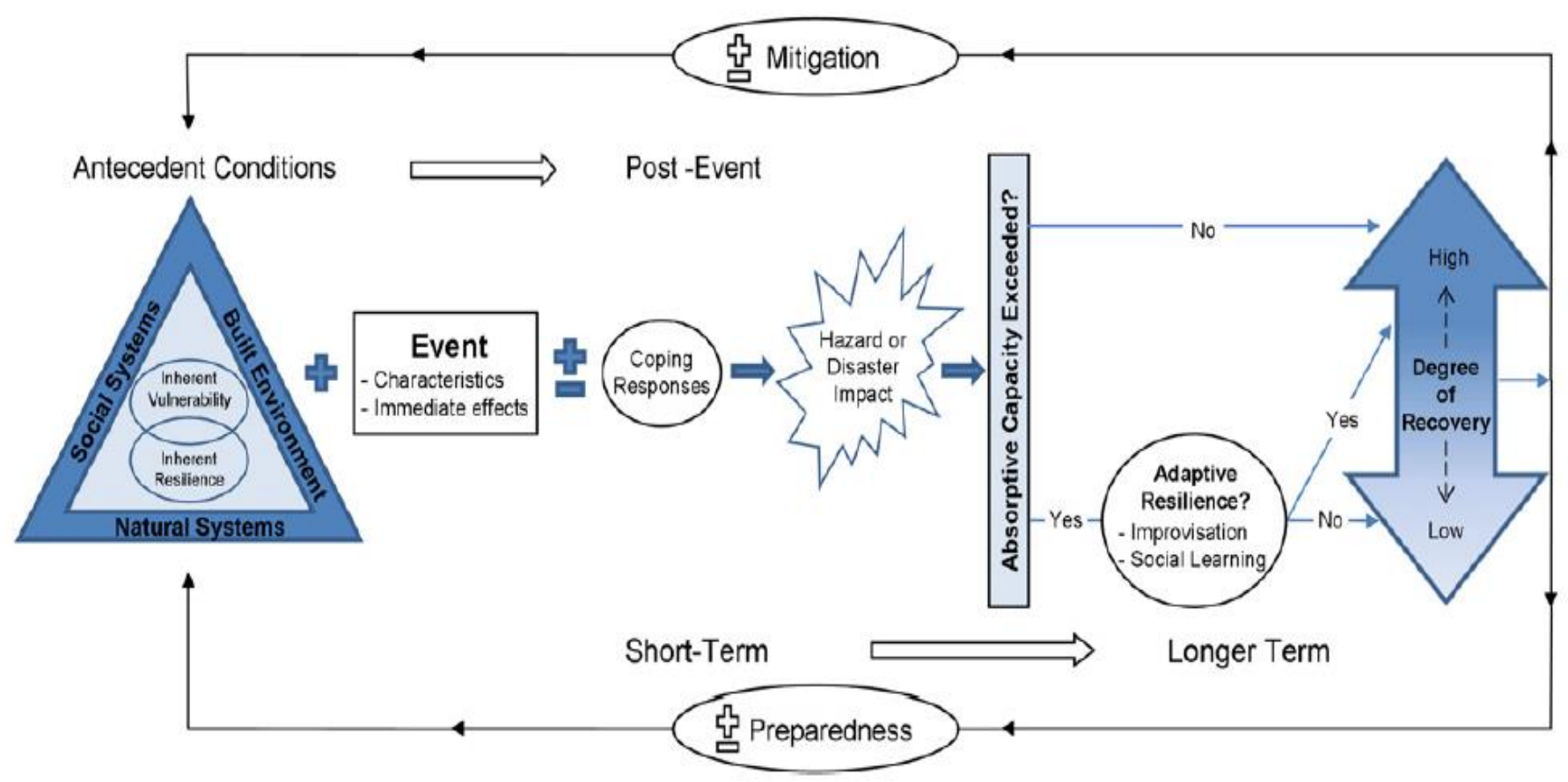

Figure 6: Visual depiction of the DROP model which integrates place and resilience (Cutter et al., 2008) 
A relational view of place would, in contrast, address not only the contextual issues of place but the multiple interpretations of place including the many intersecting and competing discourses. Rather than the solely contextual, I suggest an approach in which resilience capacities and place should be considered as co-constitutive, with both concepts informing each other as demonstrated in Figure 7. Here, place is a multiplicity of fluid imaginaries (blue circles) informed by multiple contributors to community and individual identity (grey text). Resilience is informed by these imaginaries and the associated discourses of identity. Thus place is identified not only as a contextual issue but as a facilitator of vital community attributes that feed into resilience capacity. Through this diagram it is evident that resilience can also shape place through influencing place imaginaries and affecting the physical environment.

In this theorisation, fluid place imaginaries and their constitutive discourses inform the wider interconnections between discursive realities and societal discourses which facilitate resilience characteristics. The social characteristics within resilience are considered by many academics to be the foundation for community resilience potential (Aldrich, 2010; Gunderson, 2010; Magis, 2010; Sherrieb et al., 2010; Tobin, 1999). These activities such as social support and participation and social memory are influenced by the place imaginaries of individuals that reside there. 


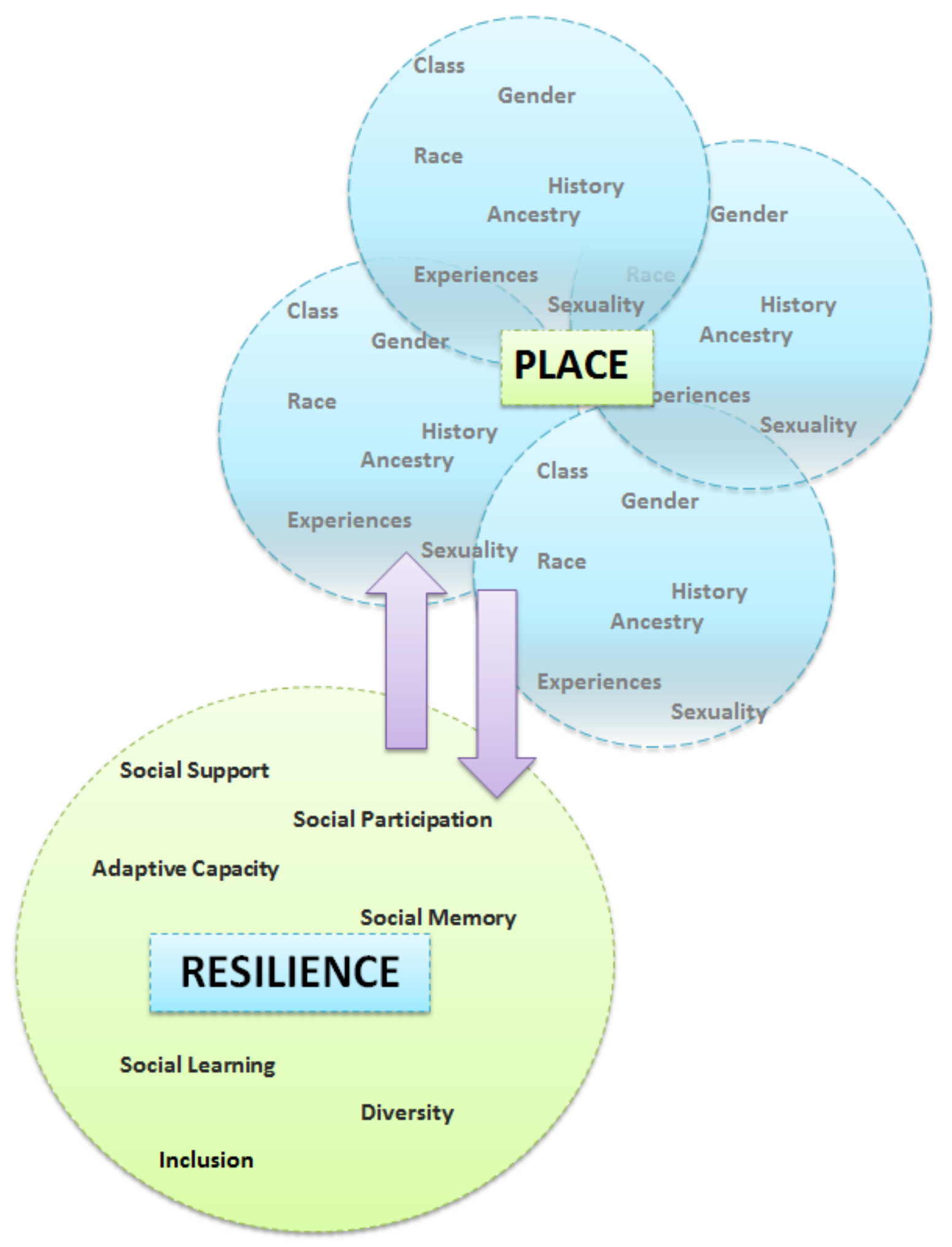

Figure 7: Visualisation showing the integration of place and resilience concepts. The diagram also displays the factors of relational identity that individuals draw on for their place identities (blue circles) (Source: Author) 
One example of a strong place imaginary that appeared to positively influence resilience which was identified in Chapter Six was the narrative of Lyttelton as a close knit and caring community. One participant suggested that this sentiment got stronger following the earthquakes:

I kind of think it set the place free...you could hear people saying, it's really sad about the buildings but it's not about buildings, it's about people (Interviewee 2).

Such discourses of place reinforce social support and participation networks within the town, enhancing resilience. This can help to increase the existence and strength of cohesive community bonds during times of crisis such as a disaster. These place imaginaries also provide a common identity for some residents through the rebuild phase when physical markers of place are being recreated and reimagined.

Another example of how place discourses present in the wider town affected resilience capacity is how the history of the port was associated with feelings of diversity and inclusivity. Diversity of people, opinions and ideas have been shown to strengthen social resilience through providing avenues for transformation and adaptation which results in greater resilience to future disturbances (Norris et al., 2007). Interviewees expressed their identification with the port town discourses through describing positive traits:

It's a sea port, every dynamic from the world has flowed in and flowed out, you've had the history, and you had pirates.... The community is actually accepting. When I was at school [1960's] the west end shop was bought by a couple of gay men. And they were totally accepted by the community. But you know, this was quite cutting edge stuff (Interviewee 4).

The way this interviewee identifies with the port town imaginary displays how such strong place narratives can affect how people view themselves and their community. In this case it has led to people feeling like there is a strong tradition of welcoming difference. This can support community capacities such as inclusivity which in turn, supports resilience.

In addition, the port town place imaginary shows the co-constituted nature of place and resilience. Resilience can also shape place imaginaries. For example, 
discourses of self-reliance and practical skills were described by participants as related not only to the working class background of residents but also the historical events of the town such as port strikes, fires and ship groundings. As mentioned in Section 5.5.1, these events serve as poignant events for communities to learn and remember how to cope with times of crises. Examples such as these display how resilient characteristics become embedded within discourses of place, illustrating the interconnected relationship of the two concepts.

Conflict has been a theme arising from the interview data which has potential to destabilise some of these positive influences on resilience. It is not a common topic in existing literature that combines place and resilience. For example, Scannell and Gifford (2010) focus more on the potential for place attachment to hinder adaptive capacity by perpetuating a desire to return to the state prior to the disaster. This research has shown that in the case of Lyttelton, those who have been in the area longer potentially have stronger attachments to history and buildings, leading to greater concern as to how the how the town is rebuilt. Those highly attached also showed dismay at the fast pace of rebuilding, wishing to take their time to decide how to proceed forward. However, those with weaker attachments to buildings and history were less bothered by the disruption, so continued with the task of rebuilding quickly.

The issue that arose was that those with stronger attachments have to cope with the double burden of grief and loss of signifiers of place, at the same time as embarking on the slow process of redeveloping new attachments. Conflict was not on the basis of opposition to rebuilding, but more related to the need for an appreciation of grief and a platform for concerns and voices to be taken into consideration in the rebuilding process. This further disagreement over the rebuild has added to the existing foundation of tension surrounding the 'identity' of Lyttelton that existed prior to the earthquakes. Such tension potentially raises a bigger threat to resilience than the attachment to history that has been raised in the literature to date.

The effect of competing place imaginaries and unresolved conflict could work to undermine the resilience capacities such as social support and participation that have been cultivated through Project Lyttelton's work and the positive aspects of 
individuals' place identities. The complex interactions between these two concepts illustrate the importance of viewing place from both a contextual and discursive approach which integrates the multidimensional nature of place identity in times of crisis.

\subsection{Possibilities for a Progressive Politics of Place}

A comprehension of a progressive politics of relational place may help to understand and potentially counter place conflict to further strengthen resilience capacities. This could possibly serve as a method for understanding and minimising the negative effects of place based conflict. Massey (1993) originally argued for a progressive politics of place in relation to increasing time space compression from globalisation affecting how people identify with places. She noted that a reactionary response to retain the perceived character of a place in the face of globalisation was unnecessarily bounded, defensive and exclusive (Massey, 1991b, 1995b, 2004). As was noted in Chapter Six, the heart of the 'old' versus 'new' conflict lies in the multiple discourses of place which have been set up against each other in competition for dominance over the 'real' identity of Lyttelton.

Through her extensive analysis of relational place identities Massey has stated that such conflict over claims to a universal, singular and stable identity for a place are counter-productive to a progressive and open society (Massey, 2005). A progressive politics of place instead postulates that places should aim for an appreciation and understanding of the coalescing, multiple and ever changing interpretations of place in the past, present and future (Massey, 1993, 1995a). Her affirmation leads to the conclusion that places can maintain their uniqueness and specificity but that individuals should not define the identity of a place as static and homogeneous (Massey, 1991). Consequently, places should be defined through their links with others, rather than their positions against elsewhere, reducing the potential for exclusionist attitudes to perceived “outsiders”(Massey, 1991, p. 315).

As a result, it is possible that while Massey's original theory was intended to be applied towards cases of globalisation, her thinking can be applied to the sudden onset change resulting from a disaster. In this case the relational place imaginaries that promote exclusive claims to identity are challenged due to a sudden 
destabilisation of place identifiers. Tension emerges from this as a result of the (re)imagination that follows the subsequent recovery.

The conflict explored in this thesis surrounding the identity of Lyttelton and its histories displays the risks involved in framing place as exclusive and bounded, especially when disruptions occur. Indeed, through the data it is evident that both 'sides' of the old and new Lyttelton dualist identity attempt to assert and rationalise their ideas of the place identity of the town. For instance, those identifying as old Lyttelton claim that the newcomers have come into "their" town, bringing with them trendy and arty ways that do not fit in with the working class ethic (Interviewee 4, EInterview 10, 12, 14). This example is similar to the Isle of Dogs case study in the London Docklands that Massey refers to in For Space (2005). In this text she describes how the claim by the current residents to an authentic working class place caused people to consider the new arrivals as "an invasion of yuppies" (Massey, 2005 , p. 167). This kind of claim to authenticity is dangerous as it obfuscates the history of the area as being subject to multiple flows of place and space through time - ignoring the influences of colonisation, migration and international trade (Massey, 1995a). Similarly, some individuals draw on the history of the port as part of their version of the 'authentic Lyttelton', despite the contradictory acknowledgement that this history led to a greater appreciation of diversity within the town.

While those who claim to be 'locals' due to their connection to and appreciation of one version of Lyttelton's history appear to be espousing a rather bounded and exclusive politics of place, those who identified as new Lyttelton also show similar attributes. As mentioned in Chapter Six - those considered new Lyttelton are by and large those who participate in Project Lyttelton. Project Lyttelton as a group espouses an open attitude and outward appreciation of diversity and difference. However, the overall approach to incorporating their vision with the rest of the community shows a potentially exclusive attitude as to what the place should and should not be like. For example, one interviewee argued that because of the organisational skills and resources of the group they had already submitted a plan for a vacant plot of council land, whereas others in the community had no way to organise for such a plan (Interviewee 4). 
This imbalance of representation surrounding issues of place is further strengthened by Project Lyttelton's normative assessment of what the future should look like. One individual interviewed discussed issues about how they needed to "bring the rest of the community with us" into their ideal future scenario, implying that the rest of the community needs to adapt to their already established vision for the future (Interviewee 5). The issue here is that others in the community feel sidelined and removed from the process of making decisions (Interviewee 1, 4, 5 EInterview 13). This shows that the power relations in the town appear to favour Project Lyttelton - they receive funding from outside organisations, employ staff, are technologically savvy and often highly mobile. This has resulted in Project Lyttelton being able to project their vision of place identity onto the town with a greater degree of material success than others have.

The idea of community is frequently used as a foundation for resilience and is also subject to critiques similar to those outlined above in relation to place based conflict surrounding unequal power relations and exclusivity (Norris et al., 2007; Panelli \& Welch, 2005; Silk, 1999; Welch \& Panelli, 2007). Community is subject to discursive, material and symbolic imaginaries in a similar way to how individuals relate to place (Panelli \& Welch, 2005). Differing place imaginaries vying for power over the (re)imagination of the town post-quake have resulted in an exacerbation of an unstable system of alliances and differences within the community. This has created what Silk (1999) describes as a hierarchy of competing subject positions. Interviewee opinions on the rebuild demonstrate such competing positions, sometimes subtly and at other times explicitly. For example:

There's not a lot of connectedness between [social] strata or acknowledgement of strata. There's growing resentment within strata. Or the powerful group doesn't even acknowledge. And that's what happens in colonisation. If you're the powerful group you don't even see that which is below you (Interviewee 4).

The participant went on to say how difficult it was for the people that felt marginalised to speak out and have their voices heard in the rebuilding process due to these feelings of resentment and exclusion. These concerns echo Silk (1999) who noted that communities can often mirror the unequal power relations found in wider 
society. The comparison to colonisation is particularly salient and draws in the competing power relations between discourses of place.

The issues of boundedness and exclusivity further promblematise the issue of community as a foundation for local scale resilience (Rose, 1997b). As Project Lyttelton aims to "build community" (Project Lyttelton, 2012), the use of these discourses of community may be contributing to the lack of progressive place politics in attitudes to differing place identities. This approach may not allow for the kind of open, multifaceted approach that Massey notes is important for establishing a progressive politics of place. In illuminating these critiques of the place politics of Lyttelton the aim is not to chastise those in the town and Project Lyttelton for their lack of progressiveness. The point is to show, as Massey (2005) does, the difficulties in achieving a progressive place politics, even in a case where a group such as Project Lyttelton is attempting to re-configure society and work in a diverse and equitable way.

Nonetheless, Project Lyttelton does incorporate a more progressive politics of place in their aim to be open to any ideas from individuals who are willing to drive their own project. They also intentionally welcome newcomers to the town and have a diverse range of ethnicities on their operating board, even though several of them are from Anglo countries. The difficulty surrounding Project Lyttelton and progressive place politics stems more from their place interactions with those who have resided in the area for a long period of time. In this situation there appears to be, on both 'sides', a lack of understanding of the multiple interpretations of place and histories, and a lack of appreciation for the diversity and difference that these interpretations can bring.

The lack of progressive place politics in these areas of tension in Lyttelton has also manifested itself in different ways following the earthquakes. Some are of the opinion that there are more "urgent things" than dealing with grief over lost buildings (Interviewee 2). Others need to grieve and preserve what is left from prior to the earthquakes. It would appear that the change brought on by the disaster can intensify the conflict surrounding place imaginaries as there is a struggle over which discourses will become dominant in the reconfiguration of the town during the rebuild. 
Differences regarding ancestry and identification with histories were often attributed as factors contributing to this recent tension. It became apparent that alongside the factors usually considered for analysing discourses of identity such as gender, class and race, one's relation to histories, ancestry and place should also be considered. As such these considerations have been included in the diagram showing the entanglements between place and resilience (Figure 7). In addition, it appears that the place identities of those in a community should also be considered as an element within the intersectionality of difference that defines how individuals relate to each other and place. Place identity discourses should be considered alongside other discourses when instigating action for diversity and inclusion. If this approach to differing perspectives on place and history were more commonly held then there may be a way forward for resolving place based conflict and tension.

\subsubsection{Implications for Resilience Theory}

As discussed in Chapters Three and Five, the inclusion of adaptive capacity in resilience frameworks allows for shifting trajectories of development that change a society or system to a more desirable, adaptive state following disturbance (Berke \& Campanella, 2006). It is this potential for system change that makes the consideration of a progressive politics of place for community oriented resilience frameworks feasible and significant. Diversity has been acknowledged as important for maintaining community capacities and ensuring adaptive trajectories (Dale et al., 2010; Magis, 2010). In addition, the related exclusionary attitudes and conflict resulting from reactionary responses to threats to place may also disrupt the community's capacity for social support, participation and inclusion.

For example, by acknowledging, as Massey (1995a) does, that the past makes the present and vice versa, there is potential to strengthen social memory through learning from and remembering the past. This would involve the acknowledgement and respect of differing historical trajectories to be recognised and used to inform decisions regarding the present risks and vulnerabilities to future disruptions and disasters (Adger, 2005). In addition, social memory means elders in the community can fulfil the role of holding onto and communicating these lessons (Berke, 2006). By not taking a progressive view on place, the nuances and specificities of different 
place identities and histories may not be utilised to the full extent possible. As a result, the adaptive capacity of a town may be compromised as there is a lack of acknowledgement of the wide and diverse range of experiences and lessons that individuals can contribute.

Herein lies the challenge with place imaginaries that are asserted in relation to difference rather than as commonalities; tensions and conflicts may lead to disenfranchisement of some within the community. This dynamic is important to understand and potentially counter because, as noted, diversity of opinion and outlook is integral to adaptive resilience (see Chapter Three) (Dale et al., 2010; Magis, 2010; Norris et al., 2007). Furthermore, it is difficult to obtain diversity in a community without an inclusive approach (Hanson et al., 1998). The approach of many grassroots groups such as Project Lyttelton which focusses on 'growing' or 'creating' community needs to be carefully assessed, especially given the issues around exclusivity and boundedness.

Because such groups often espouse a normative vision of what an 'ideal' community is, they may consciously or unconsciously exclude others with differing views. Secomb (2000, p. 137) argues that communities need to acknowledge “differing needs, objectives and views expressed through disagreement". Secomb continues on to say "community needs to be open to disagreement, resistance and fracture". Thus, there needs to be room for contestation of a community group vision in a way that challenges the normative and universal assumptions that may be being made. This approach is similar to that of Massey's progressive politics of place in that it calls for an open understanding of the state of constant contention that is place identity, that each individual has a different way of identifying and viewing place and that these identifications are not fixed (Massey, 1993).

Such a view could increase acceptance of different approaches towards resilience in a location providing greater cultural diversity to draw on in times of need. In addition, several factors that community resilience theory deems important such as social support and participation are based on social cohesion and norms of reciprocity. As was shown in Chapter 5, Project Lyttelton is doing excellent work in promoting these capacities. This was acknowledged by almost all participants, especially in relation to the earthquakes (Interviewee 1, 2, 3, 5, 6, 7, E-Interview 8, 
$9,11,12,14,15)$. The concern with the recent place based conflict in the community in regards to these resilience capacities is that the tension may erode the social fabric of the town to the point where resilience in compromised.

Incorporating a progressive politics of place into the philosophy of (re) localisation community action could lend credence to the multiple ways individuals relate to and experience place and place based change. Furthermore, this may result in a lessening of tension and the improvement of resilience capacities. Grassroots groups such as Project Lyttelton aim for sustainable and resilient communities. However, as has been shown, there are significant difficulties in avoiding the reproduction of power relations that are evident in wider society and minimising tension due to competing place imaginaries. This is evident in how certain place identities may have been privileged over others in the rebuilding process. This privileging of one perspective, whether overt or subtle, leads to feelings of marginalisation and consequently a further reactionary assertion of place identity from the group feeling marginalised. With groups such as Project Lyttelton who are committed to visioning an alternative future it is likely that taking a more progressive view of place into consideration may work to raise awareness of such tensions and conflicts. This could lead to an approach which sees place as a site of negotiation that is aware and considerate of the multiplicity of place identities.

A progressive politics of place, in combination with the framework described in Section 7.4 (the entanglement of concepts of resilience and place), may provide real potential for an evolution of understanding which works towards incorporating issues of competing discourses and power. It is highly likely that a more interconnected and relational framework could result in the strengthening of resilience capacities that are already being supported by open and diverse processes in grassroots community groups. In addition, a progressive politics of place may provide a useful tool for local government and institutions that provide support and funding for community groups both pre and post disaster. A disaster is a time when place attachments and identities are heightened, disrupted and in a process of transformation. These considerations should be taken into account when working with communities post disaster.

Consequently, place identity dynamics could also be incorporated into 
planning prior to disasters to strengthen the relational nature of place identity relations within urban and rural areas. This could be achieved by incorporating an awareness of place identity and place processes into programmes that aim to enhance resilience. This recognition of the inter-related nature of the two concepts could lead to a greater understanding of the multiplicity of ways individuals relate to place within a community. Thus, by using a progressive politics of place to deal with such conflicts, a less reactionary, more inclusive and less fraught way forward for (re)imaging places struck by disasters can be achieved.

\subsection{Summary}

The specificities of place and place imaginaries are highly likely to underlie the foundations of post disaster recovery and subsequent community resilience capacities. This interaction between place and resilience has been found to occur through several avenues. At the most basic level place affects resilience by altering the needs of a community and appropriate responses to disasters. Contextual place shapes the responses communities can make to improve their resilience and attachment to place can aid a community in pulling together through common cause in a time of need. Secondly, place imaginaries affect resilience through the process of (re)imagining place following the disruption of a disaster. Through this case study I have shown how tension over place identities can cause exacerbated conflict. This has the potential to impact resilience negatively as it may affect the ability of the town to work in an inclusive and diverse manner which would draw on a range of perspectives to envision the best possible adaptive trajectory - an important part of socio-ecological theory. I have displayed these findings in the form of a diagram which theorises the possible embedding of resilience within a relational place framework acknowledging the multiple imaginaries and discourses at work.

Consequently, there is a strong role for an ethos of a progressive politics of place to strengthen resilience capacities of grassroots community groups which can in turn support the resilience of urban areas and local communities. The challenge for grassroots groups working towards an alternative future is to engage with radical critiques of community and place to more fully alter how they operate within society and act for change. This would see groups recognize place identity as a factor in community conflicts and lead to the acknowledgement of place as a site of 
negotiation and acceptance of multiple, ever shifting and heterogeneous place identifications. There is also space for these critiques and ideas to be taken on board by institutions and officials working on disaster recovery. Institutions could then better understand the dynamics of place and place identity in the immediate phase after an earthquake and the following recovery period. 


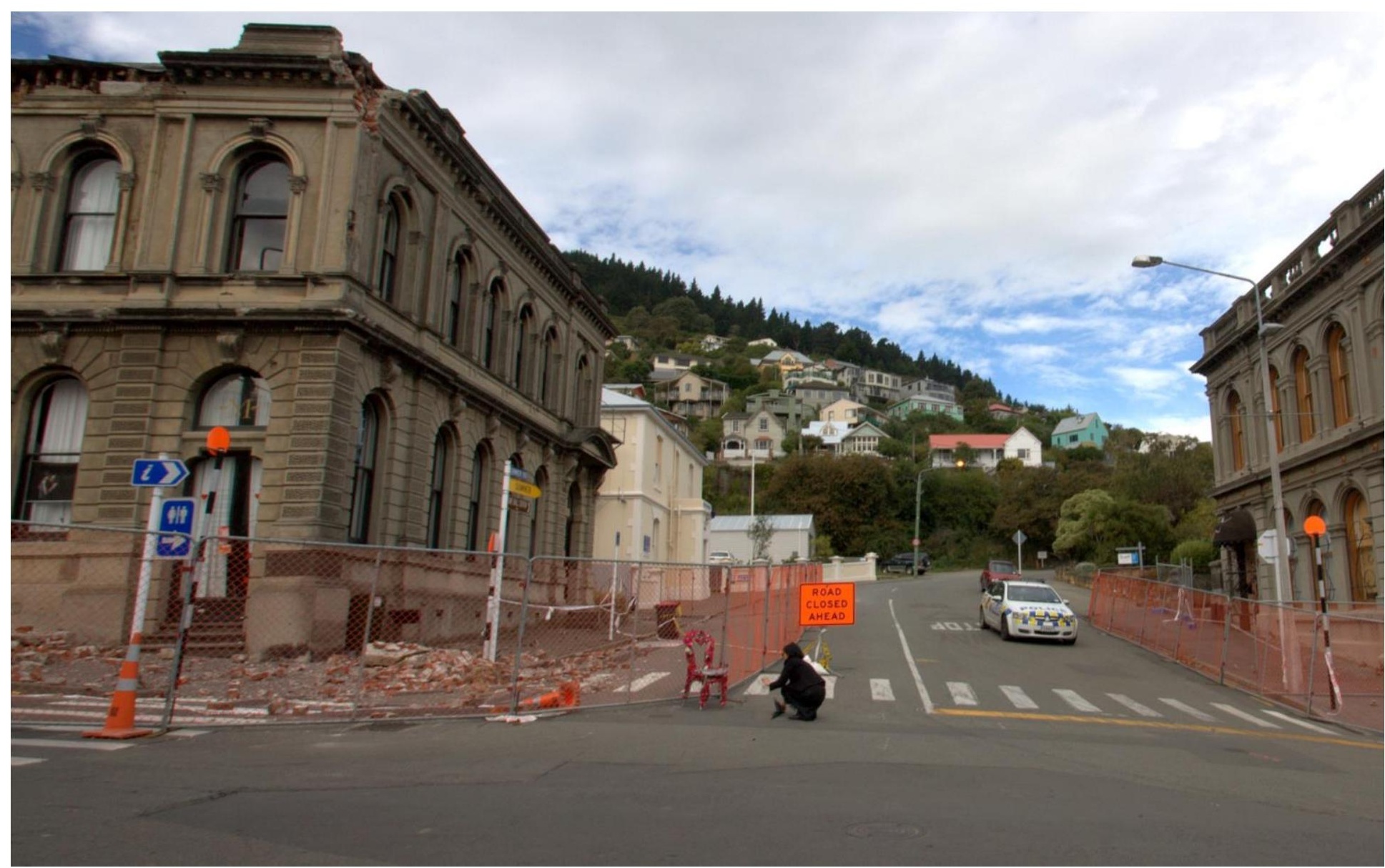

Image 13: A woman places a tribute to the fallen building on London St, Lyttelton 2011 (Source: Helen Devereux). 


\section{Chapter 8.0 Conclusions}

"I never understood how a man could dare to watch a city shaken to the ground, to feel the tremors, hear the tragic sound of houses twisting, crashing everywhere, and not be conquered by despair. Although his buildings crumble to a mound of worthless ruins, man has always found the urge to build a stronger city there.

Within my soul I made my towers high. They lie in ruins, yet I have begun to build again, now planning to restore what life has shaken to the earth; and I in faith shall build my towers towards the sun a stronger city than was there before."

-Gertrude Ryder Bennett 1931

Inscription on commemoration plaque for the 1931 Napier earthquake in which 256 people lost their lives

In conducting this research I set out to explore and further understand the role of place identity in shaping grassroots responses to disaster. The research aim was comprised of two core elements and four research questions:

1) To understand the role of grassroots community groups in understanding and facilitating resilient responses to disasters;

a. What is community resilience and how is it defined in relation to grassroots community organisations?

b. How can community organisations like Project Lyttelton facilitate the strengthening of resilience at a grassroots level?

2) To explore the role of relational place identity in shaping grassroots resilience.

a. How does place affect individual and group identity and how does this contribute to on-going community resilience?

b. How do different conceptualisations of place affect the levels of resilience enacted by a grassroots community group? 
Through the case study of Project Lyttelton I have worked alongside people directly involved in the recovery of a town from a series of devastating earthquakes. The data gathered from this thesis provide invaluable insights into the interactions of place, conflict, identity and resilience in the re-imagination of a town. There are many interpretations of resilience; the one used in this thesis relates to the capacity for adaptation and transformational change in relation to living with disturbances $(\mathrm{F}$ Berkes \& Campanella, 2006; Gunderson, 2010; Magis, 2010). In light of this, it is hoped that the results from this research will be put to use in community and disaster preparation work to better inform the role of relational place in shaping resilient responses and recovery.

Grassroots action can be seen as one of the first elements of community response to disaster. Research question one and two, relating to the role of grassroots community groups in shaping resilience, have shown the strong role for community organisations through the case of Lyttelton. Project Lyttelton has contributed greatly to the resilience of the town through the creation of networks of support and participation. These networks were able to be mobilised quickly and efficiently to provide real and effective support to those in need, as shown in Chapter Five. In addition, formalised networks such as the time bank provided a way for citizens with skills or a desire to help, to provide assistance alongside recovery agencies such as Civil Defence and the armed forces. Other activities such as the Lyttel Stitches project and the community garden provided a place for comfort and support to be provided in an informal way. The attitudes expressed by those in the group also support an inclusive attitude which in many ways aids the culture of diversity important to social resilience.

As discussed in Section 5.5, the actions of Project Lyttelton prior to and following the earthquakes led the way for adaptive learning to be undertaken through projects which seek to further strengthen resilience to future events, such as the Harbour Resilience Project. These projects and others are likely to provide a strong foundation of social memory for future generations to draw on. In addition, they will contribute to social learning which will facilitate adaptation to future events, both slow and sudden onset in nature. 
Resilience and place have not often been considered as interlinked or embedded topics in the past. This thesis has attempted to contribute to this gap through research questions three and four, relating to how place affects resilience and the role of different place imaginaries in this process. Interviews with the 15 participants provided a canvas of different place imaginaries and discourses of place in the landscape of Lyttelton. Many related strongly to the history of the town and the port town legacy from the wharves. Others strongly associated with the community groups that led to a friendly and caring atmosphere. There were also a multitude of variations that displayed the broad nature of relational place identities.

The effect of the earthquakes on the place identity of those interviewed varied. Some found the loss of buildings and monuments resulted in strong feelings of grief and loss, while others found that focussing on the needs of people and the community were more important than dwelling on buildings. One trend when discussing the impact of the earthquakes was the use of metaphors of violence to describe both the aftershocks and the physical conditions of the town. Another element that arose was that different generations felt the disturbances differently, with those who grew up in the area finding it hardest to lose buildings related to childhood memories.

These place imaginaries - consisting of individual identifications with varying discourses of place - potentially have the capacity to both positively and negatively influence resilience capacities. Place imaginaries that support narratives of community support and sharing resulted in actual assistance following each major earthquake. Similarly, discourses of self-reliance materialised in a self-sufficient attitude led many in Lyttelton to 'take care of their own' in the days and weeks immediately following the quakes. In addition, place imaginaries strongly attached to history and the past are likely to support the resilience capacities of social memory and learning and to provide repositories of stories and experiences for future generations to draw on.

Academics such Scannell and Gifford (2010), Brown and Perkins (1992)and Manzo and Perkins (2006) have briefly touched on the destabilising nature of disasters and the likelihood of disruptions to place identity negatively effecting resilience. Data from this research has in some ways strengthened this claim but 
added complexity to the equation. Through exploring the discourses of place present in Lyttelton, the data also revealed trends linked to conflict and tension as a result of the pressures of new migrants in the area. This tension has the potential to interrupt positive resilience capacities such as social support and participation and may act to exclude difference from the community. This is a concern for resilient capacities that draw on inclusion and diversity.

In order to display the interconnection between place and resilience more clearly, a complex framework emerged. This framework of interactions shows the importance of understanding both the contextual nature of place and resilience along with the relational and identity component of place, which effect how communities can foster resilience capacities. Furthering this understanding of place and resilience builds on the foundation of resilience and place as co-constituted concepts that are entangled. To fully comprehend the nuances of these connections is to more fully explore the potential for place imaginaries to support resilience and vice versa.

In addition to this understanding, it is also important to comprehend how relational place discourses affected by disasters are similar to responses to the challenges of globalisation. Due to the sudden nature of change, disaster related disruption is more instantaneous but can result in similar feelings of alienation and grief. It is this comparison that increases the relevance of Doreen Massey's work with regard to disasters. This theory sheds light on the importance of an open, relational and adaptive approach to understanding place identity during recovery from disaster. Ultimately, exclusive and bounded notions of place threaten the open and inclusive attitudes required within a community to progress from a state of crisis to one of recovery and (re)imagination of place which incorporates all forms of place identity.

\subsection{Limitations}

There are several limitations to this research. Firstly, as a Master's thesis this research was carried out under a limited budget and time frame. Consequently, I focused specifically on the Project Lyttelton organisation and place identity discourses largely related to the organisation and its members. While every attempt was made to cover a wide range of the different place identities expressed, there 
remains at least one large gap in the approach. This gap relates to the role and history of Tangata Whenua (people of the land). The Rapaki Hapu who reside in Lyttelton harbour have strong ties and links to the township and the land that extend much further into history than that of European settlers. Due to the nature of cross cultural research, and my desire to look at Project Lyttelton as a grassroots community group, I decided that I could not do justice to both elements within my limited resources. Therefore, there is little in this research that discusses Tangata Whenua place identity and their response to the earthquake - an interesting and important avenue for further research.

In addition, the research is based on only 15 people in total who participated in e-interview or face to face interviews. Due to the sensitive nature of working in a disaster recovery area I did not wish to pressure people into participating, especially given the emotional nature of recalling events. Through interviews I was told of the many requests for research participation that the community had been receiving this reinforced my decision to select a small sample and analyse the responses in depth. The e-interview process was designed to provide a less intense mode of participation, but even this did not net the number of participants expected. Thus, in order to supplement my primary data, I also drew on the Shaken Heart book produced by Project Lyttelton. This allowed me to access 32 unedited interview transcripts with residents about their experiences in the earthquakes.

Finally, the research has been undertaken at a local scale at a specific period of time. In order to more fully assess the complex nature of relational place and resilience capacities more studies are needed at varying levels of space and time.

\subsection{Recommendations}

Despite the community scale of this particular case study, my findings make a strong case for further exploration of the ways in which place and resilience are embedded within one another and what this means for resilience frameworks. In light of these findings I make the following research recommendations are made: 
1) That further research on the intricacies of place and identity in disaster zones be undertaken in different countries and cultural contexts.

2) Research be undertaken into the practicality of incorporating considerations of place into resilience enhancing projects at community and national levels.

4) The plausibility of incorporating grassroots community organisations into city and national scale disaster preparation should be investigated at both an academic and policy level.

5) Investigation into strategies for grassroots community groups to incorporate a diverse range of perspectives from the communities they are located in. This combined with a willingness to engage with different perspectives on place may help to align (re)localisation philosophies more closely to Massey's progressive politics of place.

As has been displayed in the findings of this research, to ignore relational place is to potentially jeopardise community resilience, particularly through the weakening of social factors such as social support, participation and learning. Furthermore, this research has shown the significant role of grassroots organisations in supporting community resilience, both through preventative measures and following an event. These findings should be linked to central and government level reports of disaster preparation. It is likely that due to the place specific nature of resilience work grassroots organisations will be able to implement many actions towards improving disaster resilience if appropriate resources were made available.

From the specific case study of Project Lyttelton it became particularly apparent that networks such as the time bank were integral in the grassroots response to the earthquake. As an established network that had systems and members in place prior to the disaster, the time bank appeared to be incredibly useful for quickly and efficiently mobilising civilian aid. These initiatives should be supported by local government, particularly in areas prone to disasters. While further research is needed I also recommended that the investigation of a programme aimed at preparing such organisations for disasters is instigated.

Finally, those living in a community affected by disaster are often those who understand their own needs the best. I recommend that any work being done on 
reconstruction and disaster recovery takes into account the perspectives, stories and experiences of those in the community in a genuine and considered manner. It is only with due consideration to the intricacies of the place identity of those living in a place affected by disaster that a settlement can truly recover and adapt to the challenges of post disaster realitie

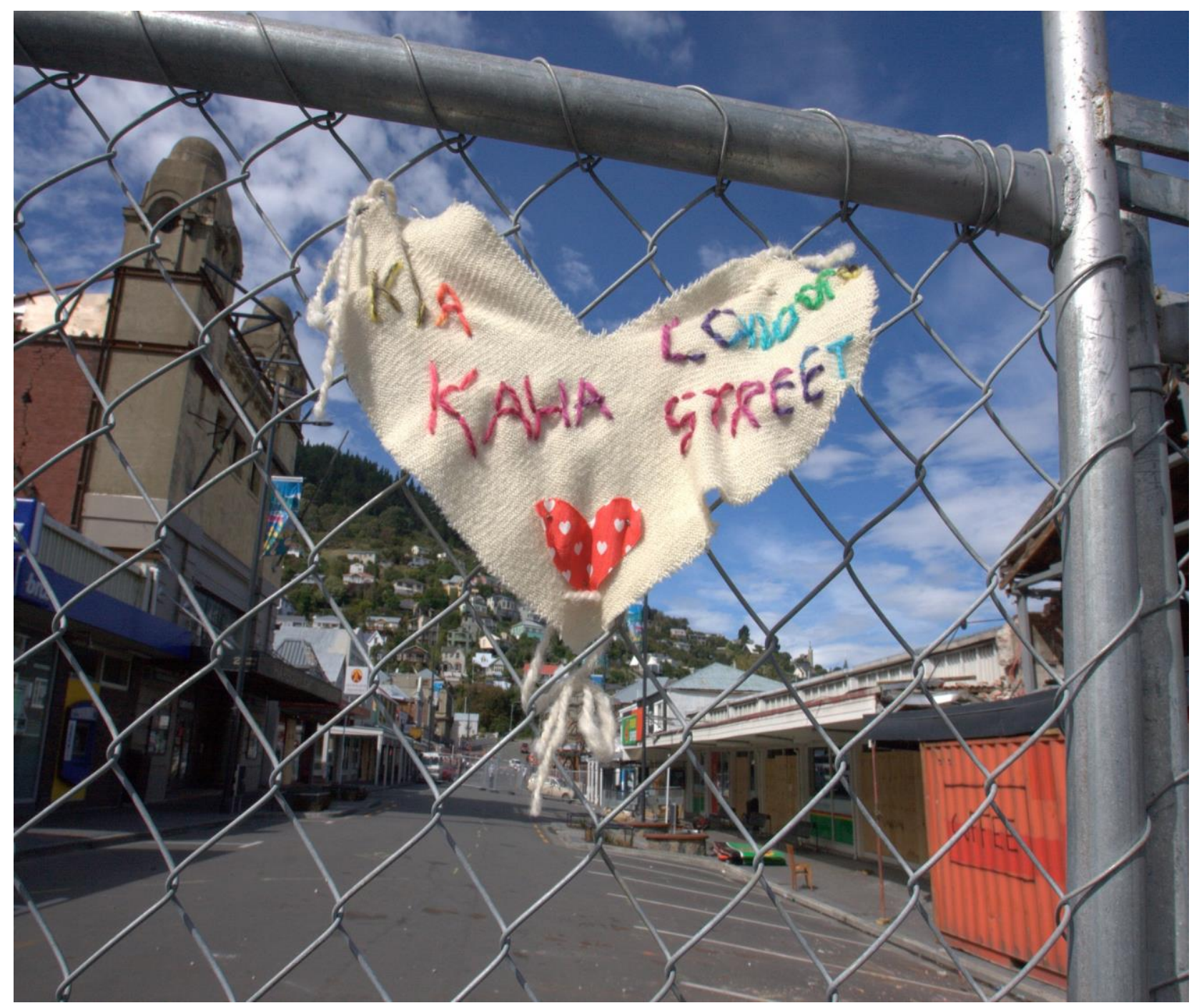

Image 13: Kia kaha (stay strong) a Lyttel Stitches heart is tied to a fence restricting entry to the London St, the main street of Lyttelton 2011 (Source: Helen Devereux). 


\section{Appendices}

\section{Appendix 1: Information Sheet}

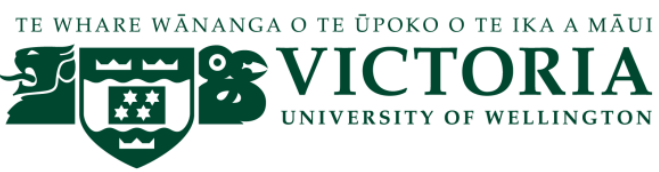

Title of project: On-going Community Resilience from the Bottom Up: A place based perspective of grassroots community resilience

Researcher: Raven Cretney: School of Geography, Environment and Earth Science, Victoria University Wellington, New Zealand.

I am a Masters student in Environmental Studies at Victoria University of Wellington. As part of this qualification I am undertaking research that will contribute to a thesis. The project I am looking into is a study of long term grassroots community resilience in a time of crisis and how the place that a community is located in can contribute to this resilience. I am working with Project Lyttelton to investigate this in the context of the recent earthquakes.

I will explore the way in which individuals identify with Lyttleton and how this affects their resilience capabilities in the period surrounding the earthquakes. Additionally I will look into how the group operates, who is involved, and the resilience of the community. Through this study, I hope to understand how the people of Lyttelton have responded to the earthquakes and how lessons can be provided for other communities at risk of crises or disasters.

All material collected will be kept confidential and no names will be released or used. Participants will be identified as members of the wider Lytteton community or Project Lyttelton and will be attributed with a pseudonym such as Community Member 1. Only myself and my supervisor will listen to the recorded interviews.

The thesis will be submitted for marking to the School of Geography, Environment and Earth Sciences at Victoria University of Wellington and once marked, will be deposited in the library. It is hoped that this research will also form the basis of one or more articles for publication in academic journals and presented at conferences.

The University has granted me ethics approval to conduct this research.

\section{What is involved?}


Interviews will be conducted by myself at a mutually agreed location. They have been designed to be 50-60minutes long. Should you choose to participate in this study, your written consent will be requested prior to it commencing.

Participation is entirely voluntary and you can decline to answer any questions, and/or withdraw from the interview at any time. You can also withdraw your opinions from the research up until the date of $1 / 11 / 2012$.

You will be asked a list of questions relating to your experiences as a member of the Lyttelton community and about your involvement with Project Lyttelton. You do not have to answer all questions.

The interview will be recorded and transcribed. These documents will be stored electronically in a password protected folder for five years after the completion of the project. After this time, files will be destroyed.

Please contact myself or my supervisor, Dr Sophie Bond, if you have any questions or would like to know further information regarding this research.

\section{Principal Investigator:}

Raven Cretney

Master of Environmental Studies Student - Victoria University Wellington raven.cretney@vuw.ac.nz

Ph: 0275120500

\section{Research Supervisor:}

Dr Sophie Bond

School of Geography, Environment and Earth Science - Victoria University of Wellington sophie.bond@vuw.ac.nz

Ph: 044635217 


\section{Appendix 2: Consent Form}

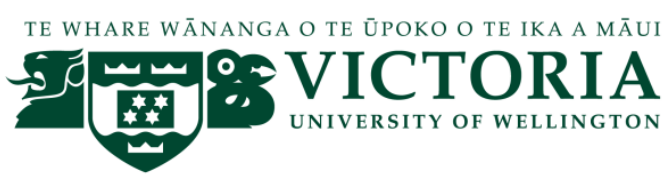

Title of project: On-going Community Resilience from the Bottom Up: A place based perspective of grassroots community resilience

-I have read and understood the attached 'Information sheet for interviews.' I have had an opportunity to ask any questions I may have about the study and about participating in the interview and have had them answered to my satisfaction.

- I agree to participate in the interview and understand that I may withdraw myself (or any information I have provided) from this project by $01 / 11 / 2012$ without having to give reasons.

-I understand that the interview will be audio recorded and transcribed, and that only the researcher and their supervisor will have access to this material. Any information I provide will be kept confidential to the researcher and her supervisor.

-I understand that all written material and audio recordings of interviews will be stored in a locked filing cabinet or as password protected electronic documents and then destroyed after 5 years.

-I understand that the data I provide will only be used for the purposes of a thesis and any articles published from the thesis. No information will be released to others without my written consent.

I (full name) hereby consent to

take part in this study by being interviewed.

Signature:

Date: 


\section{Appendix 3: Semi structured interview guide - Project Lyttelton members}

1) Tell me a bit about yourself -

a. What is your history in Lyttelton?

b. How have you been involved in Project Lyttelton?

c. How were you involved during the earthquakes and the aftermath?

2) How would you describe Lyttelton before the earthquakes?

a. Taking into consideration place, history, buildings and community spirit. How would you describe Lyttelton now?

b. Why has it changed like this?

3) What do you think a resilient community looks like?

a. Prompt for- examples of non-resilience, characteristics, looks like

b. What helps communities be resilient?

4) What role do you think PL has played in Lyttelton's response to the earthquakes? Has this improved the community's resilience?

a. Prompt for- networks, relationships, social memory, social learning

5) How do you think the characteristics of Lyttelton have contributed to the group's identity?

a. How were these effected by the earthquakes

6) How would you describe your perceptions of the people involved in Project Lyttelton?

a. Prompt for-variety of people, class, age, ethnicity

7) How do you think the wider community perceives the work that Project Lyttelton does?

a. How would you describe this community?

Do you feel like the group is inclusive, do they support or celebrate diversity?

b. Prompt for - how did this impact on EQ response/resilience?

8) What is your favourite thing about the place of Lyttelton?

9) Is there anything further you would like to say or comment on? 


\section{Appendix 4: Semi structured interview guide - Community members}

1) Tell me a bit about yourself -

a. What is your history in Lyttelton?

b. Have you or your organisation been involved in Project Lyttelton? How?

c. How were you involved during the earthquakes and the aftermath?

2) How would you describe Lyttelton before the earthquakes?

a. Taking into consideration place, history, buildings and community spirit. How would you describe Lyttelton now?

b. Why has it changed like this?

3) What do you think a resilient community is?

a. Prompt for- examples of non-resilience, characteristics, looks like

b. What helps communities be resilient?

4) What role did your organisation play during the earthquakes? How did Project Lyttelton work with your organisation during the earthquake response?

5) How would you describe your perceptions of the people involved in Project Lyttelton?

a. Prompt for-variety of people, class, age, ethnicity

6) How do you think the wider community perceives the work that Project Lyttelton does?

a. How would you describe this community?

7) What is your favourite thing about Lyttelton?

8) Is there anything further you would like to say or comment on? 


\section{Appendix 5: E-Interview Questions}

1) What is your history in Lyttelton?

2) Considering factors such as place, monuments, history, buildings and community spirit, how would you describe the Lyttelton you knew before the earthquakes?

3) Can you describe how the Lyttelton you described above has changed and been affected by the earthquakes?

4) What has your involvement with Project Lyttelton been prior to and after the earthquakes?

5) How did activities initiated by Project Lyttelton contribute to resilience after the earthquakes?

6) Do you think the nature of community in Lyttelton helped people cope and pull together during the aftermath of the earthquakes? Please give some examples.

7) How do you think Project Lyttelton's work is perceived in the wider community? Do you have any examples?

8) Do you think there are a variety of people involved in Project Lyttelton across age, gender, class and ethnic groups? Can you give some examples of this diversity? 


\section{Appendix 6: Ethics Approval}

TE WHARE WX̄NANGA O TE DPOKO O TE IKA A MĀUI

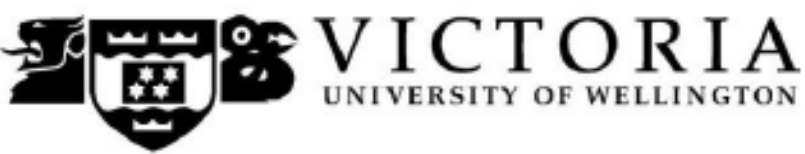

MEMORANDUM

Phone $\quad 0-4-4635676$

Fax $\quad 0-4-4635209$

Email Allison.kirkman@vuw.ac.nz

\begin{tabular}{l|l}
\hline TO & Raven Cretney \\
\hline COPY TO & Sophie Bond \\
\hline FROM & Dr Allison Kirkman, Convener, Human Ethics Committee \\
\hline
\end{tabular}

\begin{tabular}{l|l}
\hline DATE & 27 May 2012 \\
\hline PAGES & 1 \\
\hline
\end{tabular}

SUBJECT

Ethics Approval: 19311

Ongoing community resilience from the bottom up: a place based perspective of grass roots community resilience

Thank you for your application for ethical approval, which has now been considered by the Standing Committee of the Human Ethics Committee.

Your application has been approved from the above date and this approval continues until 13 March 2013. If your data collection is not completed by this date you should apply to the Human Ethics Committee for an extension to this approval.

Best wishes with the research.

Allison Kirkman

Human Ethics Committee 


\section{Chapter 9.0 References}

Adger, W. N. (2000). Social and ecological resilience: Are they related? Progress in Human Geography, 24(3), 347-364.

Adger, W. N. (2005). Social-Ecological Resilience to Coastal Disasters. Science, 309(5737), 1036-1039.

Agnew, J. (1987). Place and Politics: the geographical mediation of state and society. Boston MA: Allen and Unwin.

Ahmed, R., Seedat, M., van Niekerk, A., \& Bulbulia, S. (2004). Discerning Community Resilience in Disadvantaged Communities in the Context of Violence and Injury Prevention. Psychological Society of South Africa, 34(3), $386-408$.

Aldrich, D. P. (2010). The Power of People: Social capital's role in recovery from the 1995 Kobe earthquake. Natural Hazards, 56(3), 595-611.

Altman, I., \& Low, S. (1992). Place Attachment: A conceptual inquiry. In Place Attachment: Human Behavior and Environment (Vol. 12). New York: Plenum Press.

Antonsich, M. (2011). Grounding Theories of Place and Globalisation. Tijdschrift voor economische en sociale geografie, 102(3), 331-345.

Berkes, F, \& Campanella, T. (2006). Planning for Post Disaster Resiliency. Annals of the American Academy of Political and Social Science, 604.

Berkes, F. (2007). Understanding Uncertainty and Reducing Vulnerability: Lessons from resilience thinking. Springer Natural Hazards, 41, 283-295. 
Bodin, Ö., Crona, B., \& Ernstson, H. (2006). Social Networks in Natural Resource Management: What is there to learn from a structural perspective. Ecology and Society, 11(2).

Bodin, P., \& Wiman, B. (2004). Resilience and other Stability Concepts in Ecology: Notes on their origin, validity, and usefulness. ESS Bulletin, 2(2), 33-43.

Brown, B., \& Perkins, D. (1992). Disruptions in Place Attachment. In Place Attachment: Human Behavior and Environment (Vol. 12, pp. 279-304). New York: Plenum Press.

Brown, D., \& Kulig, J. (1996). The Concepts of Resiliency: Theoretical lessons from community research. Health and Canadian Society, 4(1).

Browne, K., Bakshi, L., \& Law, A. (2010). Positionalities: It's not about them and us, it's about us. In S. Smith, R. Pain, S. Marston, \& J. P. Jones (Eds.), The SAGE Handbook of Social Geographers. London: Sage Publishers.

Bruneau, M., Chang, S. E., Eguchi, R. T., Lee, G. C., O’Rourke, T. D., Reinhorn, A. M., von Winterfeldt, D. (2003). A Framework to Quantitatively Assess and Enhance the Seismic Resilience of Communities. Earthquake Spectra, 19, 733.

Cahn, E. (2004). No More Throw Away People - The co-production imperative (2nd ed.). Washington DC: Essential Books.

Castells, M. (1997). Information Age. Economy, Society and Culture. The Power of Identity. Oxford: Blackwell Publishers.

Cheshire, L., \& Lawrence, G. (2005). Neoliberalism, Individualisation and Community: Regional restructuring in Australia. Social Identities, 11(5), $435-445$. 
Cicognani, E., Pirini, C., Keyes, C., Joshanloo, M., Rostami, R., \& Nosratabadi, M. (2007). Social Participation, Sense of Community and Social Well Being: A study on American, Italian and Iranian university students. Social Indicators Research, 89(1), 97-112.

Coles, E., \& Buckle, D. (2004). Developing Community Resilience as a Foundation for Effective Disaster Recovery (pp. 92-106). Presented at the New Zealand Recovery Symposium Proceedings, New Zealand: Ministry of Civil Defence and Emergency Management.

Collins, S., Glavovic, B., Johal, S., \& Johnston, D. (2011). Community Engagmenet Post Disaster Case Studies of the 2008 Matata Debris Flow and the 2010 Darfield earthquake. New Zealand Journal of Psychology, 40(4).

Connors, P., \& McDonald, P. (2011). Transitioning Communities: community, participation and the Transition Town movement. Community Development Journal, 46(4), 558-572.

Cope, M. (2010). Coding Qualitative Data. In Qualtitative Research Methods in Human Geography. Oxford: Oxford University Press.

Creswell, J. (2003). Research Design: Qualitative, Quantative and Mixed Methods Approaches (2nd ed.). Oxford: Sage Publishers.

Cutter, S. L., Barnes, L., Berry, M., Burton, C., Evans, E., Tate, E., \& Webb, J. (2008). A place-based model for understanding community resilience to natural disasters. Global Environmental Change, 18(4), 598-606.

Czarniawska, B. (2004). Narratives in Social Science Research. London: Sage Publishers. 
Dale, A., Ling, C., \& Newman, L. (2010). Community Vitality: The role of community-level resilience adaptation and innovation in sustainable development. Sustainability, 2(1), 215-231.

Davidson, D. J. (2010). The Applicability of the Concept of Resilience to Social Systems: Some sources of optimism and nagging doubts. Society \& Natural Resources, 23(12), 1135-1149.

Dwyer, C., \& Limb, M. (2001). Introduction: Doing qualitative research in geography. In Qualitative Methodologies for Geographers: Issues and Debates. London: Arnold Publishers.

Easthope, H. (2004). A Place called Home. Housing, Theory and Society, 21(3), $128-138$.

Evans, B. (2012). The Shaken Heart: Earthquake stories from the heart of Lyttelton. Lyttelton, New Zealand: Project Lyttelton.

Folke, C. (2006). Resilience: The emergence of a perspective for social-ecological systems analyses. Global environmental change, 16(3), 253-267.

Foucault, M. (1986). Of Other Spaces. Diacritics, Spring, 22-27.

Ganor, M., \& Ben-Lavy, Y. (2003). Community Resilience: Lessons derived from Gilo under fire. Journal of Jewish Communal Service, 79(2/3), 105-108.

Geonet. (2012). M 6.3, Christchurch, 22 February 2011 - Earthquake. Geonet. Retrieved from http://info.geonet.org.nz/display/quake/M+6.3\%2C+Christchurch\%2C+22+F ebruary+2011

Gieryn, T. (2000). A Space for Place in Sociology. Annual Review of Sociology, 26, $463-496$. 
Godschalk, D. R. (2003). Urban Hazard Mitigation: Creating resilient cities. Natural Hazards Review, 4(3), 136-143.

Gregory, D., Johnston, R., Pratt, G., Watts, M., \& Whatmore, S. (Eds.). (2009). The Dictionary of Human Geography. Malden, MA: Blackwell. Retrieved from http://www.credoreference.com/book/bkhumgeo

Gunderson, L. (2010). Ecological and Human Community Resilience in Response to Natural Disasters. Ecology and Society, 15(2), 18.

Gyula, P. (1997). European Proverbs in 55 languages. Indiana: DeProverbio.com.

Hall, A. (2009). Project Lyttelton: Our story. Project Lyttelton.

Hanson, M. J., Wolfberg Craig, P., Morgan, M., \& Gutierrez Deidre, S. (1998). The Culture of Inclusion: Recognizing diversity at multiple levels. Early Childhood Research Quarterly, 13(1), 185-209.

Harvey, D. (1996). Justice, nature and the geography of difference. Oxford: Blackwell Publishers.

Haxeltine, A., \& Seyfang, G. (2009). Transitions for the People: Theory and practice of "transition" and "resilience" in the UK's transition movement. Tyndall Working Paper, 134.

Holling, C. (1973). Resilience and Stability of Ecological Systems. Annual Review of Ecology and Systematics, 4.

Hopkins, R., \& Brangwyn, B. (2010). Transition Initiatives Primer. Transition Network. Retrieved from http://www.transitionnetwork.org/resources/whowe-are-and-what-we-do

Jackson, A., \& Mazzei, L. (2012). Thinking with Theory in Qualitative Research: Viewing data across multiple perspectives. United Kingdom: Routledge Publishers. 
Jensen, H. (2010). The Logic of Qualitative Survey Research and its Position in the Field of Social Research Methods. Open Journal, 11(2).

Kaniasty, K., \& Norris, F., H. (1995). In Search of Altruistic Community: Patterns of social support mobilization following Hurricane Hugo. American Journal of Community Psychology, 23(4), 447-477.

Kitchen, R., \& Tate, N. (2000). Conducting Research into Human Geography. Essex: Parson Education Limited.

Klein, R. J., Nicholls, R. J., \& Thomalla, F. (2003). Resilience to Natural Hazards: How useful is this concept? Global Environmental Change Part B: Environmental Hazards, 5(1), 35-45.

Korero Maori. (2012). Whakataukī - Proverbs: Kōrero Māori. Whakatauki Proverbs. Retrieved from http://www.korero.maori.nz/forlearners/proverbs.html Krasny, M. E., \& Tidball, K. G. (2009). Community Gardens as Contexts for Science, Stewardship, and Civic Action Learning. Cities and the Environment (CATE), 2(1), 8.

Longhurst, R. (2010). Semi-structured Interviews and Focus Groups. In N. Clifford, S. French, \& G. Valentine (Eds.), Key Methods in Geography (2nd ed., pp. 101-115). London: Sage Publishers'.

Longstaff, P. H., \& Yang, S.-U. (2008). Communication Management and Trust: Their role in building resilience to "surprises" such as natural disasters, pandemic flu, and terrorism. Ecology and Society, 13(1), 3.

Lorenz, D. F. (2010). The Diversity of Resilience: contributions from a social science perspective. Natural Hazards.

Magis, K. (2010). Community Resilience: An indicator of social sustainability. Society \& Natural Resources, 23(5), 401-416. 
Manzo, L. C., \& Perkins, D. D. (2006). Finding Common Ground: The importance of place attachment to community participation and planning. Journal of Planning Literature, 20(4), 335-350.

Mason, K., \& Whitehead, M. (2011). Transition urbanism and the contested politics of ethical place making. Antipode, no-no.

Massey, D. (1991a). A Global Sense of Place. Reading human geography, 35(6), $315-323$.

Massey, D. (1991b). A global sense of place. Marxism Today, 24-29.

Massey, D. (1993). Power Geometry and a Progressive Sense of Place. In J. Bird, B. Curtis, T. Putnam, G. Robertson, \& L. Tickner (Eds.), Mapping the futures, local culture, global change. Routledge Publishers.

Massey, D. (1995a). Places and Their Pasts. History Workshop Journal, 39.

Massey, D. (1995b). The Conceptualisation of Place. In A place in the world? places, cultures and globalisation. New York: Oxford University Press.

Massey, D. (2004). Geographies of Responsibility. Geografiska Annaler, 86(1).

Massey, D. (2005). For Space. London: Sage Publishers.

Massey, D. (2006). The Geographical Mind. In Secondary geography teachers' handbook. (pp. 46-51). Sheffield,: UK Geographical Association.

Masten, A., Best, K., \& Garmezy, N. (1990). Resilience and Development: Contributions from the study of children who overcome adversity. Development and Psychopathology, 2, 425-444.

McLafferty, S. (2010). Conducting Questionnaire Surveys. In N. Clifford, S. French, \& G. Valentine (Eds.), Key Methods in Geography (2nd ed., pp. 77-88). London: Sage Publishers. 
Milligan, M. J. (1998). Interactional past and potential: The social construction pf place attachment. Symbolic Interaction, 21(1), 1-33.

Mishra, R. (1998). Beyond the State: Social policy in an age of globalisation. Social Policy and Administration, 32(5), 481-500.

Murdoch, J. (2006). Post-structuralist Geography. London: Sage Publishers.

Murphy, B. L. (2007). Locating Social Capital in Resilient Community-Level Emergency Management. Natural Hazards, 41(2), 297-315.

Nelson, V., \& Stathers, T. (2009). Resilience, Power, Culture, and Climate: A case study from semi-arid Tanzania, and new research directions. Gender \& Development, 17(1), 81-94. doi:10.1080/13552070802696946

Nicholls, W. (2009). Place, Networks, Space: Theorising the geographies of social movements. Transactions of the Institute of British Geographers, 34(1), 7893.

Norberg, J., Wilson, J., Walker, B., \& Ostrom, E. (2008). Diversity and Resilience of Social-Ecological Systems. In J. Norberg \& G. Cumming (Eds.), Complexity Theory for a Sustainable Future. New York: Columbia University Press.

Norris, F. H., Stevens, S. P., Pfefferbaum, B., Wyche, K. F., \& Pfefferbaum, R. L. (2007). Community resilience as a metaphor, theory, set of capacities, and strategy for disaster readiness. American Journal of Community Psychology, 41(1-2), 127-150.

O’Brien, K., Hayward, B., \& Berkes, F. (2009). Rethinking Social Contracts: building resilience in a changing climate. Ecology and Society, 14(2), 12.

Okvat, H. A., \& Zautra, A. J. (2011). Community Gardening: A parsimonious path to individual, community, and environmental resilience. American Journal of Community Psychology, 47(3-4), 374-387. 
Olick, J. K., \& Robbins, J. (1998). Social Memory Studies: From“ collective memory" to the historical sociology of mnemonic practices. Annual Review of sociology, 105-140.

Olwig, M. (2012). Multi-sited Resilience: The mutual construction of "local" and "global" understandings and practices of adaptation and innovation. Applied Geography, 33.

Pahl-Wostl, C., Craps, M., Dewulf, A., Mostert, E., Tabara, D., \& Taillieu, T. (2007). Social Learning and Water Resources Management. Ecology and Society, 12(2).

Panelli, R. (2004). Social Geographies. London: Sage Publishers.

Panelli, R., \& Welch, R. (2005). Why Community? Reading difference and singularity with community. Environment and Planning A, 37(9), 1589.

Paton, D., \& Johnstan, D. (2001). Disasters and Communities: Vulnerability, resilience and preparedness. Disaster Prevention and Management, 10(4), $270-277$.

Peterson, G. (2000). Political ecology and ecological resilience::: An integration of human and ecological dynamics. Ecological Economics, 35(3), 323-336.

Prilleltensky, I., \& Nelson, G. (2005). Community Psychology: In pursuit of liberation and well-being. New York: Palgrave Macmillan.

Project Lyttelton. (2012). Project Lyttelton - About. Retrieved from http://www.lyttelton.net.nz/

Roberson, Q. (2006). Disentangling the Meanings of Diversity and Inclusion in Organisations. Group and Organization Management, 31(2), 212-237. 
Rodham, M. (2003). Empowering Place: Multilocality and Multivocality. In S. Low \& D. Lawerence-Zuniga (Eds.), The Anthropology of Space and Place: Locating culture (pp. 204-223). Oxford: Blackwell Publishers.

Rolfe, R. E. (2006). Social cohesion and community resilience: A multidisciplinary review of literature for rural health research. Department of International Development Studies Faculty of Graduate Studies and Research Saint Mary's University, Halifax. Retrieved from http://www.theruralcentre.com/doc/SCCR_Lit_Review.pdf

Rose, G. (1995). Place Identity: A sense of place. In D. Massey \& P. Jess (Eds.), A place in the world? places, cultures and globalisation. Oxford: Oxford University Press.

Rose, G. (1997a). Situating Knowledges: Positionality, reflexivities and other tactics. Progress in Human Geography, 21(3), 305-320.

Rose, G. (1997b). Performing Inoperative Community: The space and the resistance of some community arts projects. In Geographies of Resistance (pp. 184202). New York: Routledge Publishers.

Rossie, L. (2010). Historic Lyttelton Buildings - Christchurch City Council's heritage assets - Christchurch City Council. Retrieved January 22, 2013, from http://www.ccc.govt.nz/cityleisure/artsculture/christchurchheritage/lytteltonh eritage/index.aspx

Ruiz-Ballesteros, E. (2011). Social-Ecological Resilience and Community-based Tourism: An approach from Agua Blanca, Ecuador. Tourism Management, $32(3), 655-666$.

Sack, R. (1997). Homogeographicus: Framework for action, awareness, and moral concern. Baltimore: John Hopkins University Press. 
Scannell, L., \& Gifford, R. (2010). Defining place attachment: A tripartite organizing framework. Journal of Environmental Psychology, 30(1), 1-10.

Schusler, T. M., Decker, D. J., \& Pfeffer, M. J. (2003). Social Learning for Collaborative Natural Resource Management. Society \& Natural Resources, 16(4), 309-326.

Secomb, L. (2000). Fractured Community. Hypatia, 15(2).

Shepherd, N. (2011). Interviewing online: Qualitative research in the network (ed) society. In Association of Qualitative Research Conference (pp. 25-26).

Sherrieb, K., Norris, F. H., \& Galea, S. (2010). Measuring Capacities for Community Resilience. Social Indicators Research, 99(2), 227-247.

Silk, J. (1999). The Dynamic of Place, Identity and Community. Environment and Planning A, 31, 5-17.

Sonn, C. C., \& Fisher, A. T. (1998). Sense of community: Community resilient responses to oppression and change. Journal of Community Psychology, $26(5), 457-472$.

Stake, R. (2005). Qualitative Case Studies. In N. Denzin \& Y. Lincoln (Eds.), The SAGE Handbook of Qualitative Research (Third.). London: Sage Publishers.

Tidball, K. G., Krasny, M. E., Svendsen, E., Campbell, L., \& Helphand, K. (2010). Stewardship, Learning, and Memory in Disaster Resilience. Environmental Education Research, 16(5-6), 591-609.

Tobin, G. A. (1999). Sustainability and Community Resilience: The holy grail of hazards planning? Global Environmental Change Part B: Environmental Hazards, 1(1), 13-25.

Transition Network. (2012). Transition Initiatives Directory. Retrieved February 2, 2012, from http://www.transitionnetwork.org/initiatives 
Tuan, Y. (1974). Topophilia: A study of environmental perception, attitudes and values. Prentice Hall: Englewood Cliffs.

Waitt, G. (2010). Doing Foucauldian Discourse Analysis- Revealing Social Realities. In I. Hay (Ed.), Qualitative Research Methods in Human Geography. Oxford: Oxford University Press.

Walker, B., Carpenter, S., Anderies, J., Abel, N., Cumming, G., Janssen, M., Pritchard, R. (2002). Resilience Management in Social-Ecological Systems: A working hypothesis for a participatory approach. Conservation Ecology, 6(1), 14.

Welch, R. V., \& Panelli, R. (2007). Questioning Community as a Collective Antidote to Fear: Jean-Luc Nancy's “singularity” and "being singular plural." Area, 39(3), 349-356.

White, P. (2010). Making Use of Secondary Data. In N. Clifford, S. French, \& G. Valentine (Eds.), Key Methods in Geography (Vol. 2nd, pp. 61-76). London: Sage Publishers.

Whitridge, P. (2004). Landscapes, Bodies, Houses, Things: "Place" and the Archaeology of Inuit Imaginaries. Journal of Archaeological Method and Theory, 11(2). 
